\title{
Rockfall characterisation and structural protection - a review
}

\author{
A. Volkwein ${ }^{1}$, K. Schellenberg ${ }^{2}$, V. Labiouse ${ }^{3}$, F. Agliardi ${ }^{4}$, F. Berger ${ }^{5}$, F. Bourrier ${ }^{6}$, L. K. A. Dorren ${ }^{7}$, W. Gerber ${ }^{1}$, and \\ M. Jaboyedoff ${ }^{8}$ \\ ${ }^{1}$ WSL Swiss Federal Institute for Forest, Snow and Landscape Research, Zürcherstrasse 111, 8903 Birmensdorf, Switzerland \\ ${ }^{2}$ Gruner+Wepf Ingenieure AG, Thurgauerstr. 56, 8050 Zürich, Switzerland \\ ${ }^{3}$ Swiss Federal Institute of Technology Lausanne EPFL, Rock Mechanics Laboratory LMR, GC C1-413 Station 18, \\ 1015 Lausanne, Switzerland \\ ${ }^{4}$ Università degli Studi di Milano-Bicocca, Dip. Scienze Geologiche e Geotecnologie, Piazza della Scienza 4, \\ 20126 Milano, Italy \\ ${ }^{5}$ Cemagref, Mountain Ecosystems and Landscapes Research, 38402 Saint Martin d'Hères Cedex, France \\ ${ }^{6}$ Cemagref, UR EMGR, 2, rue de la Papeterie, BP 76, 38402 Saint Martin d'Hères Cedex, France \\ ${ }^{7}$ Landslides, Avalanches and Protection Forest Section, Federal Office for the Environment FOEN, Bern, Switzerland \\ ${ }^{8}$ University of Lausanne, Institute of Geomatics and Analysis of Risk, Amphipole 338, 1015 Lausanne, Switzerland
}

Received: 25 March 2011 - Revised: 26 July 2011 - Accepted: 7 August 2011 - Published: 27 September 2011

\begin{abstract}
Rockfall is an extremely rapid process involving long travel distances. Due to these features, when an event occurs, the ability to take evasive action is practically zero and, thus, the risk of injury or loss of life is high. Damage to buildings and infrastructure is quite likely. In many cases, therefore, suitable protection measures are necessary. This contribution provides an overview of previous and current research on the main topics related to rockfall. It covers the onset of rockfall and runout modelling approaches, as well as hazard zoning and protection measures. It is the aim of this article to provide an in-depth knowledge base for researchers and practitioners involved in projects dealing with the rockfall protection of infrastructures, who may work in the fields of civil or environmental engineering, risk and safety, the earth and natural sciences.
\end{abstract}

\section{Introduction}

Rockfall is a natural hazard that - compared to other hazards - usually impacts only small areas. However, the damage to the infrastructure or persons directly affected may be high with serious consequences. It is often experienced as a harmful event. Therefore, it is important to provide the best possible protection based on rigorous hazard and risk management methods. This contribution gives an overview of the assessment on parameters needed to deal effectively with

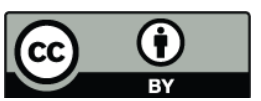

Correspondence to: A. Volkwein (volkwein@wsl.ch) a rockfall event from its initiation to suitable protective measures. This includes a presentation of typical applications as well as an extensive literature survey for the relevant topics that are evaluated and discussed with regard to their performance, reliability, validation, extreme loads, etc. Contributions include

- Rockfall susceptibility together with hazard assessment and zoning.

- Rockfall initiation and runout modelling

- Design and performance evaluation of rockfall protection systems, with particular attention paid to structural countermeasures such as fences, walls, galleries, embankments, ditches or forests

Rockfall hazard (or risk) can be assessed using different approaches (Einstein, 1988), depending on the characteristics of the investigated areas. Often the hazard must be assessed along a communication (transport) route; in this case, field records and lists of past rockfall events (inventories) are often used (Luckman, 1976; Bunce et al., 1997; Hungr et al., 1999), but have proved to be limited. For example, on 31 May 2006 a major rockfall $\left(5000 \mathrm{~m}^{3}\right)$ killed two tourists on the main highway crossing the Alps through the Gotthard Tunnel in Switzerland (Liniger and Bieri, 2006). The event caused global headlines and led to somewhat emotional media reporting of major rockfall incidents in the Alps in the following weeks, including rockfall on the Eiger mountain (Hopkins, 2006; Oppikofer et al., 2008). Another recent event shows the difficulties of forecasting rockfall events.

Published by Copernicus Publications on behalf of the European Geosciences Union. 


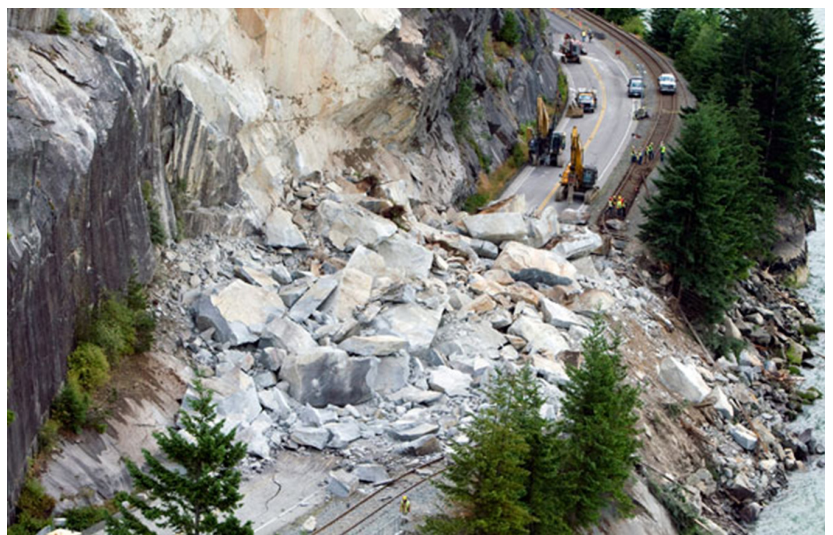

Fig. 1. Rockfall on Sea to Sky highway (B.C.). Note the jointed structure of the source area (Canadian Press photos).

During the night of 29 July 2008, a rockfall blocked the highway Sea to Sky joining Vancouver to the ski resort Whistler (Fig. 1). This road is the cover picture of the well-known rock mechanics book by Hoek and Bray (1981). The area has been extensively investigated for risk analysis in the past (Bunce et al., 1997) and still is, because of an increase in population density (Blais-Stevens, 2008) and the Olympics Games in 2010.

Further difficulties exist when the goal is to assess risk (or hazard) on a regional scale for a limited area or over an entire territory. Generally, inventories exist only in inhabited areas. Moreover, some studies suggest that the number of events increases in proportion to urbanization (Baillifard et al., 2004). As a consequence, it is necessary to find ways that allow one to detect rockfall hazard source areas in the absence of any inventory or clear morphological evidence, such as scree slopes or isolated blocks.

This article is structured following the typical workflow when dealing with rockfall in practice (Vogel et al., 2009), covering rockfall occurrence and runout modelling approaches, hazard zoning and protection measures.

When a rockfall hazard or risk analysis (including the protective effect of forests) reveals a threat to people, buildings or infrastructures (see Sect. 2), suitable structural protection measures have to be selected according to the expected event frequency and impact energies. For proper design and dimensioning of the measures, it is essential to know the magnitude of the impact loads and the performance of the structures. This knowledge can be obtained from rockfall onset susceptibility/ hazard analysis, numerical simulations, experiments, models or existing guidelines, and provides guidance on the design of roof galleries, fences, embankments and forests as a natural protection system.

However, rockfall protection considerations involve not only structural protection measures but also the avoidance of infrastructure or buildings in endangered areas. Firstly, it has to be clarified why and where rocks are released and the total volume or extent. The rockfall initiation also depends on different factors, mostly not yet quantified, such as weathering, freezing/melting cycles or heavy rainfall (see Sect. 3). Subsequent trajectory analyses determine the areas that have to be protected by measures. To account for their high sensitivity to just small changes in the landscape, such as bedrock, dead wood, small dips, etc., stochastic analyses are usually performed, preferably including an evaluation of the accuracy of the results. This is described in more detail in Sect. 4. However, for a quick preliminary analysis and estimation of the rockfall hazard, simpler and manual calculation methods might also be useful as described in Sect. 4.4.1.

There is a large variety of structural protection measures against rockfall. These include natural protection by means of forests, semi-natural structures such as embankments and ditches and fully artificial structures such as fences, galleries or walls. The structural part of this contribution focuses mainly on fences and galleries. A short summary for embankments is also given. Natural protection by means of forests is mentioned in Sect. 5.5.

\section{Rockfall hazard: definition, assessment and zonation}

Rockfall is a major cause of landslide fatality, even when elements at risk with a low degree of exposure are involved, such as traffic along highways (Bunce et al., 1997). Although generally involving smaller rock volumes compared to other landslide types (e.g., rock slides/rock avalanches), rockfall events also cause severe damage to buildings, infrastructures and lifelines due to their spatial and temporal frequency, ability to easily release and kinetic energy (Rochet, 1987b). The problem is even more relevant in large alpine valleys and coastal areas, with a high population density, transportation corridors and tourist resorts. Rockfall protection is, therefore, of major interest to stakeholders, administrators and civil protection officers (Hungr et al., 2005). Prioritization of mitigation actions, countermeasure selection and land planning should be supported by rockfall hazard assessment (Raetzo et al., 2002; Fell et al., 2005, 2008). On the other hand, risk analysis is needed to assess the consequences of expected rockfall events and evaluate both the technical suitability and the cost-effectiveness of different mitigation options (Corominas et al., 2005; Straub and Schubert, 2008).

\subsection{Rockfall hazard: a definition}

Landslide hazard has been defined as the probability that a landslide of given magnitude occurs in a given area over a specified time interval (Varnes, 1984; Einstein, 1988). This definition envisages the concepts of spatial location, temporal frequency and intensity. Nevertheless, for longrunout landslides, such as rockfall or rock avalanches, the definition of the occurrence probability needs to account for 
the concept of landslide propagation. This means the transfer of landslide mass and energy from the source to the maximum runout distance of up to tens of kilometres for rock avalanches and debris flows or several hundred metres for fragmental rockfall, characterised by poor interaction between falling blocks with volumes up to $10^{5} \mathrm{~m}^{3}$ (Evans and Hungr, 1993). Thus, rockfall hazard depends on (Jaboyedoff et al., 2001; Crosta and Agliardi, 2003; Jaboyedoff et al., 2005b, Fig. 2)

- the probability that a rockfall of given magnitude occurs at a given source location resulting in an onset probability

- the probability that falling blocks reach a specific location on a slope (i.e., reach probability), and on

- rockfall intensity.

The latter is a complex function of block mass, velocity, rotation and jump height, significantly varying both along single fall paths and laterally, depending on slope morphology and rockfall dynamics (Broili, 1973; Bozzolo et al., 1988; Azzoni et al., 1995; Agliardi and Crosta, 2003; Crosta and Agliardi, 2004). Rockfall hazard can, thus, be better defined as the probability that a specific location on a slope is reached by a rockfall of given intensity (Jaboyedoff et al., 2001), and expressed as:

$H_{i j k}=P(L)_{j} \cdot P(T \mid L)_{i j k}$

where $P(L)_{j}$ is the onset probability of a rockfall event in the magnitude (e.g., volume) class $j$, and $P(T \mid L)_{i j k}$ is the reach probability. This is the probability that blocks triggered in the same event reach the location $i$ with an intensity (i.e., kinetic energy) value in the class $k$. Since both probability and intensity strongly depend on the initial magnitude (i.e., mass) of rockfall events, rockfall hazard must be assessed for different magnitude scenarios, explicitly or implicitly associated to different annual frequencies or return periods (Hungr et al., 1999; Dussauge-Peisser et al., 2003; Jaboyedoff et al., 2005b).

\subsection{Hazard assessment}

In principle, rockfall hazard assessment would require the evaluating of:

(a) the temporal probability (annual frequency or return period) and the spatial susceptibility of rockfall events;

(b) the 3-D trajectory and maximum runout of falling blocks;

(c) the distribution of rockfall intensity at each location and along each fall path.

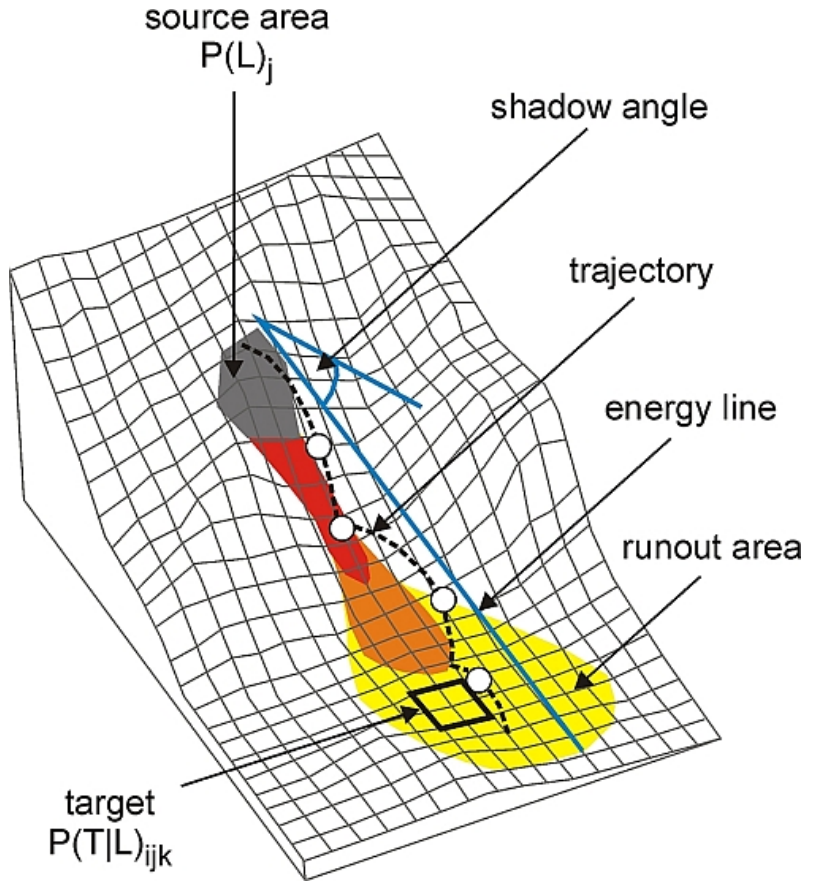

Fig. 2. Definition of rockfall hazard and related parameters (modified, after Jaboyedoff et al., 2001).

Exposed elements at risk are not considered in the definition of hazard. Nevertheless, hazard assessment approaches should be able to deal with problems characterised by different spatial distributions of potentially exposed targets, pointlike (houses), linear (roads, railways) or areal (villages). Moreover, targets of different shape and size are likely to involve a different number of trajectories running out from different rockfall sources (Jaboyedoff et al., 2005b, Fig. 2), influencing the local reach probability. Thus, assessment methods should be able to account for the spatially distributed nature of the hazard (Crosta and Agliardi, 2003). Although several hazard assessment methods have been proposed, very few satisfy all these requirements. They differ from one another in how they account for rockfall onset frequency or susceptibility, estimated reach probability, and combine them to obtain quantitative or qualitative hazard ratings.

\subsubsection{Onset probability and susceptibility}

The frequency of events of given magnitude (volume) should be evaluated using a statistical analysis of inventories of rockfall events, taking into account the definition of suitable magnitude-frequency relationships (Dussauge-Peisser et al., 2003; Malamud et al., 2004). They are also called magnitude-cumulative frequency distributions (MCF; Hungr et al., 1999). Although this approach is well established in the field of natural hazards (e.g., earthquakes), its application to landslide hazards is limited by the scarce availability 
of data and by the intrinsic statistical properties of landslide inventories (Malamud et al., 2004). The frequency distribution of rockfall volumes has been shown to be well fitted by the power law:

$\log N(V)=N_{0}-b \cdot \log V$

where $N(V)$ is the annual frequency of rockfall with a volume exceeding $V, N_{0}$ is the total annual frequency of rockfall and $b$ is the power law exponent, ranging between 0.4 and 0.7 (Dussauge-Peisser et al., 2003). According to Hungr et al. (1999), magnitude-cumulative frequency curves (MCF) derived from rockfall inventories allows for the estimating of the annual frequency of rockfall events in specified volume classes, thus, defining hazard scenarios. Major limitations to this approach include the lack of rockfall inventories for most sites and the spatial and temporal heterogeneity of available inventories. These are possibly affected by censoring, hampering a reliable prediction of the frequency of either very small and very large events (Hungr et al., 1999; Dussauge-Peisser et al., 2003; Malamud et al., 2004). The hazard has been completely assessed using this approach by Hungr et al. (1999) in the case of a section of highway. On a regional scale, Wieczorek et al. (1999) and Guzzetti et al. (2003) partially included the MCF within the method; while Dussauge-Peisser et al. (2002, 2003) and Vangeon et al. (2001) formalized the use of the MCF on a regional scale merging it with susceptibility mapping.

Where site-specific rockfall inventories are either unavailable or unreliable, the analysis of rockfall hazard can only be carried out in terms of susceptibility. This is the relative probability that any slope unit is affected by rockfall occurrence, given a set of environmental conditions (Brabb, 1984). Onset susceptibility (see Sect. 3) can be assessed

- in a spatially distributed way by heuristic ranking of selected instability indicators (Pierson et al., 1990; Cancelli and Crosta, 1993; Rouiller and Marro, 1997; Mazzoccola and Sciesa, 2000; Budetta, 2004),

- by deterministic methods (Jaboyedoff et al., 2004a; Guenther et al., 2004; Derron et al., 2005) or

- by statistical methods (Frattini et al., 2008).

\subsubsection{Reach probability and intensity}

The reach probability and intensity for rockfall of given magnitude (volume) depends on the physics of rockfall processes and on topography (see Sect. 4). The simplest methods describing rockfall propagation are based on the shadow angle approach, according to which the maximum travel distance of blocks is defined by the intersection of the topography with an energy line having an empirically-estimated inclination (Evans and Hungr, 1993, Fig. 2). Unfortunately, with this approach there is no physical process model for rockfall and its interaction with the ground behind and only the maximum extent of rockfall runout areas is estimated (Fig. 3a). However, this approach has been implemented in a GIS tool (CONEFALL, Jaboyedoff and Labiouse, 2003) allowing a preliminary estimation of rockfall reach susceptibility and kinetic energy (Fig. 3b), according to the energy height approach (Evans and Hungr, 1993). Many existing hazard assessment methodologies estimate reach probability and intensity using 2-D rockfall numerical modelling (Matterock, Rouiller and Marro,1997; Rockfall Hazard Assessment Procedure RHAP, Mazzoccola and Sciesa, 2000; Cadanav, Jaboyedoff et al., 2005b). This provides a more accurate description of rockfall physics and allows for a better evaluation of rockfall reach probability (i.e., relative frequency of blocks reaching specific target locations) and of the spatial distribution of kinetic energy). However, 2-D modelling neglects the geometrical and dynamic effects of a 3-D topography on rockfall, leading to a subjective extension of simulation results between adjoining 2-D fall paths (Fig. 3c). Although this limitation has, in part, been overcome by introducing pseudo 3-D assumptions (Jaboyedoff et al., 2005b), full 3-D numerical modelling has been shown to be required to account for the lateral dispersion of 3-D trajectories and the related effects on reach probability and intensity. Nevertheless, a few hazard assessment methodologies based on 3-D numerical modelling are available (Crosta and Agliardi, 2003, Fig. 3d).

\subsection{Hazard zoning: current practice and unresolved questions}

Rockfall hazard or susceptibility mapping/zoning is the final step of hazard assessment, leading to the drafting of a document useful for land planning, funding prioritization or the preliminary assessment of suitable protective measures. The major issue in hazard zoning is to find consistent criteria to combine onset probability or susceptibility, reach probability and intensity in a map document, especially when formal probabilities cannot be evaluated.

Swiss guidelines (Raetzo et al., 2002, see Fig. 4) require that rockfall hazard are zoned according to the onset probability (i.e., return period) and intensity (i.e., kinetic energy), thus, defining three hazard zones, namely red, blue and yellow. Nevertheless, these do not explicitly account for the reach probability and the spatial variability of kinetic energy. Thus, Jaboyedoff et al. (2005b) proposed a methodology (Cadanav) based on 2-D numerical modelling to map hazard according to the probability where blocks involved in events with a specified return period reach a specific location along a 2-D profile with a given kinetic energy.

When only onset susceptibility can be evaluated, hazard zoning is based on the combination of hazard indicators or reclassified values of the parameters contributing to the hazard to obtain suitable hazard indices. Some authors (Rouiller and Marro, 1997; Jaboyedoff et al., 2001; Derron et al., 2005; Copons and Vilaplana, 2008) used simple methods for 

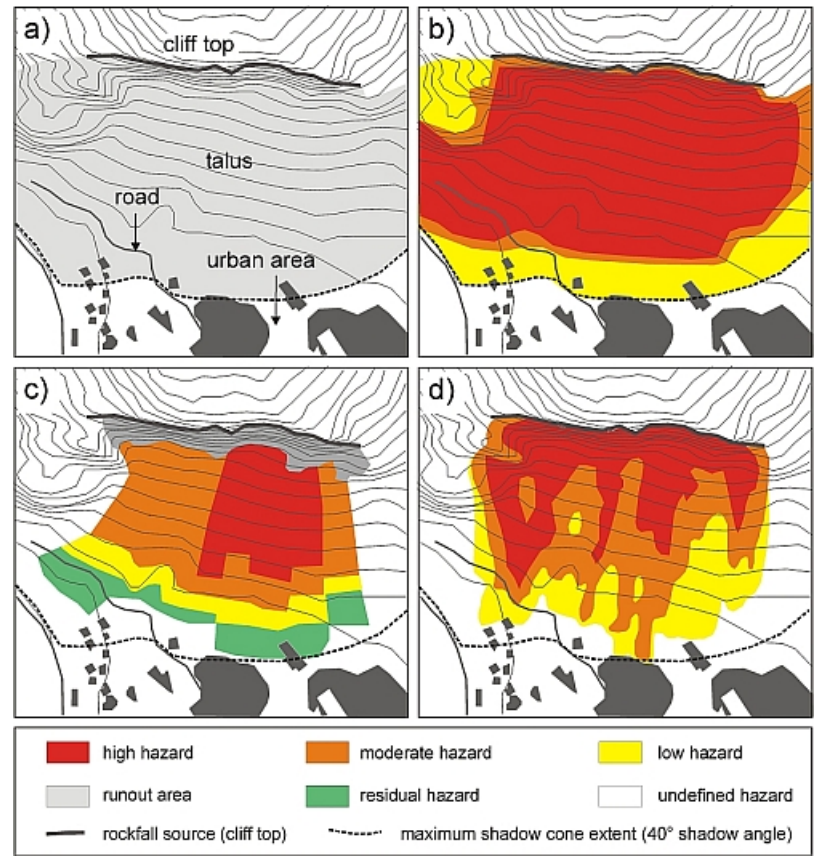

Fig. 3. Comparison of hazard maps derived for the area of Mt. S. Martino (Lecco, Italy; Jaboyedoff et al., 2001; Crosta and Agliardi, 2003) using different modelling approaches and zoning methods. (a) Maximum runout area estimated by a shadow angle approach using the code CONEFALL (Jaboyedoff and Labiouse, 2003); (b) hazard map obtained by applying the RHV methodology (Crosta and Agliardi, 2003) to the reach probability and kinetic energy estimated by CONEFALL; (c) rockfall hazard map obtained by 2-D numerical modelling using the RHAP methodology (modified after Mazzoccola and Sciesa, 2000); (d) rockfall hazard map obtained by 3-D numerical modelling using the code HY-STONE and the RHV methodology (modified after Crosta and Agliardi, 2003).

large scale susceptibility mapping, based on the use of onset susceptibility indicators and the shadow angle method (Fig. 3a). Mazzoccola and Sciesa (2000) proposed a methodology (RHAP) in which 2-D numerical simulation is used to zone reach probability along profiles, later weighted according to indicators of cliff activity (Fig. 3c). Crosta and Agliardi (2003) combined reclassified values of reach susceptibility and intensity values such as kinetic energy or jump height derived by distributed 3-D rockfall modelling to obtain a physically-based index (Rockfall Hazard Vector, RHV). This allows for a quantitative ranking of hazards, accounting for the effects of 3-D topography (Fig. 3d) while keeping information about the contributing parameters. This approach was implemented by Frattini et al. (2008) to include a quantitative evaluation of onset susceptibility by means of multivariate statistical techniques.

When drafting hazard maps for practical purposes, it must be kept in mind that the reliability (and practical applicabil-

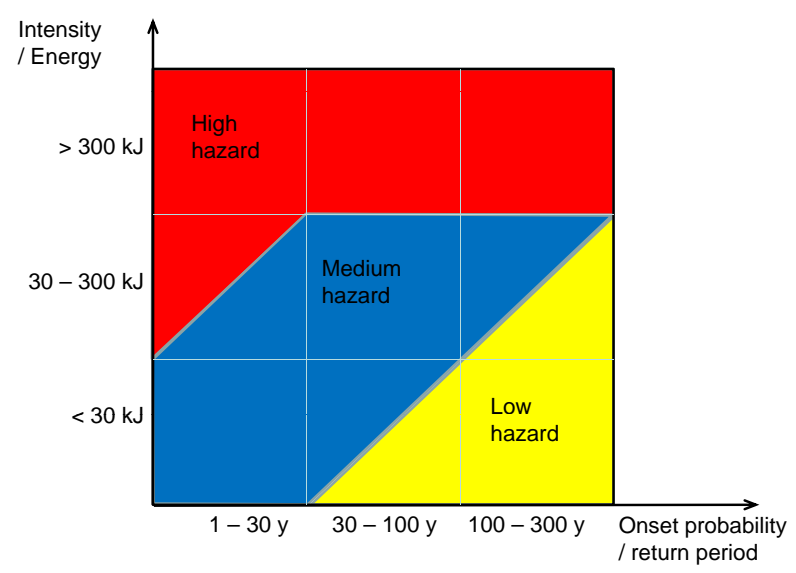

Fig. 4. Hazard classification for rockfall in Switzerland

ity) of hazard maps depends on a number of factors. Different descriptions of rockfall dynamics can be adopted to model rockfall trajectories (e.g., 2-D or 3-D, empirical, kinematical or dynamic). Moreover, complex phenomena, such as block fragmentation or the effects of vegetation, may be accounted for in different ways (Crosta et al., 2004; Dorren et al., 2004) and greatly influence all the hazard components related to rockfall propagation and, thus, the final hazard map. The spatial resolution of the adopted description of topography, especially when 3-D models are used, controls primarily the lateral dispersion of rockfall trajectories and the computed dynamic quantities, thus, affecting the local reach probability and intensity (Crosta and Agliardi, 2004). The applicability of hazard models on different scales and with different aims also depends on model resolution, thus, requiring tools with multi-scale assessment capabilities. Major uncertainties in rockfall hazard zoning are also related to the uncertainty of rockfall onset frequency when required (e.g., Swiss Code). This is often unknown, thus, requiring that a set of scenario-based hazard maps rather than a single map are produced (Jaboyedoff et al., 2005b). From this perspective, the choice of the design block volume scenario is critical to avoid either risky underestimation or costineffective overestimation of a hazard. Finally, the extent of mapped hazard zones is greatly influenced by subjectivity in establishing class boundaries for parameters contributing to the hazard. These should be constrained by physicallybased criteria depending on the envisaged use of the maps (e.g. land planning or countermeasure design; Crosta and Agliardi, 2003; Jaboyedoff et al., 2005b).

\subsection{From hazard to quantitative risk assessment}

Although hazard zoning is a useful tool for land planning, risk analysis should be carried out to support the design and optimization of both structural and non-structural protective 
actions (Fell et al., 2005; Straub and Schubert, 2008). Nevertheless, a standard risk analysis approach for rockfall is yet to be proposed because of the still difficult assessment of hazards. In fact, when a hazard is expressed as susceptibility, risk can only be assessed through relative scales or matrices (Guzzetti et al., 2004; Fell et al., 2005). The simplest form of rockfall risk analysis consists of analysing the distribution of elements at risk with different postulated vulnerability in different hazard zones (Acosta et al., 2003; Guzzetti et al., 2003, 2004). However, this approach does not fully account for the probability of rockfall impact, the vulnerability and value of exposed targets. Guidelines for Quantitative Risk Analysis (QRA) based on Hong Kong rockfall inventories (Chau et al., 2003) were proposed by GEO (1998), whereas Straub and Schubert (2008) combined probability theory and 2-D numerical modelling in order to improve risk analysis for single countermeasure structural design. Bunce et al. (1997) and Hungr et al. (1999) quantitatively estimated rockfall risk along highways in British Columbia, based on inventories of rockfall events. Nevertheless, major efforts are still required to perform a quantitative evaluation of rockfall risk in spatially distributed situations (e.g., urban areas; Corominas et al., 2005), where long runout and complex interactions between rockfall and single elements at risk occur, requiring a quantitative assessment of vulnerability.

In this perspective, Agliardi et al. (2009) proposed a quantitative risk assessment framework exploiting the advantages of 3-D numerical modelling to integrate the evaluation of the temporal probability of rockfall occurrence, the spatial probability and intensity of impacts on structures, their vulnerability, and the related expected costs for different protection scenarios. In order to obtain vulnerability curves based on physical models for reinforced concrete buildings, Mavrouli and Corominas (2010) proposed the use of Finite Element (FE)-based progressive collapse modelling.

\section{Rockfall source areas}

\subsection{Influencing factors}

As pointed out in Sect. 2, the rockfall hazard $H$ at a given location and for a given intensity and scenario depends on two terms, namely: the onset probability (i.e., temporal frequency of rockfall occurrence) of a rockfall instability event and the probability of propagation to a given location (see Eq. 1) (Jaboyedoff et al., 2001). The latter, $P(T \mid L)_{i j k}$, can be evaluated by propagation modelling or by observation. In order to evaluate $P(L)$, it is first necessary to identify potential rockfall sources, whereas their susceptibility is mainly based on rock slope stability analysis or estimates and can be evaluated by field observations or modelling. Anyway, it must be kept in mind that inventories are the only direct way to derive the true hazard in small areas. For rockfall involving limited volumes (i.e., fragmental rockfall, usually
$<100000 \mathrm{~m}^{3}$ ) methods of rock slope stability analysis are well established and their application is relatively easy when the slope and the source area are well characterised (Hoek and Bray, 1981; Norrish and Wyllie, 1996; Wyllie and Mah, 2004). However, this procedure does not give any information about time-dependence and is difficult to apply on a regional scale (Guenther et al., 2004).

Most rockfall source area assessment methods are based on stability assessment or on rockfall activity quantification. In order to get an estimate of rockfall activity, either inventories or indirect methods, such as dendrochronology, are needed (Perret et al., 2006; Corominas et al., 2005). Several parameters can be used to create a hazard map for rockfall source areas, which, most of the time, involves susceptibility mapping (Guzzetti et al., 1999). The parameters used depend mainly on the availability of existing documents or the budget available to collect field information (Jaboyedoff and Derron, 2005).

Source area susceptibility analysis has often used multiparameter rating systems derived from tunnelling and mining engineering, such as Rock Mass Rating (Bieniawski, 1973, 1993, RMR;). Its evolution to the Slope Mass Rating SMR (Romana, 1988, 1993) led to more suitable results by adding an explicit dependence on the joint-slope orientation relationship. Recently, Hoek (1994) introduced the Geological Strength Index (GSI) as a simplified rating of rock quality. In recent years, it has been applied successfully to slope stability analysis (Brideau et al., 2007). A similar approach was proposed by Selby $(1980,1982)$ for geomorphological applications. Later, with the increasing availability of digital elevation models (DEM; Wentworth et al., 1987; Wagner et al., 1988) and of geographic information systems (GIS), several other techniques (heuristic and probabilistic) have been explored (Van Westen, 2004). However, this can be refined conceptually because a slope system can be described in terms of internal parameters (IP) and external factors (EF), which provide a conceptual framework to describe the instability potential using the available data (Fig. 5). Therefore, instability detection requires locating (1) the pre-failure processes and (2) the areas sensitive to rapid strength degradation leading to slope failure (Jaboyedoff et al., 2005a; Leroueil and Locat, 1998). IP are the intrinsic features of the slopes. Some examples are summarized below (Jaboyedoff and Derron, 2005):

(a) Morphology: slope types (slope angle, height of slope, profile, etc.), exposure, type of relief (depends on the controlling erosive processes), etc.

(b) Geology: rock types and weathering, variability of the geological structure, bedding, type of deposit, folded zone, etc.

(c) Fracturing: joint sets, trace lengths, spacing, fracturing intensity, etc.

(d) Mechanical properties of rocks and soil: cohesion, friction angle, etc. 


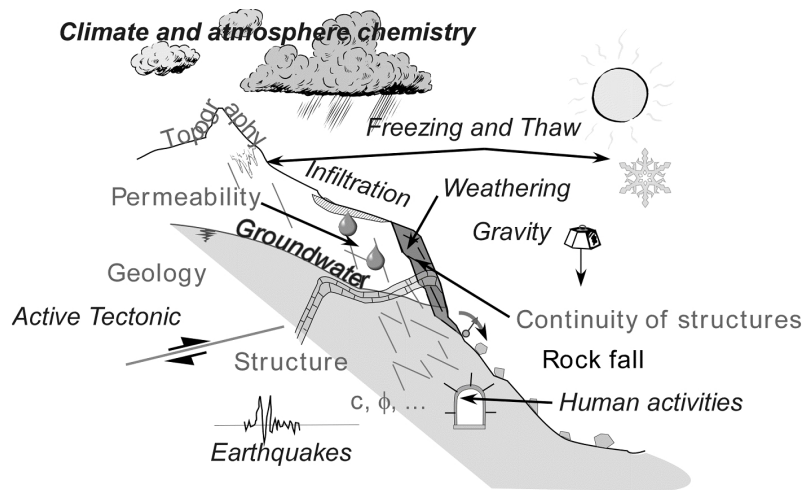

Fig. 5. EF and IP for rockfall (modified from Jaboyedoff and Labiouse, 2003; Jaboyedoff and Derron, 2005).

(e) Activity: movements or rockfall, etc.

(f) Hydrogeology: permeability, joint permeability, etc.

Note that within a given framework, the joint sets or discontinuities are the anisotropies that mainly control the stability (Hoek and Bray, 1981); points b to d are related to these properties. The link between rockfall activity and the intensity of pre-existing fracturing, as in fold hinges with a steep limb, has been demonstrated by Coe and Harp (2007).

The IP can evolve with time due to the effects of the EF, which are (Jaboyedoff and Derron, 2005):

- gravitational effects;

- water circulation: hydrology or hydrogeology, climate, precipitation in the form of rainfall or snow, infiltration rates, groundwater;

- weathering;

- erosion;

- seismicity;

- active tectonics;

- microclimate including freezing and thawing, sun exposure, permafrost, which are increasingly invoked to explain rockfall activities (Frayssines, 2005; Matsuoka and Sakai, 1999; Matsuoka, 2008; Gruner, 2008);

- nearby instabilities;

- human activities (anthropogenic factors);

- etc.

These lists of internal parameters and external factors are not exhaustive, but allow one to introduce key points for the following different methods that have been proposed to assess the value of failure frequency $P(L)$ in general by using susceptibility mapping. GIS and related software allow one to manage most of these parameters regionally. For example, in Switzerland the $1: 25^{\prime} 000$ topographic vectorized maps include the cliff area as polygons (Jaboyedoff and Labiouse, 2003; Loye et al., 2009).

\subsection{Methods of identification and description}

\subsubsection{Methods using regional geomechanical approaches}

Basically, methods such as the Rock Fall Hazard Rating System (RFHRS, Pierson et al., 1990) or the Missouri Rockfall Hazard Rating System (MRFHRS, Maerz et al., 2005) mix both $P(L)$ and $P(T \mid L)$ estimates at the same level, as well as risk. Both methods are designed for talus slopes close to roads and have been refined in two ways, i.e., simplifying the number of parameters from 12 (or 18) to 4 for the RHRS (Santi et al., 2008) or by mixing them with the RMS parameters (Budetta, 2004). These methods mix IP and EF at the same levels.

In addition to the classical rock mass characterisation (Bieniawski, 1973; Romana, 1988), some methods are proposed to regionalise susceptibility parameters. Using mixed IP and EF Mazzoccola and Hudson (1996) developed a rating system based on the matrix interaction approach of the Rock Engineering System (RES) methodology (Hudson, 1992). This allows one to create a modular rock mass characterisation method of slope susceptibility ranking. Based on a similar approach, Vangeon et al. (2001) proposed to calibrate a susceptibility scale using a geotechnical rating with a regional inventory, designed for a linear cliff area (Carere et al., 2001). Rouiller et al. (1998) developed a susceptibility rating system based on 7 criteria mixing IP and EF.

\subsubsection{GIS and DEM analysis-based methods}

The first studies on rockfall using DEM or GIS were performed by Toppe (1987a), using simply the slope angle criterion, and by Wagner et al. (1988) and Wentworth et al. (1987); Wu et al. (1996); Soeters and Van Westen (1996), using structural data for slope modelling. Of course, the simplest way to detect a source area is to use a slope angle threshold (Guzzetti et al., 2003), or to add some other criteria such as the presence of cliff areas (Jaboyedoff and Labiouse, 2003). The slope threshold can be deduced from a detailed slope angle statistical analysis permitting one to identify cliff areas (Strahler, 1954; Baillifard et al., 2003, 2004; Loye et al., 2009). In addition, some other approaches can be used for assessing the susceptibility of source areas, such as using an index obtained by the back-analysis of rockfall propagation. This index links the source area to the deposit, by counting the number of intersections of the trajectories 
with the scree slopes. This can be performed either using the shadow angle method (Baillifard, 2005) or the HY_STONE programme by intersecting the trajectory simulation with the scree slopes (Frattini et al., 2008).

Along one particular road in Switzerland, five parameters: proximity to faults, nearness of a scree slope, cliff height, steep slope and proximity to road, were used to obtain good results using a simple classical GIS approach (Baillifard et al., 2003).

The major improvement related to GIS or/and the use of DEM is the automatic kinematical analysis (Wagner et al., 1988; Rouiller et al., 1998; Gokceoglu et al., 2000; Dorren et al., 2004; Günther, 2003; Guenther et al., 2004), which allows one to determine whether the discontinuity sets are able to create instabilities. Using the standard stability criterion (Norrish and Wyllie, 1996) and a statistical analysis of the kinematical tests, Gokceoglu et al. (2000) were able to produce maps of probability of sliding, toppling or wedge type failures. Günther (2003) and Guenther et al. (2004) used a partial stability analysis using a Mohr-Coulomb criterion and an estimate of the stress state at a given depth of about $20 \mathrm{~m}$ at each pixel of the DEM, also integrating in the analysis the regionalisation of discontinuities such as folded bedding and geology. The number of slope failures linked to joint sets depends on the apparent discontinuity density at the ground surface, which can also be used as an input for the rock slope hazard assessment and to identify the most probable failure zone (Jaboyedoff et al., 2004b). In addition to structural tests, it may also be possible to combine several of the EF and IP, such as water flow, erodible material volume, etc., to obtain a rating index (Baillifard et al., 2004; Oppikofer et al., 2007).

Rock failure is mainly controlled by discontinuities. The main joint sets can be extracted from the orientation of the topography (DEM) using different methods and software (Derron et al., 2005; Jaboyedoff et al., 2007; Kemeny et al., 2006; Voyat et al., 2006). Extracting the discontinuity sets from DEM allows one to perform a kinematic test on a regional area (Oppikofer et al., 2007). New techniques such as ground based LiDAR DEM allow one to extract the full structures, even in the case of inaccessible rock cliffs (Lato et al., 2009; Sturzenegger et al., 2007a; Voyat et al., 2006).

In landslide hazard assessment, many statistical or other modern techniques are now used (Van Westen, 2004); e.g., Aksoy and Ercanoglu (2006) classified the susceptibility of source areas using a fuzzy logic-based evaluation.

\subsection{Concluding remarks on source detection}

Until now, most rock slope systems have been described by considering the EFs and IPs that control stability. This procedure only gives approximate results, mainly because field access is usually limited. Moreover, to assess the hazard from susceptibility maps remains very difficult. Nevertheless, recently developed technologies like photogrammetry or LiDAR (Kemeny et al., 2006) permit one to extract high quality data from DEM that - regarding some points - is better than that from standard fieldwork, especially for geological structures (joint sets, fractures). However, for a local fully detailed analysis, on-site inspection using Alpine techniques is unavoidable in order to correctly asses the amount of openings, fillings or roughness of joints or to verify automatically determined rock face properties.

At the present time, the attempt to extract information such as GSI from LiDAR DEM is still utopian (Sturzenegger et al., 2007b), but we can expect future generations of terrestrial LiDAR to allow the extraction of such information. The analysis of geological structures in high resolution DEM and the simulation of all possible instabilities in a slope have already been performed at the outcrop level (Grenon and Hadjigeorgiou, 2008). We can expect that such methods will be applicable on a regional scale within the next $10 \mathrm{yr}$ by using remote-sensing techniques associated with limited field acquisition that will provide rock parameters, structures and include stability simulations. However, the goal of hazard assessment will not be reached as long as this analysis does not account for temporal dependencies. That can only be achieved if we understand the failure mechanisms, i.e., the degradation of the IP under the action of EF, such as weathering (Jaboyedoff et al., 2007). Expected climate changes will affect the frequency and magnitude of the EF. There is a need to understand their impact on rock slope stability, otherwise we will either miss or overestimate a significant amount of potential rockfall activity.

\section{Trajectory modelling}

It is important to describe the movement of a falling rock along a slope, i.e., its trajectory. This allows the description of existing hazard susceptibility or hazard assessment for a certain area. In addition, the information on boulder velocity, jump heights and spatial distribution is the basis for correct design and the verification of protective measures.

A description of rockfall trajectories can be roughly obtained by analytical methods (see Sect. 4.4.1). If more detailed analyses are needed and stochastic information has to be considered, numerical approaches are recommended.

This section, therefore, attempts to summarize the numerous currently available rockfall trajectory simulation models. To do this, existing models are grouped firstly according to their spatial dimensions: (1) two-dimensional (2-D) trajectory models, (2) 2.5-D or quasi-3-D trajectory models and (3) 3-D trajectory models, and secondly according to the underlying calculation principles. Whether a rockfall trajectory model is 2-D or 3-D, irrespective of its underlying calculation procedure, the experience in applying the model and a knowledge of its sensitivity to parameter settings, as well as how to determine model parameter values in the field, is a prerequisite to obtaining acceptable results. Berger and Dorren (2006) defined the latter as results with an error of $20 \%$. 


\subsection{Types of rockfall model}

\subsubsection{2-D rockfall trajectory models}

We define a 2-D trajectory model as a model that simulates the rockfall trajectory in a spatial domain defined by two axes. This can be a model that calculates along a user-defined slope profile (Azzoni et al., 1995) that is defined by a distance axis (x or y) and an altitude axis (z). Such a profile often follows the line of the steepest descent. Table 1 shows that the majority of the rockfall trajectory models belongs to this group. In the second type of 2-D model rockfall trajectories are calculated in a spatial domain defined by two distance axes $\mathrm{x}$ and $\mathrm{y}$, e.g., a raster with elevation values or a map with contour lines. Such models generally calculate the rockfall path using topographic-hydrologic approaches and velocity and runout distance with a sliding block approach (cf. Van Dijke and van Westen, 1990; Meissl, 1998). As such these models do not provide information on rebound heights.

\subsubsection{5-D rockfall trajectory models}

The second group of trajectory models defined here are 2.5D models, also called quasi-3-D models. These are simply 2-D models assisted by GIS to derive pre-defined fall paths. The key characteristic of such models is that the direction of the rockfall trajectory in the $\mathrm{x}, \mathrm{y}$ domain is independent of the kinematics of the falling rock and its trajectory in the vertical plane. In fact, in these models the calculation of the horizontal fall direction (in the $\mathrm{x}, \mathrm{y}$ domain) could be separated completely from the calculation of the rockfall kinematics and the rebound positions and heights. This means that these models actually carry out two separate 2-D calculations. The first one determines the position of a slope profile in an $\mathrm{x}, \mathrm{y}$ domain and the second one is a 2-D rockfall simulation along the previously defined slope profile. Examples of such models are those that calculate rockfall kinematics along a slope profile that follows the steepest descent as defined using digital terrain data, as in the model Rocky3 (Dorren and Seijmonsbergen, 2003).

\subsubsection{3-D rockfall trajectory models}

These models are defined as trajectory models that calculate the rockfall trajectory in a 3-dimensional plane (x, y, z) during each calculation step. As such, there is an interdependence between the direction of the rockfall trajectory in the $\mathrm{x}, \mathrm{y}$ domain, the kinematics of the falling rock, its rebound positions and heights and if included, impacts on trees. Examples of such models are EBOUL-LMR (Descoeudres and Zimmermann, 1987), STONE (Guzzetti et al., 2002), Rotomap (Scioldo, 2006), DDA (Yang et al., 2004), STAR3-D (Dimnet, 2002), HY-STONE (Crosta et al., 2004) and Rockyfor3-D (Dorren et al., 2004), RAMMS:Rockfall (Christen et al., 2007); Rockfall-Analyst (Lan et al., 2007), PICUS-ROCKnROLL (Rammer et al., 2007; Woltjer et al.,
2008) or as shown in Masuya et al. (1999). The major advantage of 3-D models is that diverging and converging effects of the topography, as well as exceptional or surprising trajectories, i.e., those that are less expected at first sight in the field, are clearly reflected in the resulting maps. A disadvantage of 3-D models is the need for spatially explicit parameter maps, which require much more time in the field than parameter value determination for slope profile-based trajectory simulations.

\subsection{Calculation approaches}

A second main characteristic that allows one to distinguish between different rockfall trajectory models, which is closely related to the calculation of the rebound, is the representation of the simulated rock in the model. As shown in Table 1, this can be done firstly by means of a lumped mass, i.e., the rock is represented by a single, dimensionless point. The second approach is the rigid body, i.e., the rock is represented by a real geometrical shape, which is often a sphere, cube, cylinder or ellipsoid. In general, this approach is used in the deterministic models mentioned above. The last approach is the hybrid approach, i.e., a lumped mass approach for simulating free fall and a rigid body approach for simulating rolling, impact and rebound (Crosta et al., 2004; Frattini et al., 2008; Agliardi et al., 2009).

Most of the rockfall trajectory models use a normal and a tangential coefficient of restitution for calculating the rebound of simulated rock on the slope surface and a friction coefficient for rolling. Details on these coefficients are, among others, presented in Guzzetti et al. (2002). An overview of typical values of the coefficients of restitution can be found in Scioldo (2006). The models that use these coefficients generally apply a probabilistic approach for choosing the parameter values used for the actual rebound calculation (see Table 1). This is to account for the large variability in the real values of these parameters, due to the terrain, the rock shape and the kinematics of the rock during the rebound. Bourrier et al. (2009b) presented a new rebound model that linked the impact angle, the translational and the rotational velocity before and after the rebound based on multidimensional, stochastic functions, which gave promising results for rocky slopes. There are also models that use deterministic approaches for calculating the rockfall rebound. These models use mostly a discrete element method (Cundall, 1971), such as the Discontinuous Deformation Analysis (Yang et al., 2004) or percussion theory (Dimnet, 2002).

The parabolic free falls are calculated with standard algorithms for a uniformly accelerated parabolic movement, except for those models that use the sliding block theory for calculating the rockfall velocity over its complete trajectory. 
Table 1. Main characteristics of a selection of existing rockfall trajectory models (modified from Guzzetti et al., 2002).

\begin{tabular}{|c|c|c|c|c|c|}
\hline Model/programme name & Reference/Year & Spatial Dimensions & Approach & Probabilistic & Forest* \\
\hline N.N. & (Ritchie, 1963) & 2-D (slope profile) & Lumped-mass & No & No \\
\hline Discrete Element Method & (Cundall, 1971) & 2-D (slope profile) & Rigid body & No & No \\
\hline Computer Rockfall Model & (Piteau and Clayton, 1976) & 2-D (slope profile) & Lumped-mass & Partly & No \\
\hline N.N. & (Azimi et al., 1982) & 2-D (slope profile) & Lumped-mass & Yes & No \\
\hline N.N. & (Falcetta, 1985) & 2-D (slope profile) & Rigid body & No & No \\
\hline ROCKSIM & $(\mathrm{Wu}, 1985)$ & 2-D (slope profile) & Lumped-mass & Yes & No \\
\hline SASS & (Bozzolo and Pamini, 1986) & 2-D (slope profile) & Hybrid & Yes & No \\
\hline EBOUL-LMR & $\begin{array}{l}\text { (Descoeudres and Zimmermann, 1987) } \\
\text { (Labiouse et al., 2001) }\end{array}$ & 3-D $(x, y, z)$ & Rigid body & No & No \\
\hline PROPAG/CETE Lyon & (Rochet, 1987a) & 2-D (slope profile) & Lumped-mass & No & No \\
\hline N.N. & (Hungr and Evans, 1988) & 2-D (slope profile) & Lumped-mass & No & No \\
\hline CRSP (4.0) & $\begin{array}{l}\text { (Pfeiffer and Bowen, 1989) } \\
\text { (Jones et al., 2000) }\end{array}$ & 2-D (slope profile) & Hybrid & Yes & No \\
\hline N.N. & (Van Dijke and van Westen, 1990) & 2-D (x,y) & Lumped-mass & No & No \\
\hline N.N. & (Kobayashi et al., 1990) & 2-D (slope profile) & Rigid body & No & No \\
\hline Rotomap & (Scioldo, 1991) & $3-\mathrm{D}(\mathrm{x}, \mathrm{y}, \mathrm{z})$ & Lumped-mass & Yes & No \\
\hline CADMA & (Azzoni et al., 1995) & 2-D (slope profile) & Hybrid & Yes & No \\
\hline Rockfall (Dr. Spang) & (Spang and Sönser, 1995) & 2-D (slope profile) & Rigid body & Yes & Yes \\
\hline ROFMOD 4.1 & $\begin{array}{l}\text { (Zinggeler et al., 1990) } \\
\text { (Krummenacher and Keusen, 1996) }\end{array}$ & 2-D (slope profile) & Hybrid & Yes & Yes \\
\hline 3-D-GEOTEST-Zinggeler & (Krummenacher et al., 2008) & 3-D $(x, y, z)$ & Hybrid & Yes & Yes \\
\hline RocFall & (Stevens, 1998) & 2-D (slope profile) & Lumped-mass & Yes & No \\
\hline Sturzgeschwindigkeit & (Meissl, 1998) & 2-D (x,y) & Lumped-mass & No & No \\
\hline STONE & (Guzzetti et al., 2002) & 3-D $(x, y, z)$ & Lumped-mass & Yes & No \\
\hline STAR3-D & $\begin{array}{l}\text { (Dimnet, 2002) } \\
\text { (Le Hir et al., 2006) }\end{array}$ & $3-\mathrm{D}(\mathrm{x}, \mathrm{y}, \mathrm{z})$ & Rigid body & No & Yes \\
\hline Rocky3 & (Dorren and Seijmonsbergen, 2003) & $\begin{array}{l}2.5-\mathrm{D} \text { (x.y coupled } \\
\text { with slope profile) }\end{array}$ & Hybrid & Yes & Yes \\
\hline HY-STONE & $\begin{array}{l}\text { (Crosta et al., 2004) } \\
\text { (Frattini et al., 2008) } \\
\text { (Agliardi et al., 2009) }\end{array}$ & $3-\mathrm{D}(\mathrm{x}, \mathrm{y}, \mathrm{z})$ & Hybrid & Yes & Yes \\
\hline RockyFor & $\begin{array}{l}\text { (Dorren et al., 2004) } \\
\text { (Dorren et al., 2006) } \\
\text { (Bourrier et al., 2009a) }\end{array}$ & 3-D (x,y,z) & Hybrid & Yes & Yes \\
\hline DDA & (Yang et al., 2004) & & & & \\
\hline RAMMS::Rockfall & (Christen et al., 2007) & 3-D (x,y,z) & Rigid body & Yes & Yes \\
\hline RockFall Analyst & (Lan et al., 2007) & 3-D $(x, y, z)$ & Lumped-mass & Partly & No \\
\hline PICUS-ROCKnROLL & $\begin{array}{l}\text { (Woltjer et al., 2008) } \\
\text { (Rammer et al., 2007) }\end{array}$ & 3-D (x,y,z) & Lumped-mass & Yes & Yes \\
\hline
\end{tabular}

* Forest characteristics such as tree density and corresponding diameters can be taken into account explicitly

\subsection{Block-slope interaction}

The trajectories of falling rocks can be described as combinations of four types of motion: free fall, rolling, sliding and bouncing of a falling block (Ritchie, 1963; Lied, 1977; Descoeudres, 1997). The occurrence of each of these types strongly depends on the slope angle (Ritchie, 1963). For steep slopes, free fall is most commonly observed, whereas for intermediate slopes, rockfall propagation is a succession of free falls and rebounds. For gentle slopes, the prevalent motion types are rolling or sliding.

A significant number of rockfall simulation programmes exist to perform trajectory analyses. The challenge is not in the free flight simulation, but in modelling the interactions between the falling block and the slope's surface. Models are usually classified into two main categories, the rigidbody and the lumped-mass methods (Giani, 1992; Hungr and Evans, 1988). Rigid-body methods consider the block as a body with its own shape and volume, solve the fundamental equations of dynamics and account for all types of block movement, including rotation (Azzoni et al., 1995; Cundall, 1971; Descoeudres and Zimmermann, 1987; Falcetta, 1985). Lumped-mass methods consider the block to have either no mass or a mass concentrated into one point and do not take into account either the shape of the blocks or rotational movement (Guzzetti et al., 2002; Hoek, 1987; Hungr and Evans, 1988; Piteau and Clayton, 1977; Ritchie, 1963; Stevens, 1998). 


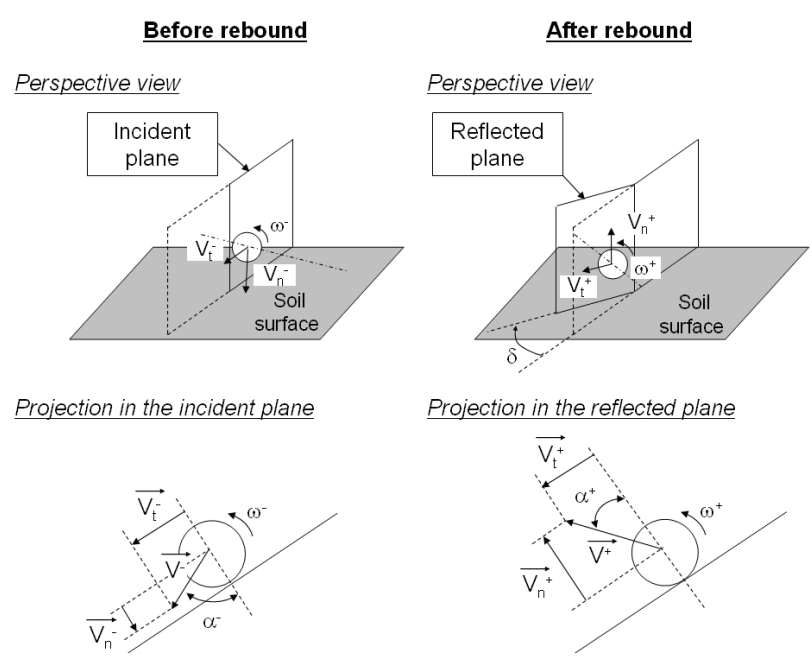

Fig. 6. Definition of the block velocity before and after rebound.

There are other programmes that could be considered as hybrid, taking advantage of the fast and easy simulation of free flight for lumped masses while considering geometrical and mechanical characteristics of the slope and the block to model the impact (Azimi and Desvarreux, 1977; Bozzolo and Pamini, 1986; Dorren et al., 2004; Jones et al., 2000; Kobayashi et al., 1990; Pfeiffer and Bowen, 1989; Rochet, 1987b; Crosta et al., 2004).

If 3-D rockfall simulations are based on a "pseudo-2-D" approach (see Sect. 4) the block's tangential $V_{t}^{-}$and normal $V_{n}^{-}$velocity components (before rebound) with respect to the slope surface allow definition of a plane called the incident plane (Fig. 6). Similarly, the tangential $V_{t}^{+}$and normal $V_{n}^{+}$components of the velocity after rebound also allow the definition of a plane called the reflected plane. The angle $\delta$ between these two planes is called the deviation angle. The normal, tangential and rotational $\omega^{+}$velocities after rebound are computed from the normal, tangential and rotational $\omega^{-}$ velocities before rebound using a rebound model, and the deviation angle $\delta$ is determined, leading to the complete definition of the rock velocity after rebound.

\subsubsection{Sliding and rolling models}

Sliding mainly occurs at small velocities, when a block starts to move or comes to rest. It is not accounted for in many rockfall models because it does not entail large propagations of the blocks. Pure rolling is quite a rare motion mode, except on soft soils when the boulder penetrates the soil (Bozzolo and Pamini, 1986; Ritchie, 1963). The distinction between the rolling and sliding modes is sometimes difficult since a combination of the two movements can occur (Descoeudres, 1997; Giani, 1992). On stiffer outcropping materials, due to the slope surface's irregularity and the rock shape, the rolling motion is more a succession of small bounces.

Therefore, most rockfall models simulate trajectories as successions of free fall and bouncing phases. Only a few consider sliding and rolling motions (e.g., Azzoni et al., 1995; Bozzolo and Pamini, 1986; Statham, 1979). In these models a tangential damping coefficient related to the rolling and/or sliding friction between block and slope is introduced. The sliding friction is defined by means of the normal component with respect to the soil surface of the block's weight according to Coulomb's law. For rolling motion, according to Statham (1979), a fairly accurate description is also given by using Coulomb's law with a rolling friction coefficient that depends on the characteristics of the block (size and shape) and the slope (type and size of debris).

The transition condition between the bouncing and the rolling mode is discussed in Piteau and Clayton (1977), Hungr and Evans (1988) and Giani (1992). The transition from sliding to rolling is defined in Bozzolo et al. (1988).

The whole rockfall trajectory is sometimes modelled as the sliding or rolling of a mass on a sloping surface with an average friction angle assumed to be representative of the mean energy losses along the block's path (Evans and Hungr, 1993; Govi, 1977; Hungr and Evans, 1988; Japan Road Association, 1983; Lied, 1977; Rapp, 1960; Toppe, 1987b). This method (called the Fahrböschung, the shadow angle or the cone method) provides a quick and low-cost preliminary delineation of areas endangered by rockfall, either on a local or a regional scale (Jaboyedoff and Labiouse, 2003; Meissl, 2001).

\subsubsection{Rebound models}

Bouncing occurs when the falling block collides with the slope surface. The height of the bounce and the rebound direction depend on several parameters characterising the impact conditions. Of the four types of movement that occur during rockfall, the bouncing phenomenon is the least understood and the most difficult to predict.

A number of rockfall models represent the rebound in a simplified way by one or two overall coefficients, which are called restitution coefficients. Some models use only one restitution coefficient, quantifying the dissipation in terms of either velocity magnitude loss (Kamijo et al., 2000; Paronuzzi, 1989; Spang and Rautenstrauch, 1988; Spang and Sönser, 1995) or kinetic energy loss (e.g., Azzoni et al., 1995; Bozzolo and Pamini, 1986; Chau et al., 1999a; Urciuoli, 1988). In this case, an assumption regarding the rebound direction is necessary to fully determine the velocity vector after impact (i.e., the $\alpha^{+}$angle in Fig. 6). The $R_{v}$ coefficient is considered for the formulation in terms of velocity loss and the $R_{E}$ coefficient is used for the formulation in terms of kinetic energy (neglecting in general the rotational part):

$$
R_{V}=\frac{V^{+}}{V^{-}} \quad \text { and } \quad R_{E}=\frac{1 / 2\left[I\left(\omega^{+}\right)^{2}+m\left(V^{+}\right)^{2}\right]}{1 / 2\left[I\left(\omega^{-}\right)^{2}+m\left(V^{-}\right)^{2}\right]}
$$


However, the most common definition of block rebound involves differentiation into tangential $R_{t}$ and normal $R_{n}$ restitution coefficients (Budetta and Santo, 1994; Evans and Hungr, 1993; Fornaro et al., 1990; Giani, 1992; Guzzetti et al., 2002; Hoek, 1987; Kobayashi et al., 1990; Pfeiffer and Bowen, 1989; Piteau and Clayton, 1976; Urciuoli, 1988; Ushiro et al., 2000; Wu, 1985):

$$
R_{t}=\frac{V_{t}^{+}}{V_{t}^{-}} \quad \text { and } \quad R_{n}=\frac{V_{n}^{+}}{V_{n}^{-}}
$$

These coefficients are used conjointly and characterise the decrease in the tangential and the normal components of the block velocity, respectively. This definition fully determines the rebound direction ( $\alpha^{+}$angle in Fig. 6) and no further assumption is needed to characterise it.

An alternative approach is based on impulse theory (Frémond, 1995; Goldsmith, 1960; Stronge, 2000) and considers the change in the momentum of the block during the compression and restitution phases of impact (Bozzolo et al., 1988; Descoeudres and Zimmermann, 1987; Dimnet, 2002; Dimnet and Frémond, 2000).

According to Newton's theory of shocks, the restitution coefficients should have a constant value irrespective of the impact energy ("elastic" collision) and of the impact direction. However, since this assumption does not match observations, several models have been developed to account for the dependency of the block velocity after rebound on the kinematical conditions before impact (Bourrier et al., 2009b; Chau et al., 2002; Dorren et al., 2004; Heidenreich, 2004; Pfeiffer and Bowen, 1989). These models can be considered as extensions to classical models based on constant restitution coefficients.

In addition, some very detailed models have been elaborated for the interaction between the block and the slope (Azimi et al., 1982; Falcetta, 1985; Ushiro et al., 2000). They differentiate between impact on hard and soft ground materials, considering for the latter the penetration of the block into the soil modelled with a perfectly plastic or elasto-plastic behaviour. As for the fragmentation of blocks that can occur with impact on hard ground, it is rarely accounted for (Azimi et al., 1982; Chau et al., 1998a; Fornaro et al., 1990) as modellers generally assume that unbreakable blocks propagate further than breakable ones.

Finally, apart from the rigid-body models which integrate the fundamental equations of motion, only a few models account for the rotational velocity along the block path. In this case, a relationship between translation and rotation is usually established, assuming that blocks leave the ground after impact in a rolling mode. Either sticking or slipping conditions are considered at the contact surface (Chau et al., 2002; Kawahara and Muro, 1999; Ushiro et al., 2000).

\subsubsection{Barrier effect of trees}

There are only a few spatial rockfall trajectory models that explicitly (i.e., spatial distribution of different forest stands, stand densities, distribution of diameters at breast height $\mathrm{DBH}$ and species) take into account the mitigating effect of existing forest cover (e.g., Dorren et al., 2006; Crosta et al., 2004; Krummenacher et al., 2008; Woltjer et al., 2008; Masuya et al., 2009). These models would allow determining optimal combinations and locations of technical and silvicultural measures at a given site. Furthermore, they enable rockfall hazard zoning with and without the mitigation effect of forests. Recent data describing the energy dissipative effect of trees is published in Dorren and Berger (2006) and Jonsson (2007). Older data seriously underestimated the energy dissipative capacity of trees, i.e., mature coniferous trees were thought to dissipate up to $15 \mathrm{~kJ}$ instead of 200$500 \mathrm{~kJ}$ (cf. the review on the interaction between trees and falling rocks by Dorren et al., 2007).

\subsubsection{Modelling variability}

A deterministic prediction of the interaction between a block and the slope's surface is not relevant because our understanding of the phenomena is insufficient and many parameters are not completely characterised. Uncertainties are related to the block (shape, dimensions), the topography (inclination, roughness) and the outcropping material (strength and stiffness). As a consequence, even with a thorough field survey, data collection cannot be exhaustive and the rebound prediction should take into consideration a certain variability.

Stochastic rebound models have, therefore, been proposed (Agliardi and Crosta, 2003; Azzoni et al., 1995; Bourrier et al., 2009b; Dudt and Heidenreich, 2001; Guzzetti et al., 2002; Paronuzzi, 1989; Pfeiffer and Bowen, 1989; $\mathrm{Wu}, 1985)$. A model correctly assessing rebound variability should separate the different sources of uncertainty (due to randomness of characteristics or lack of data) and quantify the variability associated with each of them separately. The variability of the bouncing phenomenon is quantified by several statistical laws that need to be calibrated based on the statistical analysis of impact results.

Back-analysis of observed events or field experiments is not feasible for this purpose because either the dataset is incomplete or reproducible impact conditions are difficult to achieve. On the other hand, extensive laboratory experiments, or thoroughly calibrated numerical simulations, can be used. These approaches have already been used for coarse soils (Bourrier et al., 2009b). The challenge for such an approach is the generation of appropriate datasets composed of results for different ground properties and kinematical conditions before rebound. 
Table 2. Parameters assumed to influence the bouncing phenomenon (Labiouse and Descoeudres, 1999).

\begin{tabular}{|c|c|c|}
\hline $\begin{array}{l}\text { Slope } \\
\text { characteristics }\end{array}$ & $\begin{array}{l}\text { Rock } \\
\text { characteristics }\end{array}$ & Kinematics \\
\hline $\begin{array}{l}\text { strength } \\
\text { stiffness } \\
\text { roughness } \\
\text { inclination }\end{array}$ & $\begin{array}{l}\text { strength } \\
\text { stiffness } \\
\text { weight } \\
\text { size } \\
\text { shape }\end{array}$ & $\begin{array}{l}\text { velocity (translational } \\
\ldots \text { and rotational) } \\
\text { incidence angle } \\
\text { configuration of... } \\
\text {...the rock at impact }\end{array}$ \\
\hline
\end{tabular}

\subsubsection{Relevance of impact parameters}

As emphasized by the number of different definitions of the restitution coefficients used in computer codes, the rebound of rock blocks on a slope's surface is still a poorly understood phenomenon. In particular, modelling by means of constant restitution coefficients only as a function of the slope material is not very satisfactory, at least from a scientific point-ofview. Indeed, as mentioned above, the rebound also depends on several parameters related to the boulder and its kinematics before impact (Table 2). Experimental investigations of the influence of these parameters are, therefore, worthwhile for reaching a deeper understanding of the mechanisms occurring during impact and to put forward mathematical expressions between the restitution coefficients and those parameters. These studies also attempt to determine reliable values for the parameters used in the rebound models.

Experimental investigations were carried out both in the field (e.g., Azzoni and De Freitas, 1995; Azzoni et al., 1992; Berger and Dorren, 2006; Bozzolo et al., 1988; Broili, 1977; Evans and Hungr, 1993; Fornaro et al., 1990; Giacomini et al., 2009; Giani, 1992; Japanese highway public corporation, 1973; Kirkby and Statham, 1975; Kobayashi et al., 1990; Lied, 1977; Pfeiffer and Bowen, 1989; Ritchie, 1963; Statham, 1979; Statham and Francis, 1986; Teraoka et al., 2000; Urciuoli, 1996; Wu, 1985; Yoshida, 1998) and in the laboratory (Azimi and Desvarreux, 1977; Azimi et al., 1982; Bourrier, 2008; Camponuovo, 1977; Chau et al., 1998a, 1999a, 2002, 1999b, 1998b; Heidenreich, 2004; Kamijo et al., 2000; Kawahara and Muro, 1999; Murata and Shibuya, 1997; Statham, 1979; Ujihira et al., 1993; Ushiro et al., 2000; Wong et al., 2000, 1999; Masuya et al., 2001). These experiments contributed to determining the most important impact parameters and to quantifying their influence on block rebound.

Experimental investigations have shown the dependence of block bouncing on geometrical parameters and, in particular, on the roughness of the slope (usually characterised by the ratio of block size to average debris particle size). The influence of slope roughness on rebound is generally reported as an explanation for size sorting along slopes (Kirkby and Statham, 1975; Statham and Francis, 1986). Indeed, when the falling block size is greater than the average debris particle size, rolling is the prevailing movement and the block propagates further (Bozzolo and Pamini, 1986; Evans and Hungr, 1993; Giani, 1992; Kirkby and Statham, 1975; Ritchie, 1963; Statham and Francis, 1986). However, on loose soils, increasing block weight induces greater plastic deformation of the soil (formation of a bigger crater), which somewhat reduces the previous influence. As for the shape of blocks, tests carried out with cubic blocks have shown that the impact configuration (e.g., impact on face, edge or corner) has a very significant influence on the block's movement during and after impact (Giani, 1992; Heidenreich, 2004).

Bouncing is found to depend significantly on the transfer of energy between the block and the slope. The initial kinetic energy of the block is converted into kinetic energy after rebound, together with diffused and dissipated energies inside the slope material. Elastic deformation of the slope material also occurs, but, in general, can be neglected. Energy diffusion is due to wave propagation from the impact point (Bourrier et al., 2008; Giani, 1992), while energy dissipation is related to frictional (plastic) processes inside the slope material during impact (Bourrier et al., 2008; Bozzolo and Pamini, 1986; Giani, 1992; Heidenreich, 2004) and is also due to block and/or soil particle fragmentation (Azimi et al., 1982; Fornaro et al., 1990; Giani, 1992). The magnitude of energy dissipation is mainly governed by the ratio between the block and the slope particles (Bourrier et al., 2008; Statham, 1979), the soil properties (Azzoni et al., 1995, 1992) and the block shape and incident orientation (Chau et al., 1999a; Falcetta, 1985; Heidenreich, 2004). Energy diffusion and dissipation processes are also strongly dependent on the kinetic energy of the block before impact, which is related to its mass $m$ and its velocity before rebound $V^{-}$, i.e., $E_{c}=1 / 2 \times m \times\left(V^{-}\right)^{2}$. The effects of variations in block mass (Jones et al., 2000; Pfeiffer and Bowen, 1989; Ushiro et al., 2000) and in block velocity before rebound (Urciuoli, 1988; Ushiro et al., 2000) are different due to the linear and square dependencies.

Another very important feature observed in many experiments is the strong influence of the kinematical conditions before rebound. In particular, experiments show that small impact angles result in greater energy conservation by the block (Bozzolo and Pamini, 1986; Chau et al., 2002; Heidenreich, 2004; Ushiro et al., 2000; Wu, 1985). Indeed, only a small part of the kinetic energy before impact is associated with normal to soil surface velocity and consequently less energy is dissipated into the soil. On the other hand, a significant part of the kinetic energy related to the tangential component of velocity is retained by the block after impact and a part of it (up to $30 \%$ ) is transformed into rotational energy (Kawahara and Muro, 1999; Ushiro et al., 2000). The reflected rotational velocity depends, to a large extent, on the incidence angle and on the soil type. It is governed by the interaction conditions at the contact surface, either sticking or slipping (Chau et al., 2002). 
Given the limited amount of results, most of the abovementioned experimental investigations were insufficient for a thorough understanding of the phenomenon or for statistical and parametric analyses. Therefore, some systematic experimental investigations were carried out in laboratories on small- and medium-scale models (Bourrier, 2008; Chau et al., 2002; Heidenreich, 2004). These experiments were dedicated to analyse the influence on the rebound of parameters related to the ground, the block and the kinematics. Blocks (mainly spherical) were released on different soil materials with different degrees of compaction either normally or with different incidences using specific throwing devices. All experiments were filmed using high-speed cameras. Contrary to field experiments, controlled laboratory experiments provide precisely measured and reproducible results that are valid over larger domains. The trends obtained can, therefore, be used with confidence to improve rebound models. The results from laboratory experiments also provide a lot of information, much of it relevant in the calibration of numerical models of the impact that can, in turn, be used to study energy transfer during impact (Bourrier et al., 2008). However, the quantitative interpretation of laboratory experiments is not straightforward, because matching the similitude requirements for all the parameters involved in the dynamic process can be difficult (Bourrier, 2008; Camponuovo, 1977; Heidenreich, 2004).

The main results gathered from these experimental investigations confirm the general trends obtained in previous studies. Regarding the influence of the slope material characteristics, the motion of the block during and after impact is found to be significantly influenced by the degree of compaction of the soil material and somewhat less by its friction angle (Bourrier, 2008; Heidenreich, 2004). As for the influence of the kinematics before impact, experiments confirm a clear dependency of the restitution coefficients on the block velocity and the impact angle on the slope surface. The influence of the latter seems to prevail (Bourrier, 2008; Chau et al., 2002; Heidenreich, 2004). Additionally, the dependency on block mass and size is more marked for normal than for smaller impact angles because energy transfer to the soil is greater for normal impact (Bourrier, 2008; Heidenreich, 2004). The shape of the block and its configuration at impact were also shown to have a clear influence on the motion of the block after impact and especially on the rotational rate. Finally, the large amount of experimental results allowed, for coarse soils in particular, quantifying the high variability of the kinematics of the block after rebound depending on both the surface shape and the geometrical configuration of soil particles near the point of impact (Bourrier et al., 2009b, 2008).

The results from the above-mentioned laboratory experiments allowed determining the most important geometrical and geotechnical parameters that influence rebound and proposing mathematical expressions for the restitution coefficients as a function of the impact characteristics (Bourrier,
2008; Chau et al., 2002; Heidenreich, 2004). From a practical point-of-view, the implementation in computer codes of the mathematical relationships deduced from the laboratory tests should lead to better predictions of rebound. This can improve the determination of areas at risk, particularly for sites where no rockfall events have been experienced and monitored.

However, from a scientific point-of-view, the relevance of restitution coefficients expressed for the mass centre of the blocks (Eqs. 3-4) is challenged (Labiouse and Heidenreich, 2009). Indeed, from a thorough analysis of impact films, the movement of blocks during impact is found to consist of three main interdependent mechanisms: a normal translation (penetration), a tangential translation (sliding) and a rotation. It is illusory to model this complexity by means of two overall restitution coefficients expressed for the mass centre of the block, as adopted by most existing rockfall trajectory codes. Only rigid-body methods that take into consideration the shape of the blocks and fully consider the interaction between boulder and ground material at the contact surface (including the creation of a crater) would be able to model the impact phenomenon.

\subsubsection{Concluding remarks on block-slope interaction}

The number of different rebound models used in rockfall simulations emphasizes that block-slope interaction is still poorly understood. This complex phenomenon depends not only on the ground conditions (stiffness, strength, roughness, inclination), but also on the block's characteristics (weight, size, shape, strength) and the kinematics before impact (velocities, collision angle, configuration of the block at impact).

One should, therefore, keep in mind that if common rebound models are used, the predictive ability of rockfall simulation is conditioned by a good calibration of its parameters on already experienced or monitored rockfall at the site of interest. In cases where data on natural or artificial events is lacking for the specific site, one should be aware that calculations of rock trajectories can be very misleading when performed with the restitution coefficients stated in the literature or assessed from in situ rockfall events or back-analyses of events on other slopes.

To achieve better reliability in trajectory simulations, several studies have been carried out, or are still in progress, to develop rebound models that account for the influence of the most important impact parameters. The parameters can then be calibrated by a more objective field data collection. To achieve this goal, many experimental investigations were conducted, either in the field or in the laboratory, to reach a deeper understanding of the mechanisms involved during impact and to quantify the influence of the most important geometrical and geotechnical parameters. After a thorough calibration using experimental data, numerical modelling can contribute to studying energy transfer during impact and to assess the influence of parameters outside the range of tested 
values. From these studies, mathematical expressions for the rebound models' parameters can be derived as a function of the impact characteristics.

Implementation of the rebound models in rockfall simulation codes should provide more accurate predictions of rockfall trajectories and energies and consequently improve the delineation of areas at risk and the design of protection structures.

\subsection{Rebound model calibration}

In general, the rebound parameters used for trajectory calculations are estimated on the basis of a rough description of the slope material (rock, scree deposits, loose soil), sometimes complemented by information regarding its roughness, its degree of compaction and the vegetation cover. Now, as mentioned by several authors who have experienced natural and/or artificial in situ rockfall (e.g., Azimi et al., 1982; Azzoni and De Freitas, 1995; Falcetta, 1985; Giani, 1992; Hungr and Evans, 1988), the characteristics of motion after impact are conditioned by several factors other than the slope material properties, such as the weight, size and shape of the blocks, as well as their velocity, collision angle and configuration at impact. Consequently, the restitution coefficients that characterise the rebound of blocks during rockfall are not only a function of the slope material.

Owing to our incomplete knowledge both of and in modelling the bouncing phenomenon and to the rather subjective description of the slope material, the reliability of the simulation results could be improved. This is evident when comparing the results provided by different models on a specific site, or even by the same programme used by different users (Berger and Dorren, 2006; Labiouse, 2004; Labiouse et al., 2001). The limits of predictions are also clear when values of model parameters taken from the literature or obtained by in situ tests or back-analyses of natural events on particular slopes do not provide satisfactory results when used on other slopes.

To achieve good reliability of trajectory predictions, the programme parameters must be thoroughly calibrated at the site of interest. For this purpose, during the field data collection, particular attention should be paid to gain information on the rockfall paths of previous events, such as scars on cliffs, impacts on slopes, damage to vegetation and accumulation zones. Provided the numerical model is well calibrated with these field observations, confidence in the trajectory results will be greatly enhanced.

\subsubsection{Field data collection and analysis}

For a complete back-analysis of the rock's trajectory, the altitudes of the release and deposition positions must be known. In addition, all traces should be recorded on a map in order to obtain the horizontally projected length of the trajectory. Along this, as many follow-up impact craters as pos-

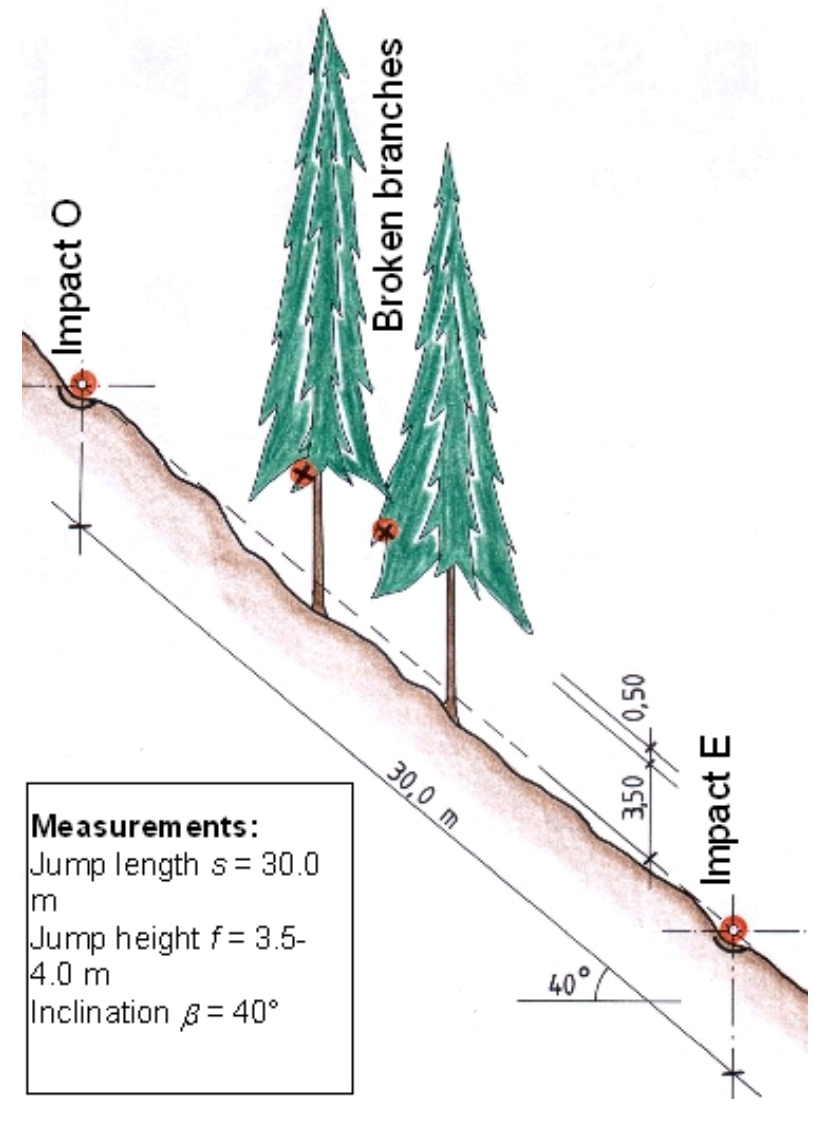

Fig. 7. Schematic illustration of rockfall traces on the ground and tree branches.

sible should be detected with their (inclined) distance $s$ and the slope inclination. Additional traces above ground allowing for a derivation of the jump height should also be logged. However, these traces usually belong to the centre of gravity of the block, whereas the traces on the ground belong to its lower boundary. This has to be considered dealing with small jump heights in combination with large blocks. In rare cases, even the (vertically measured) maximum jump height $f$ in the middle of the jump $(s / 2$ if the inclination of the slope doesn't change significantly) can be measured (Fig. 7). In most cases, however, the jump height $f$ must be estimated based on the inclined jump length $s$. Observations show the following relations to be valid for characteristic jumps:

$$
\begin{aligned}
& f / s=1 / 6 \text { for high jumps } \\
& f / s=1 / 8 \text { for normal jumps } \\
& f / s=1 / 12 \text { for shallow jumps }
\end{aligned}
$$

If the traces on the ground cannot be assigned to the single jumps because of several overlapping rockfall trajectories, the terrain profile of the potential trajectory should be 


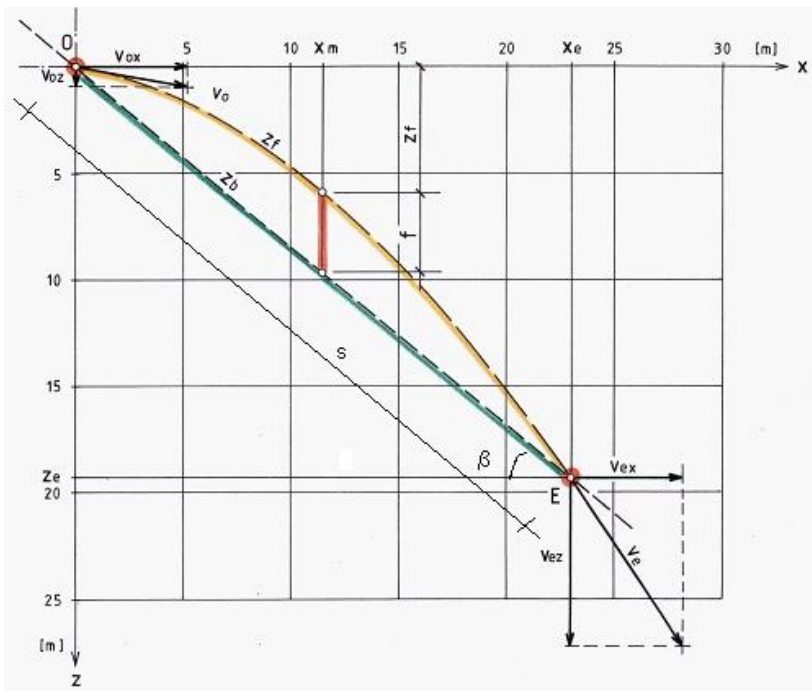

Fig. 8. Details of air parabola with velocity vectors.

recorded. This may allow a later modelling of the rock's movements.

From the field data, the "air parabolas" of the single jumps can be derived with the corresponding velocities. The upper impact crater $O$ is the starting point of a parabola, the other end is defined by the lower crater $E$. The start velocity is called $v_{O}$ and $v_{E}$ defines the next impact velocity split into horizontal and vertical components $x$ and $z$ :

$$
\begin{aligned}
& v_{O x}=\text { lift-off velocity in horizontal direction } \\
& v_{O z}=\text { lift-off velocity in vertical direction } \\
& v_{E x}=\text { impact velocity in horizontal direction } \\
& v_{E z}=\text { impact velocity in vertical direction }
\end{aligned}
$$

The jump height $f$ is defined in the middle of the jump length $s$ (Fig. 8). The horizontal and vertical fractions of the jump length $s$ with a slope inclination $\beta$ are:

$x=s \cos \beta \quad$ and $\quad z=s \sin \beta$

The coordinate components of the lift-off velocity $v_{O}$ are

$v_{O x}=x \sqrt{\frac{g}{8 f}} \quad$ and $\quad v_{O z}=(z-4 f) \sqrt{\frac{g}{8 f}}$

resulting in a total lift-off velocity of

$v_{O}=\sqrt{x^{2}+(z-4 f)^{2}} \sqrt{\frac{g}{8 f}}$.

Herein, $g$ stands for the gravitational constant $g=9.81 \mathrm{~m} \mathrm{~s}^{-2}$ and the vertical direction is used with a positive sign if directed upwards. Accordingly, the impact velocity $v_{E}$ is

$v_{E}=v_{E x}+v_{E z}=\sqrt{x^{2}+(z+4 f)^{2}} \sqrt{\frac{g}{8 f}}$.
Table 3. Start and end velocities of a parabolic trajectory for different values of jump height

\begin{tabular}{lrrr}
\hline Jump height $f$ & $3.50 \mathrm{~m}$ & $3.75 \mathrm{~m}$ & $4.0 \mathrm{~m}$ \\
\hline Jump length $s$ & $30.0 \mathrm{~m}$ & $30.0 \mathrm{~m}$ & $30.0 \mathrm{~m}$ \\
Inclination $\beta$ & $40^{\circ}$ & $40^{\circ}$ & $40^{\circ}$ \\
Jump length $x$ & $22.98 \mathrm{~m}$ & $22.98 \mathrm{~m}$ & $22.98 \mathrm{~m}$ \\
Jump length $z$ & $19.28 \mathrm{~m}$ & $19.28 \mathrm{~m}$ & $19.28 \mathrm{~m}$ \\
& & & \\
Lift-off velocity $v_{O x}$ & $13.60 \mathrm{~m} \mathrm{~s}^{-1}$ & $13.14 \mathrm{~m} \mathrm{~s}^{-1}$ & $12.72 \mathrm{~m} \mathrm{~s}^{-1}$ \\
Lift-off velocity $v_{O z}$ & $3.13 \mathrm{~m} \mathrm{~s}^{-1}$ & $2.45 \mathrm{~m} \mathrm{~s}^{-1}$ & $1.82 \mathrm{~m} \mathrm{~s}^{-1}$ \\
Lift-off velocity $v_{O}$ & $14.0 \mathrm{~m} \mathrm{~s}^{-1}$ & $13.4 \mathrm{~m} \mathrm{~s}^{-1}$ & $12.9 \mathrm{~m} \mathrm{~s}^{-1}$ \\
& & & \\
Impact velocity $v_{E x}$ & $13.60 \mathrm{~m} \mathrm{~s}^{-1}$ & $13.14 \mathrm{~m} \mathrm{~s}^{-1}$ & $12.72 \mathrm{~m} \mathrm{~s}^{-1}$ \\
Impact velocity $v_{E z}$ & $19.70 \mathrm{~m} \mathrm{~s}^{-1}$ & $19.60 \mathrm{~m} \mathrm{~s}^{-1}$ & $19.54 \mathrm{~m} \mathrm{~s}^{-1}$ \\
Impact velocity $v_{E}$ & $23.9 \mathrm{~m} \mathrm{~s}^{-1}$ & $23.6 \mathrm{~m} \mathrm{~s}^{-1}$ & $23.3 \mathrm{~m} \mathrm{~s}^{-1}$ \\
\hline
\end{tabular}

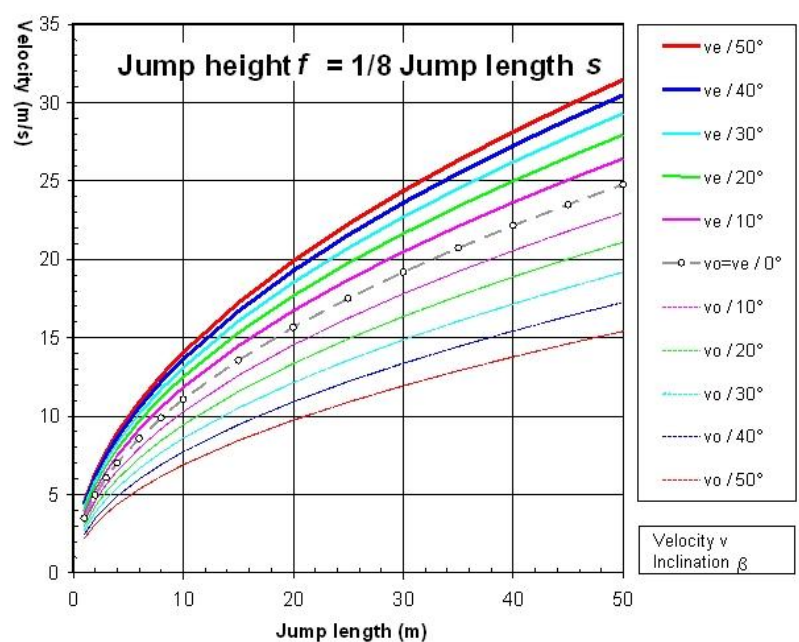

Fig. 9. Lift-off and impact velocity for an assumed jump height of $f / s=1 / 8$ as a tool for rapid trajectory analyses in the field.

As an example, the series of measured values (see Fig. 7) would result in the velocities shown in Table 3 . The different assumed jump heights of $3.5-4.0 \mathrm{~m}$ result in similar lift-off and impact velocities.

The determination of the start and end velocities $v_{O}$ and $v_{E}$ can be simplified and speeded up by making use of a diagram that depends on the jump length $s$ and slope inclination $\beta$ paired with an assumed jump height relationship of $f / s=1 / 8$. Such graphics can be easily prepared for any other relation of $f / s$.

\section{Structural countermeasures}

In the case of infrastructure or buildings situated within a rockfall hazard zone, either suitable newly planned/built 
protection measures are needed or are necessitated by changed boundaries of rockfall occurrence. This section gives an overview of modern protection systems and provides a short summary for dams, embankments and ditches in Sect. 5.2. A more comprehensive state-of-the-art report deals with fences and galleries (Sects. 5.3 and 5.4). For forests, reference should be made to a recent review of the protection of forests in Sect. 5.5.

\subsection{Action of rocks on protection structures}

For a long time, estimations of the impact load caused by a rockfall were only drawn from empirical relationships based on experimental observations. Then several other formulations were developed from theoretical considerations assuming the ground behaviour to be elastic, plastic or elastoplastic. The first family of relationships, derived from Hertz's elastic contact theory, assumes that a rigid ball impacts an elastic medium (Goldsmith, 1960; Japan Road Association, 1983; Lang, 1974; Tonello, 1988). Other formulations are based on a plastic or elasto-plastic behaviour of the ground material (Azimi and Desvarreux, 1988; Habib, 1976; Heierli, 1984; Lang, 1974; Tonello, 1988). Recently, formulas were derived from the penetration of nondeformable ogive-nose projectiles onto concrete and soil targets (Pichler et al., 2005). For roughly the last decade, many efforts are devoted to the numerical modelling of the impact on rockfall protection structures, using finite element (FE) and discrete element (DE) methods (Bertrand et al., 2006; Calvetti, 1998; Calvetti et al., 2005; Magnier and Donzé, 1998; Masuya and Kajikawa, 1991; Nakata et al., 1997; Nicot et al., 2007; Peila et al., 2002, 2007; Plassiard et al., 2004). The DE method seems quite promising for studying impact problems, provided that a careful calibration of the parameters is first achieved.

To gather data on the action of rocks on protection structures and then to calibrate numerical codes, experimental campaigns are essential. Several half-scale and full-scale experimental studies have been conducted to determine the damping abilities of the cushion covering rockfall protection galleries (often called rock sheds) for design purposes, by dropping blocks of different weights and shapes from various heights on concrete slabs covered with different absorbing materials (Calvetti et al., 2005; Chikatamarla, 2006; Labiouse et al., 1996; Montani-Stoffel, 1998; Murata and Shibuya, 1997; Sato et al., 1996; Schellenberg et al., 2008; Yoshida et al., 1988). Other testing campaigns were carried out on gravel layers (Pichler et al., 2005), embankments (Blovsky, 2002; Burroughs et al., 1993; Lepert and Corté, 1988; Peila et al., 2002; Yoshida, 1999) and composite structures (Lambert et al., 2009; Lorentz et al., 2006). Parametrical analyses performed in the framework of these experimental campaigns allowed for the determining of the most important factors and quantifying their influence on the impact force. They are related to the block (mass, shape) and its kinematics (velocity and impact angle) and to the layer of absorbing material (thickness, compaction degree). For rockfall protection galleries, the action on the structure is also found to depend on the structure's stiffness.

Most of the above-mentioned studies provided quantitative data on the temporal evolution of the impact force induced by the block (measured accelerations by means of accelerometers on the boulder and/or using image processing of highspeed camera films to obtain the evolution of velocity over time), on the penetration of the block into the absorbing material and, for some of them, on the earth pressures acting at the base of the cushion layer (i.e., on the structure). The data gathered provide information on the transfer of energy during the impact and on the force exerted on the structure. Formulas were worked out to assess the magnitude of the forces, with the aim of improving the design of protection structures (e.g., SBB, 1998). However, these results and formulas must be interpreted with caution because the thickness of the absorbing cushion and the boundary conditions strongly influence the dynamics of the interaction (Calvetti, 1998; Montani-Stoffel, 1998).

When carefully calibrated on the experimental data, numerically modelling the impacts can help to better understand and quantify the energy diffusion and dissipation inside the absorbing cushion. It can also contribute to assessing the influence of various parameters that could not be studied, or only in a limited range of values, during the experimental campaigns, and to improving the design of protection structures.

\subsection{Embankments and ditches}

Embankments and ditches belong to the quasi-natural class of protection measures against rockfall. Their construction along the side of the infrastructure is efficient and they are one of the most reliable protection measures. Therefore, they are more likely to be used to protect permanent buildings. Embankments are able to withstand high impact energies of e.g., $20 \mathrm{MJ}$ (personal communication with practitioners). However, the cross sections of embankments and ditches require a rather large area in front of the protected object.

For structural measures, like fences or galleries, the performance of the protective system is quite well known and the planning of protection measures does not have to take into account the deceleration process. However, this has to be clarified for the structural safety of earth embankments. This includes the questions: What is the impact load as a function of the impact energy? What is the effect of changing mass or impact velocity? What is the limit state of the embankment? What is the influence of soil properties such as density, strength, angle of internal friction? What is the penetration depth? How does the cross section of an embankment or ditch affect the interaction with the block?

For example and theoretically, the front face taking the impact could be (at least partially) vertical. This might deviate 
the block into a vertical path and its rotation does not cause it to roll over the embankment or roll out of a ditch. In practice, several impacts on rockfall embankments are documented where the construction fulfilled its task for inclined hillslide slopes even with angles that represent the friction angles of the construction material. The geometry of the embankment should, therefore, reflect more the local geometrical boundaries and can also be strongly influenced by the existence and width of a hillside catchment zone (e.g., being covered by a damping layer to dissipate energy and reduce bouncing height). Furthermore, rather low inclined hillside slopes of embankments covered by a damping layer (built with its friction angle) will prevent a rolling block to overcome the construction as the material reacts with ground failure as soon as the block induces shear forces to the slope. Therefore, it should be noted, that for the design of the geometry of the embankment (especially the inclination of the hillside slope) should be done with respect to the geometry of the slope where the construction will be done. Ideally the slope of the embankment will be rectangular to the hillslope.

The deceleration process into soil has been investigated on different scales, i.e., small (Heidenreich, 2004), large (Labiouse et al., 1996; Montani-Stoffel, 1998) and full scale (Gerber, 2008). The main results are the maximum deceleration and penetration of blocks. Both results are important for galleries (see Sect. 5.3) to design the strength of the underlying structures and the thickness of the soil layer (Labiouse et al., 1996; ASTRA, 2008; Schellenberg et al., 2008). The dynamic decelerating force is then usually transformed into a statically-equivalent force.

Most experiments presented in Montani-Stoffel (1998); Gerber (2008); Pichler et al. (2005) deal with experimental data gained in an effort to quantify forces acting on a horizontal and stiff concrete slab covered by various damping layers. The impact in these experiments is done by free fall in a vertical direction. Opposed to these experiments, the impact acting on rockfall embankments (being usually constructions built with compacted soils and not featuring stiff layers) will most probably react differently to the behaviour of the tested structures. The few projects dealing with embankments built from soil exclusively deal with real scale experiments (Peila et al., 2002, 2007) or model tests (Blovsky, 2002) made from geogrid reinforced soil embankments. This reveals that further tests to characterise the behaviour of earth embankments with and without geogrid reinforcements are necessary.

Gerber (2008) measured the impact on soil of varying thickness of free falling blocks of 800 and $4000 \mathrm{~kg}$ with falling heights varying from $2 \ldots 15 \mathrm{~m}$ resulting in impact energies in the range 20 to $600 \mathrm{~kJ}$. Based on these experiments the following formulas for the maximum deceleration $a$ and penetration depth $p$ due to an impact velocity $v$ have been proposed:

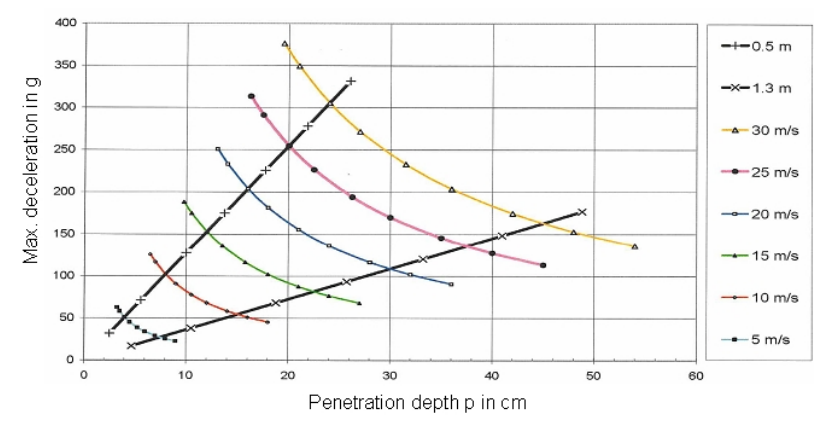

Fig. 10. Penetration and deceleration of impacting rocks onto consolidated soil of thickness $0.5 \mathrm{~m}$ and $1.3 \mathrm{~m}$ for different impact velocities.

$a=0.8 v^{2} /(g t)$

$p=0.8 v^{2} / a$

Thus, the relationship between penetration depth and maximum deceleration can be formulated as a function of the soil layer thickness (see Fig. 10). However, the formulas result from experiments and the parameters measured after the impacts of rigid bodies on cushion layers after a vertical fall. The cushion layer overlies a stiff construction and, therefore, cannot easily be transferred to earth embankments, which feature elasto-plastic deformation in the direction of a free surface (valley-side slope of the embankment). Furthermore, the measured parameters $p$ and $a$ are difficult to obtain in the field without having appropriate data on the behaviour of the block at the impact on the surface of an embankment. The data from vertical falling tests on damping layers above a stiff layer do not necessarily reflect the load-case experienced on rockfall embankments, but might be used as long as no better results are available.

To optimize embankment dimensions, further full-scale tests on earth embankment structures are necessary. In Peila et al. (2002) and Peila et al. (2007) the performance of reinforced embankments is described showing penetration depths of $0.6-1.1 \mathrm{~m}$ for embankments with a base width of $5 \mathrm{~m}$ and a height of around $4.5 \mathrm{~m}$ and rockfall impact energies between 2400 and $4200 \mathrm{~kJ}$. An overview on the design methods for embankments is given by Lambert and Bourrier (2011) and an example of the design of a rockfall protection embankment is given in Baumann (2008).

\subsection{Rockfall protection galleries}

There are many different types of rockfall protection galleries with regard to structural design (Fig. 11). The most common type in Switzerland is a monolithic reinforced concrete structure covered by a cushion layer (Schellenberg and Vogel, 2005). 

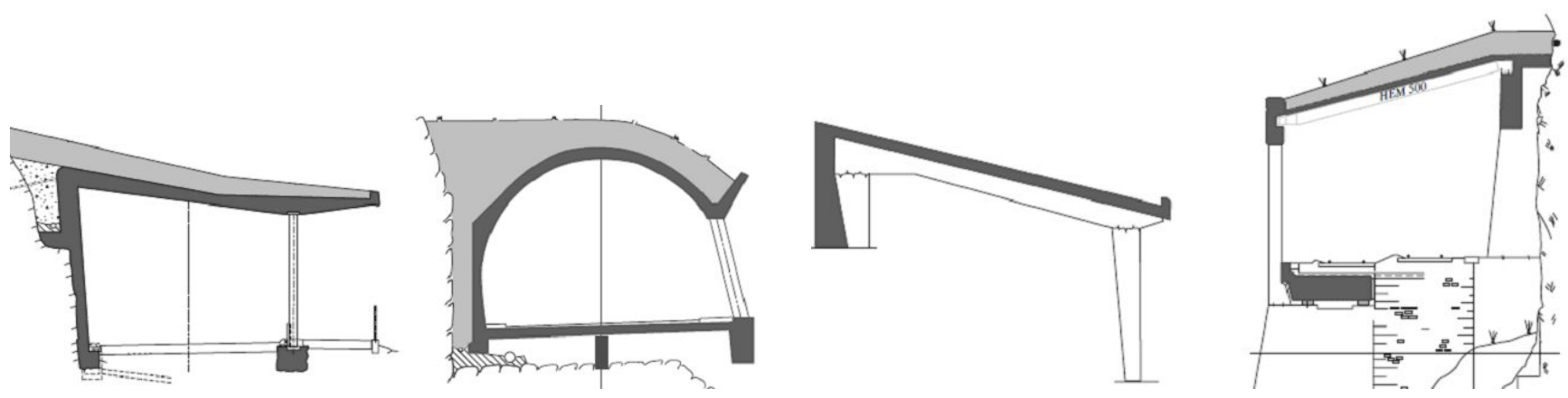

Fig. 11. Different types of shed structures (fltr): reinforced-concrete slab, shell type, in situ reinforced concrete, and steel-concrete-composite type (from Vogel et al., 2009).
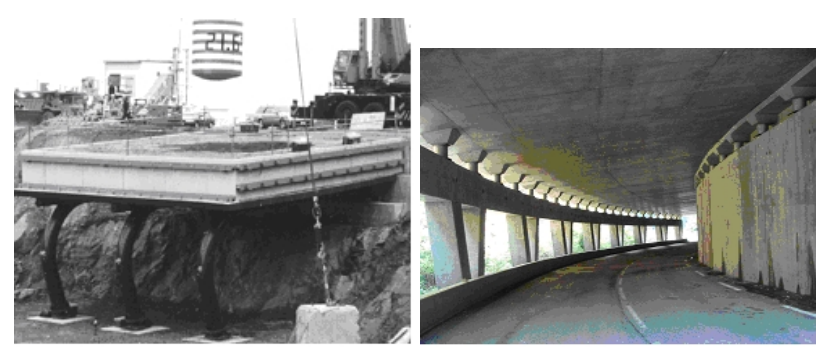

Fig. 12. Full-scale steel-concrete composite rock shed subjected to a falling weight (left; Maegawa et al., 2003), gallery with PSD dissipation system in Val d'Arly, France (right; taken from Masuya, 2007).

Rockfall galleries are appropriate protective measures for small and well-defined endangered zones with a high rate of medium magnitude events (Jacquemoud, 1999). While providing protection against high energy impacts, galleries can provide a low maintenance solution for frequent low energy events, for which the rocks accumulating on the gallery are removed at given time intervals.

The working range of galleries has been estimated to be for impact energies up to about $3000 \mathrm{~kJ}$ (ASTRA, 2003). Based on recent research which focuses on either improving the damping properties of the cushion layer, increasing the structural capacity or adding energy-dissipating supports, the galleries can provide protection for up to $5000 \mathrm{~kJ}$ (Vogel et al., 2009).

Steel-concrete-composite galleries (Fig. 12 Maegawa et al., 2003) or composite sandwich structures with hightensile bolt connections (Fig. 13 Konno et al., 2008) have been evaluated in Japan and could provide future solutions for specific applications.

The following section gives a summary of research related to protection galleries with emphasis on the cushion layer and the structural evaluation of the galleries.

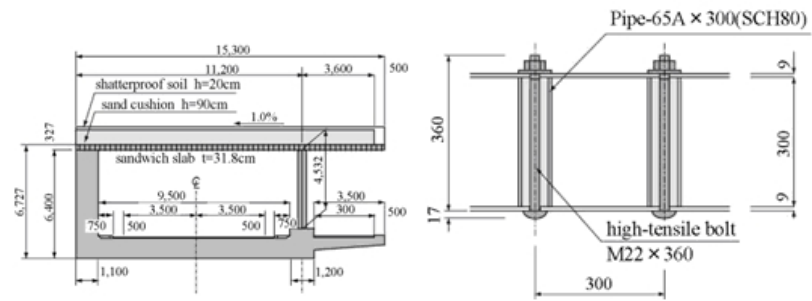

Fig. 13. Steel-concrete composite structure for a rockfall protection gallery (Konno et al., 2008)

\subsubsection{Cushion layer}

The main function of a cushion layer is to act as a shock absorbers (Jacquemoud, 1999). Shock waves in reinforced concrete structures could cause the separation of the concrete cover on the soffit, so called scabbing, even for impacts with less intensity than the structural capacity (Herrmann, 2002).

The cushion layer also dissipates some of the impact energy, distributes the contact stresses, decreases the peak loading on the impacted structure and also increases the duration of impact. For economic reasons, locally available granular material is often used as a cushion material, whereas in Japan sand is generally used (Ishikawa, 1999).

The dynamic force applied to the top of the cushion layer due to a falling block is empirically given by Eq. (11) (Montani-Stoffel, 1998). The impact force depends on the E-Moduli of the cushion layers $M_{E}$ as well as on the block radius $r$ and the rock's kinematic energy, expressed in terms of mass $m$ and impact velocity $v$.

$P_{\max }=1.765 \times r^{0.2} \times M_{E}^{0.4} \times\left(\frac{m \times v^{2}}{2}\right)^{0.6}$

For structural design purposes, however, the forces transmitted across the interface between the cushion layer and structure are required. Of interest are the definitions of load magnitude and loading area. Both, of course, vary with time 
during the impact process and depend on the material properties of the cushion layer.

In experimental research (Kishi et al., 1993), the transmitted force was found to be about 1.8 times the impact force in the case of a sand cushion layer or only half the impact force for a special three layer cushion system (Ishikawa, 1999). The transmitted force, which is the load acting on the structures, can also be determined numerically. A simplified method using an ordinary FE code, assuming onedimensional stress wave propagation and elastic-plastic soil properties was used to estimate the stress distributions for relatively small impact loads (Sonoda, 1999).

Today, advanced FE models (e.g., LS-DYNA code) are used to model entire galleries including the cushion layer and are able to match results from large scale tests (Kishi et al., 2009). In the latest simulations for the cushion layer, a cap-hardening model is used, in which parameters are determined by curve fitting using experimental data (GhadimiKhasraghy et al., 2009).

Numerical simulations, by means of the DE method, have been applied for rockfall impact on embankments (Plassiard and Donzé, 2009) and could potentially lead to future improvements in the design of rockfall protection galleries. It has also been proposed to simulate the processes taking place within the cushion layer by a rheological model (Calvetti and Di Prisco, 2009) or by a simplified nonlinear spring describing the overall relationship between force and rock penetration into the cushion layer (Schellenberg, 2009).

The selection of the cushion material can significantly improve the capacity of the gallery. The energy dissipation for different materials and mixtures has been studied in centrifuge tests, with the result that a mixture of sand-rubber (70\%-30\%) with clay lumps seems to be an efficient cushion material (Chikatamarla, 2006).

Full scale tests in Japan showed that the impact forces can also be substantially reduced by the above-mentioned threelayered absorbing system (TLAS), which is composed of an EPS (expanded polystyrol) layer, a reinforced concrete core slab and a sand layer (Nakano et al., 1995). A large-scale test in Switzerland with foam glass as cushion layer material also showed promising results (Schellenberg et al., 2007, Fig. 14top). Lorentz et al. (2008) investigated the performance of sandwich structures composed of two or three reinforced concrete layers separated by tyres (Fig. 14bottom).

A different approach to dissipate energy without a cushion layer is the PSD system (Pare-blocs Structurellement Dissipantes) proposed in France and shown in Fig. 12 right. The slab is subjected to direct impact and energy absorbing devices are placed at the slab supports (Tonello, 2001). Test results on a scale of $1 / 3$ are presented in (Berthet-Rambaud, 2004).
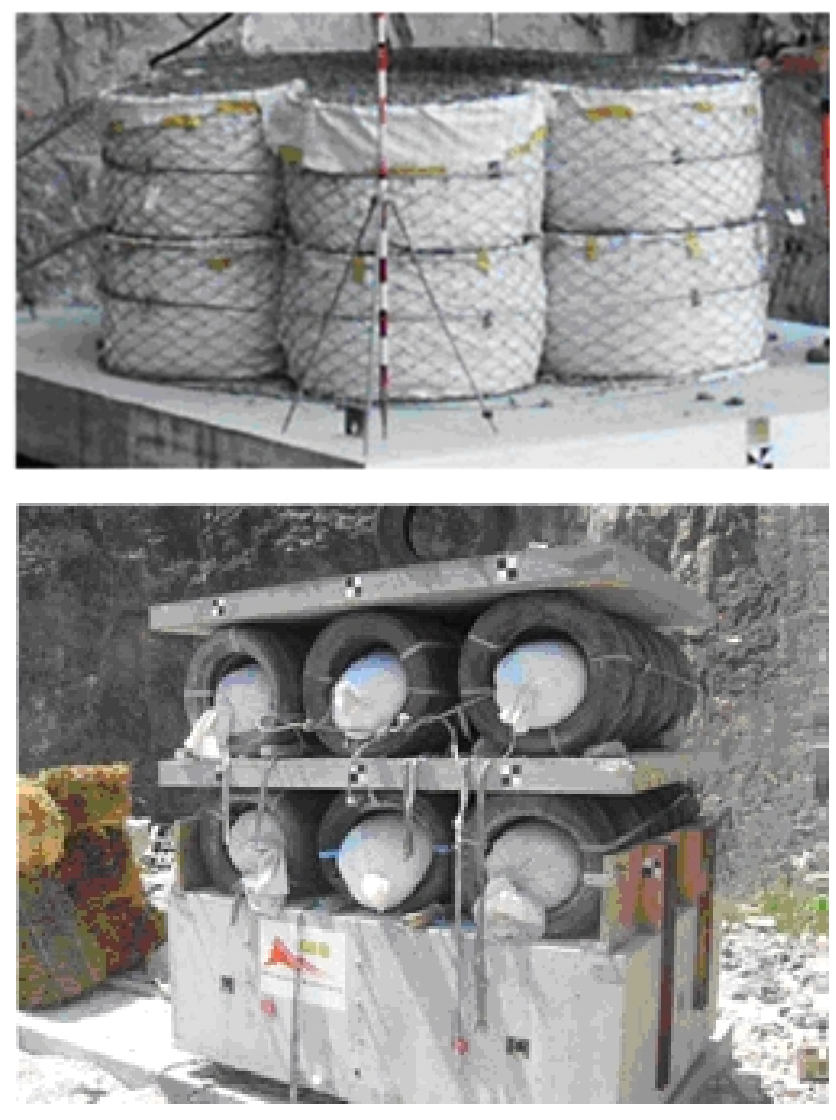

Fig. 14. Alternative cushion layers: (top) Fence box structure with cellular glass material (Schellenberg, 2008), (bottom) Multi-layer sandwich structure (Lorentz et al., 2008).

\subsubsection{Structural evaluation}

To date guidelines for the design of rockfall galleries have been published in Switzerland and in Japan (ASTRA, 2008; Japan Road Association, 2000). In both cases, a staticequivalent force is applied, which apart from the rock mass and velocity depends mostly on the geotechnical conditions of the cushion layer. This approach is simple to use by practicing engineers, but presents difficulties in accounting for the complex dynamic processes during the impact. A summary of older formulations for the impact force is given in Montani-Stoffel (1998) and a comparison of the different calculation methods can be found in Casanovas (2006).

Based on a system of multiple degrees of freedom for impact loads (Comité-Euro-International du Béton, 1988), a new analytical model has been proposed for the design of rockfall galleries, which allows predicting both shear and bending failure (Schellenberg et al., 2008, Fig. 15).

The time histories of the spring forces are derived from the equations of motion with the given masses and spring properties described above. The peak loads are performancebased results and can be compared with the resistance in the critical sections of the slab. 
a)

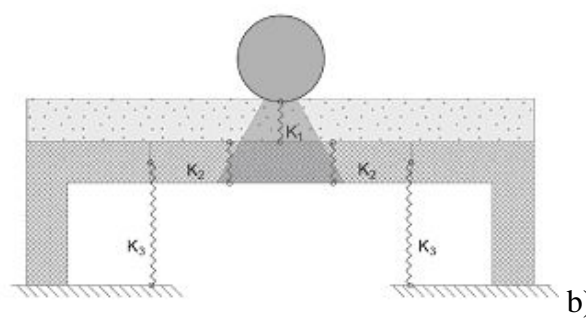

b)

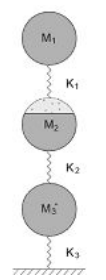

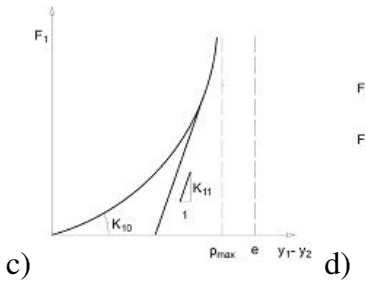

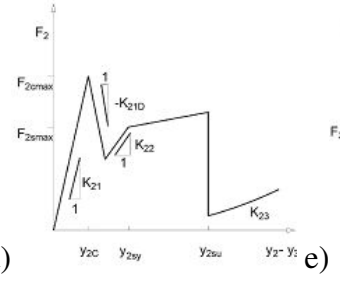

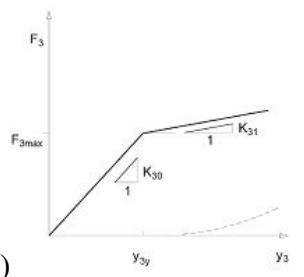

Fig. 15. System with multiple degrees of freedom (SMDF) (a) and (b), from the section of a gallery to the model definition together with the force-displacement relationship of the springs for (c) cushion layer, (d) shear behaviour and (e) global bending stiffness (from Schellenberg and Vogel, 2009).

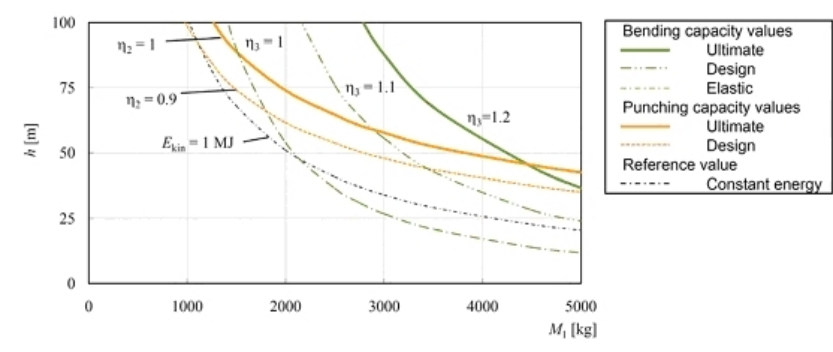

Fig. 16. Loading capacity of protection gallery Axen-Süd for different impact masses (from Schellenberg, 2009).

With this model relative values between the maximum forces and the load bearing capacities for punching $\left(\eta_{2}\right)$ and bending failure $\left(\eta_{3}\right)$ are obtained, leading to an iterative process for the structural design.

This procedure is particularly suitable for the evaluation of existing galleries. Figure 16 shows the ratio values reached for rocks with different masses falling from different heights for the gallery Axen-Süd in Switzerland. Future evaluations of the force penetration relationship of the rock into the cushion layer would improve this model.

In recent years, significant advances have been made regarding numerical simulations to aid structural design (Kishi et al., 2009; Masuya and Nakata, 2001). The simulations allow a detailed evaluation of the structure and its response to rockfall impact (Fig. 17). This approach, however, requires experimental data for calibration and significant resources, limiting its application in practice. Such efforts, though, are useful for the development of design guidelines and for evaluating critical sections and parametric influences.

Despite advances in understanding the structural performance of rockfall galleries, there are still large uncertainties regarding the definition of design situations. Therefore, probabilistic methods are attractive tools because the uncertainties can be better quantified. In addition, future developments in the design of new protection galleries or the evaluation of existing sheds might involve evaluating the failure probability for different design situations and select the design situations based on overall risk acceptance criteria.

\subsection{Flexible protection systems}

Today, one of the most common protection measures against rockfall is the use of flexible protection systems. Such barriers are usually installed like fences along the boundary of an infrastructure or in front of buildings acting as a passive protection system, i.e., they are meant to stop a moving block. Much research has already been performed on such barriers in recent years. At first, the research work concentrated on the general ability of flexible systems to reliably retain falling rocks (Sect. 5.4.1). Later, the emphasis was on how to improve our knowledge of such barriers, e.g., by means of systematic and extensive testing (Grassl, 2002), overall evaluations (Spang and Bolliger, 2001) or numerical simulations (see Sect. 5.4.5). The knowledge gained thereby formed the basis for standardization as described in Sect. 5.4.2. Because the research is usually rather application-oriented and carried out in close cooperation with the manufacturers, typically the published results consider just one barrier type. However, it still would be possible to compare the different systems regarding their performance, braking distance, energy balance, etc., as done by Gerber and Volkwein (2007).

Today, after several decades of development and improvement, a typical flexible rockfall protection system consists of a steel net attached longitudinally to so-called support ropes. The nets with mesh openings ranging from $5-35 \mathrm{~cm}$ are made from chain-link meshes, wire-rope nets or steel rings, the latter being concatenated like a historical byrnie and originate from the torpedo protection nets used in front of harbours and ships in the 2nd World War. Only limited knowledge exists on the use of alternative net materials (Tajima et al., 2003). The support ropes (rope section diameter $12-22 \mathrm{~mm}$ ) are spanned between steel posts with typical lengths between 2 and $7 \mathrm{~m}$ and field spacings varying between 5 and $12 \mathrm{~m}$. The posts are fixated by ground plates either by clamped support or hinged support with additional upslope ropes at the post head. Details regarding the state-of-the-art post foundations including suggestions for load measurements can be found in Turner et al. (2009). Additional ropes may be placed depending on the individual systems. Connections to the ground are usually achieved by drilled anchors. For higher impact 


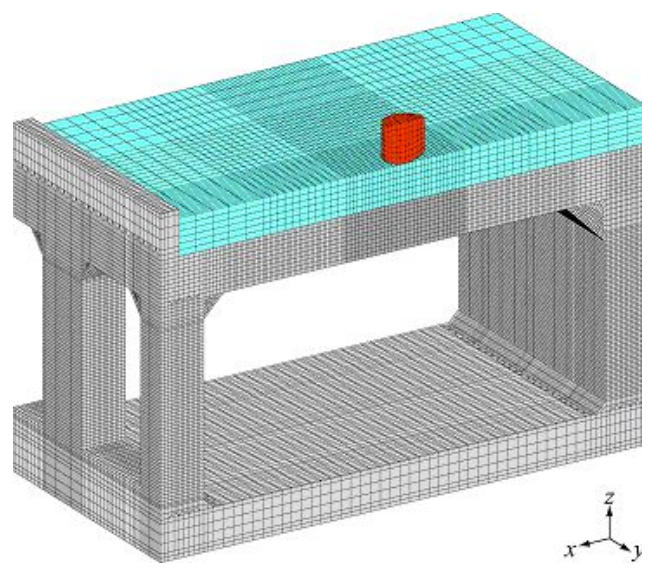

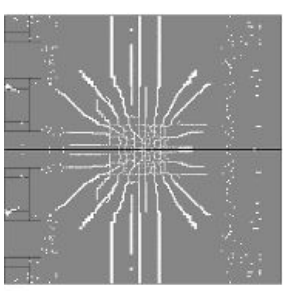

(a)

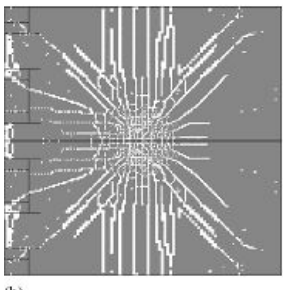

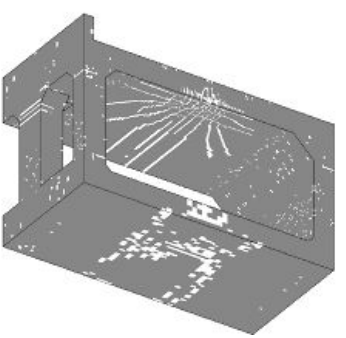
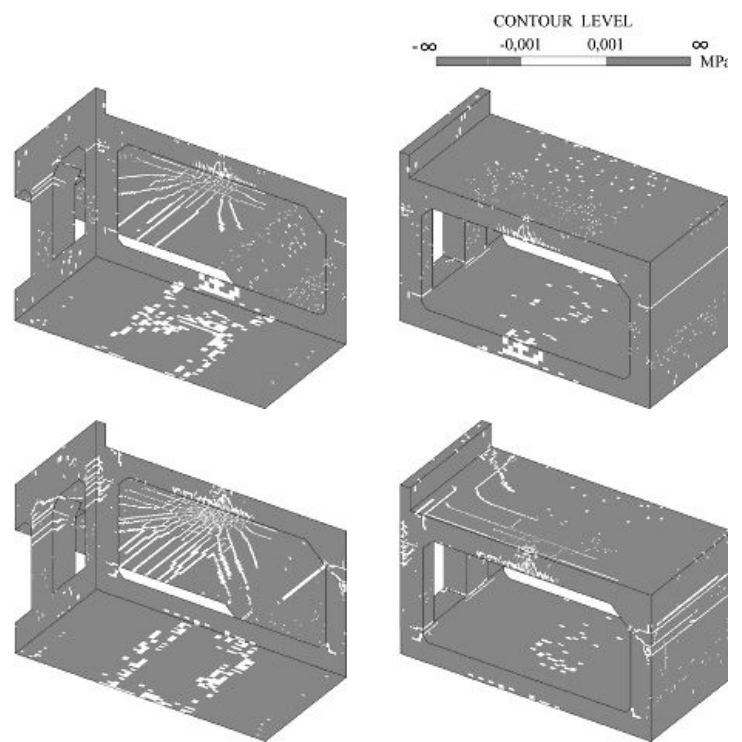

Fig. 17. General view of an FE analysis model of an impacted rock shed and the resulting crack patterns for different loading cases (from Kishi et al., 2009).

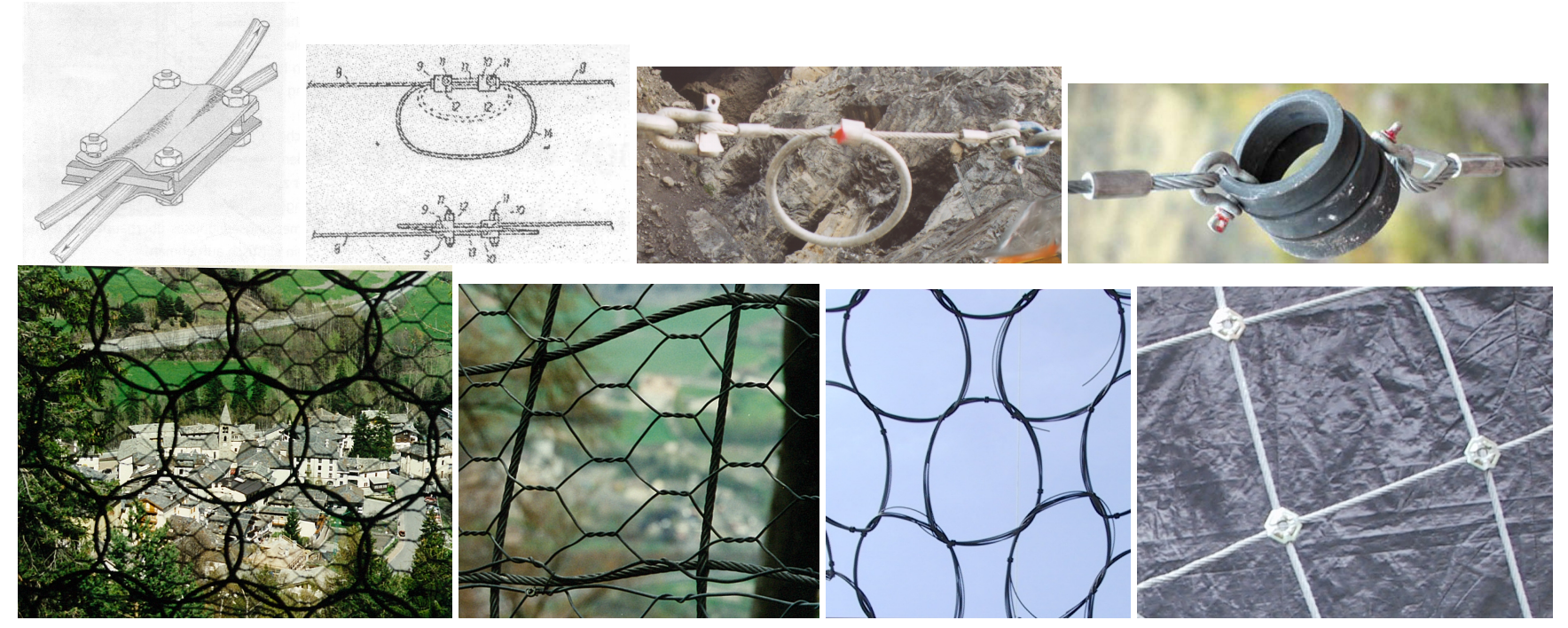

Fig. 18. Different types of energy absorbing barrier components (friction of tensioned rope between friction plates, friction between rope clamps, bent steel pipe circle narrowing under tension and elongating spiral structures) and mesh types (original anti-submarine net, hexagon mesh and spliced rope net, ring net, rope net with clamps).

energies most systems have additional energy absorbing elements attached to the ropes. Such elements deform plastically with large displacements (up to $2 \mathrm{~m}$ ) increasing the flexibility of the supporting structure. Figure 18 shows some typical braking elements. The barriers are usually erected by local mounting teams according to the manufacturer's installation manual that comes with the barrier.

There are various advantages favouring flexible nets for an increasingly wide distribution. They are cheaper compared with other protection systems, e.g., about one tenth of a gallery structure. They are quickly installed requiring little equipment. Their performance is effective, efficient and reliable. The impact on the landscape during construction is low and a certain transparency afterwards is guaranteed. Due to their wide range of energy retention capacity, flexible fence systems can be used for most applications. And, finally, an increasing number of manufacturers results in healthy competition, guaranteeing continuous development and improvements with a parallel reduction in prices. 


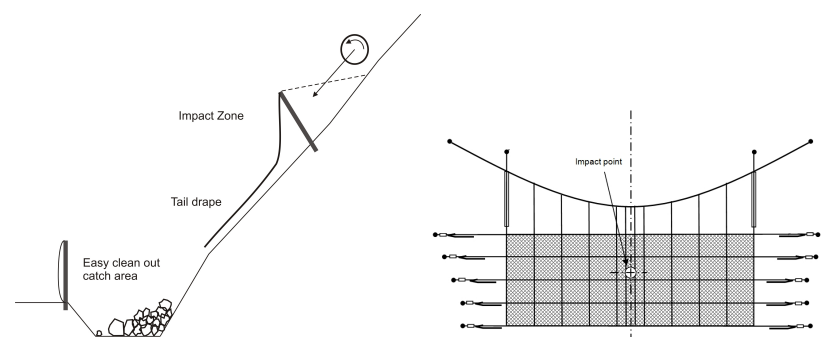

Fig. 19. Principle mode of operation for rockfall attenuating system (left, Glover et al., 2010) and system sketch for typical hanger net system (right).

However, there are some limiting factors in the case of flexible barriers. Long-term protection against corrosion must be guaranteed; working life is defined in EOTA (2008) with $25 \mathrm{yr}$ (or even shorter if installed in aggressive environmental conditions). If a barrier has experienced at least one medium-sized rockfall event, it is usually deformed resulting in a reduced barrier height after a successfully resisted rockfall event. Further, after large-sized rockfall events, the remaining retention capacity might be reduced requiring immediate maintenance. Therefore, regular inspection is necessary for all installed barriers to prevent reduced performance as a result of, e.g., barriers being partially filled by small rocks, wood, etc. Flexible barriers cannot be used if the expected impact energies are too high or if the calculated block trajectories would overtop the barriers reaching the object to be protected. If the place of installation is also subject to avalanches in winter, up till now a rockfall protection system has not been capable of withstanding the dynamic snow load (Margreth, 1995; Nicot et al., 2002b,a). In such a case, the alternatives would be a partial removal and re-installation every year or an alternative protection measure such as galleries.

In the recent years new rockfall mitigation measures have gained increasing attention. So-called attenuating systems do not try to stop a falling rock, but to catch it and to guide it downhill in a controlled manner (see Fig. 19). Such barriers are also called Hybrid Barriers or Hanger Nets (Glover et al., 2010; Dhakal et al., 2011a).

\subsubsection{Historical development and current research}

Mostly, the old-type fences were able to withstand just small rockfall events. Only in the early 1990s, with research on how to stop falling rocks efficiently, was the dynamics of the decelerating process considered and used to design new retention systems (Hearn et al., 1992). This also included the development of fences with retention capacities of up $50 \mathrm{~kJ}$ based on dynamic design approaches (Duffy, 1992; Duffy and Haller, 1993). Since then continuous research and engineering development has increased their retention capacities to around $5000 \mathrm{~kJ}$. However, it must be stated that research related to flexible fence systems generally involves cooperation between a research institute and a particular fence manufacturer focusing only on its own products (Grassl, 2002; Volkwein, 2004; Nicot, 1999; Wienberg et al., 2008; Peila et al., 1998). There are only few studies which compare different net systems. For instance, Gerber and Volkwein (2007) analysed the performance of different systems for either soft or hard dynamic decelerating processes. The growing understanding of fence systems and their dynamic behaviour also allows the use of various net-type systems to resist impact forces caused by other natural hazards such as avalanches (Margreth, 1995), falling sliding trees (Volkwein et al., 2009; Hamberger and Stelzer, 2007), debris flows (Wendeler, 2008) or shallow landslides (Bugnion et al., 2008).

\subsubsection{Standardization}

It is important for the planning and design of effective protection systems that their behaviour is well understood and thoroughly verified. This also ensures an efficient use of public investment. Due to the complex, dynamic and difficult to describe decelerating process a typical barrier design is based on prototype testing. This procedure has also been adapted to produce standardization guidelines defining the minimum performance limits of solid barriers.

The first guideline world-wide was initiated in Switzerland in 2000 (Gerber, 2001a). This guideline defines the testing procedures that allow a posteriori evaluation of the barriers with respect to the maximum energy retention capacity, the actual rope forces, the braking distance, the remaining barrier height, the performance for small and medium-sized rockfall events and the corresponding maintenance work.

In 2008, the European Guideline ETAG 027 was published (EOTA, 2008; Peila and Ronco, 2009.). By letter of the European Commission to the Member States, the 1st of February 2008 was considered the date of its availability and applicability. ETAG 027 defines a testing procedure similar to the Swiss guideline and - after successful system testing and identification testing of the main components as well as after initial factory production inspection by the involved approval body - allows the producers to attach the CE marking for the barrier on the basis of relevant EC certificate of a notified certification body and EC declaration of conformity by the manufacturer. The basis for issuing the EC certificate is the European technical approval as the concerned harmonized technical specification, issued by an approval body entitled for these tasks and the implementation of a factory production control system on the basis of the control plans, accompanying the European technical approval. It is typical for such a broad guideline that many different interests have to be combined and formulated. This usually becomes a quasi-minimum standard requiring National Application Documents for the single member states. 

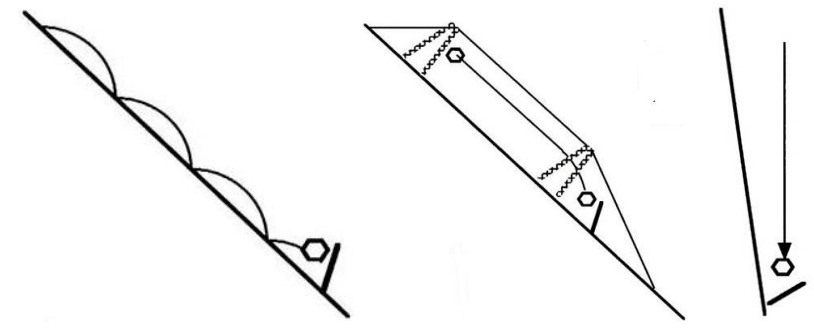

Fig. 20. Different testing methods for rockfall protection systems: free trajectory (left) with impact including rotation, but imprecise impact location; cable car guided oblique (middle) and vertical (right) impact with precise impact location.

It must also be borne in mind that there will always be load cases outside the scope of the guidelines, such as eccentric impact forces, post or rope strikes, high or low speed rockfall events with the same impact energy, etc., (Wienberg et al., 2008; Volkwein et al., 2009).

\subsubsection{Dimensioning}

If a flexible protection fence is suitable for a specific site it has to be located in the field in such a way that it covers most trajectories and that the falling rock does not come to rest, e.g., on the road to be protected, or reaches the clearance section of road or railway during deceleration process. A suitable fence system is selected according to the expected maximum impact energy obtained with the aid of geological expertise. The arrangement of the barrier in the field has to follow the installation instructions given in the accompanying manual. A ready-made design load for the anchors according to the measured rope forces during prototype tests (see Sect. 5.4.4) is sometimes available online (BAFU Bundesamt für Umwelt, 2011). In Switzerland, a partial safety factor of 1.3 has to be applied in compliance with (SIA261, 2003) on the load side. The safety of anchorage (e.g., micropiles, bolts and anchors) has to be guaranteed according to CEN (2010). Shu et al. (2005) describe results from anchorage testing.

\subsubsection{Field testing}

In order to verify and validate the setup for newly-developed rockfall protection fences, full-scale field tests are necessary. Field testing was performed from the beginning (Hearn et al., 1992; Duffy, 1992) and continues to the present day (Zaitsev et al., 2010). A summary of flexible barrier testing to withstand rockfall up to 2008 can be found in Thommen (2008). Since then, the testing methods have not changed significantly. But, due to better measurement methods, more detailed results can be obtained, as shown for example in Gottardi and Govoni (2010).
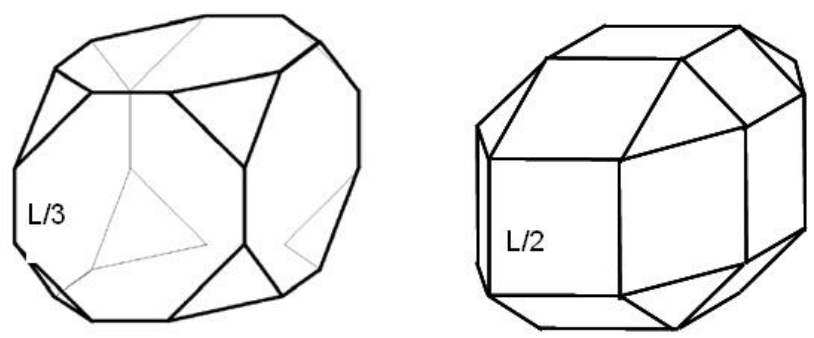

Fig. 21. Standardized test blocks for flexible rockfall protection systems related to a regular cube with edge length $L$ according to the approval guidelines of Switzerland (left, Gerber, 2001a, until 2008) and the European Union (right, EOTA, 2008).

For the tests, mainly two different setups are possible depending on how the falling rock is accelerated: inclined guidance of test blocks along a track cable or their vertical drops (see Fig. 20, Gerber, 2001b). The barrier is then usually installed with an inclination so that an impact angle between barrier and rockfall trajectory of $60^{\circ}$ (Gerber, 2001a) or $\pm 20^{\circ}$ between barrier and reference slope (EOTA, 2008) is obtained. This represents a typical situation for free rockfall when impacting a barrier in the field.

The test results are retrieved using different measurement systems. The geometry of the barrier before and after the test is surveyed using leveling instruments or tachymeters with additional manual measurements of brake element elongations, post inclinations, etc. The braking process for the falling rock can be obtained either from frame-per-frame analysis of high-speed video recordings (min. 100 frames per second recommended) or from numerical integration of the block's internal acceleration measurements (sample rate $>1-2 \mathrm{kHz}$ recommended).

The typical test boulders are specially manufactured concrete elements (see Fig. 21) with different masses according to guideline energy classes with an impact velocity of minimum $25 \mathrm{~m} \mathrm{~s}^{-1}$. This velocity is considered being in the upper range of rockfall events.

In recent years the investigations have concentrated more on the testing of attenuating systems, e.g., Glover et al. (2010). Here, oblique impact is mandatory and vertical testing impossible due to the aim not to stop the falling block, but to deviate it and simply to control its trajectory.

\subsubsection{Numerical modelling}

Flexible rockfall protection barriers have reached a development stage where considerable effort would be required to extend their rockfall retention capacity. A corresponding numerical simulation enables a more efficient development or optimization of new types due to a reduced number of expensive prototype field tests. In addition, the use of 
software allows the simulation of designed barriers by considering special load cases that cannot be reproduced in field tests (high-speed rockfall, post/rope strikes, etc.), as well as special geometrical boundary conditions for individual topographical situations or the influence of structural changes on barrier performance (Fornaro et al., 1990; Mustoe and Huttelmaier, 1993; Akkaraju, 1994; Nicot et al., 1999, 2001; Cazzani et al., 2002; Anderheggen et al., 2002; Volkwein, 2004; Sasiharan et al., 2006). Apart from the numerical modelling of full protection systems, also single components can be evaluated numerically. Related work has been done, for example, energy dissipating elements (del Coz Díaz et al., 2010; Studer, 2001; Dhakal et al., 2011b) or net rings (Nicot et al., 1999; Volkwein, 2004).

Large deformations causing geometrical nonlinearity, the short-time simulation period and nonlinear material behaviour requires explicit $\mathrm{FE}$ analysis strategies such as the Central Differences Method used e.g., by Bathe (2001); Anderheggen et al. (1986). This provides a detailed view of the system's dynamic response. It can also deliver information on the loading and degree of utilisation of any modelled system configuration. The simulation of the falling rock should take into account large three-dimensional displacements and rotations. When impacting a steel net at any location, special contact algorithms prevent the net nodes from penetrating the rock permitting only tangential movements. All sliding effects taking place in the model usually occur over long distances and also cause friction between the various components.

Up till now, different strategies to model flexible rockfall fences have been pursued. The design of a special tailormade software allows one to focus on the relevant details and neglect unwanted parts and, therefore, speeds up the computations (Nicot et al., 1999; Volkwein, 2004). Such an approach also facilitates the setup of different barrier models, because all software elements are already optimized for the simulated components. This method, however, needs a large amount of time until usable results are available. Therefore, the use of common multi-purpose FE codes is also recommendable because it saves the time-consuming development of routine functions (Fornaro et al., 1990). This again is at the risk of non-ideal element properties or performance. Finally, more abstract models, e.g., with a numerically much simplified net performance, allow the simulation with systems that have not yet been fully explored.

Regardless of the approach adopted to simulate a flexible barrier, the results of the simulations should be validated by full-scale rockfall field tests measuring the cable and support forces as well as accelerations and the trajectory of the falling rock.

\subsection{Forests}

The most natural type of protection is a forest. Its protective effect is basically due to the barrier effect (energy dissipation) of standing and lying trees. Whether this barrier effect is effective or not is determined by the size and kinetic energy of the rock, the total basal area that is available to intercept the falling rock, as well as the tree species (Berger and Dorren, 2007). In rockfall protection forests, the concept of the basal area is important as it comprises both the density of the forest (how many tree stems per hectare are present) and the diameter distribution of the trees. The definition of total basal area is the total area covered by all trunks in cross section, usually measured at breast height, per hectare. Basal area is, therefore, expressed in $\mathrm{m}^{2} \mathrm{ha}^{-1}$. The lower limit of an effective protection forest is about $10 \mathrm{~m}^{2} \mathrm{ha}^{-1}$, whereas a forest with $25 \mathrm{~m}^{2} \mathrm{ha}^{-1}$ will be able to provide a significant level of protection against rockfall. This, however, depends on the previously mentioned factors (rock energy, species, and length of forested slope, etc.). An assessment of the protective function of the forest can be carried out using rapid assessment tools and protection forest guidelines (e.g., Frehner et al., 2005; Berger and Dorren, 2007) or with more complex rockfall trajectory models that account for the barrier effect of single trees (e.g., Dorren, 2010; Rammer et al., 2010).

Various research investigations have been carried out to obtain a detailed knowledge of the capacity of a forest to stop falling rocks, as shown in the fundamental summary on the state of the art of rockfall and forest interactions (Dorren et al., 2007). It is generally agreed that not only large trees are required in a rockfall protection forest, but that well-structured stands with a wide diameter distribution and a mosaic of different forest development phases provide the best rockfall protection. Experiments have shown clearly that small trees are capable of stopping large rocks, provided that a large part of the kinetic energy has already been dissipated during preceding impacts against large trees.

The repartition of large and small trees, which usually also corresponds to the height of the trees, is referred to as the vertical forest structure. Furthermore, the higher the stand density, the higher the contact probability, but this also depends on the rock size since small rocks have a lower encounter probability than large rocks. A problem in protection forest management is that dense forest stands cannot be maintained over a long period of time by having thick trees and a high stability. Therefore, a compromise has to be found between an optimal protective function while assuring forest stability and renewal (Brang, 2001). The number of tree stems and their spatial repartition is referred to as the horizontal forest structure. An important characteristic with respect to the horizontal structure that determines the protection against rockfall is the length and number of gaps and couloirs in the forest. 
Over the last decade, research on the interaction between rockfall and protection forest has intensified. Examples are Lundström (2010) and Jonsson (2007), who studied the mechanical stability and energy absorption of single trees. A link between the protective capacity of a single tree and the efficacy of a forest stand has been made by Kalberer (2007). Jancke et al. (2009) investigated the protective effect of different coppice stands. Le Hir et al. (2006), Rammer et al. (2010) and Dorren (2010) have proposed new approaches for integrating forest in rockfall trajectory models. Monnet et al. (2010) showed, by way of an example, how laser-scanning data can be used for the automatic characterisation of rockfall protection. Advances in dendro-geomorphology provide an improved spatiotemporal analysis of the silent witnesses of rockfall (e.g., Schneuwly and Stoffel, 2008). Important remaining subjects in this area are the effect of lying stems on rockfall trajectories, decomposition of lying and standing dead wood and the optimal protection forest stand characteristics for different rockfall settings (coppice stands, homogeneous beech forest, maximum gap length, etc).

\section{Summary and outlook}

Todays rockfall hazard issues and estimation of the risk of rockfall are considered essential. Research on rockfallrelated topics is an important task and advances are clearly visible. In addition, structural countermeasures also based on uncertainty models are also of practical interests. This article, therefore, consists of four main chapters, namely rockfall hazard, rockfall source areas, trajectory modelling and structural countermeasures.

Numerical simulation nowadays allows for a calculation of trajectories at a very high level of precision (see Sect. 4). For example, the rockfall process can be simulated using the DE method based on highly detailed laser scans as input, etc. However, such a detailed level would also require the consideration of the block's shape, its exact position before the release, etc. Therefore, an alternative approach also has its validity: There is no essential need for sophisticated simulation models to estimate the velocities in rockfall events. A few clearly visible impact locations and some basic mathematics are sufficient to calculate the trajectory (see Sect. 4.4.1). The positions of impact locations on the ground, the inclinations between them and - if available - above ground traces on tree branches permit the definition of the block's lift-off and impact velocities. This contribution includes the formulas necessary to calculate the velocities and with the possibility of graphical presentation.

What are the questions needing attention in the immediate future? Here are some suggestions:

- Firstly, there is a definite need to improve the prediction of probabilities in hazard and risk assessment in order to better quantify the risk of rockfall and to improve hazard and risk maps. In this context, in addition rockfall susceptibility vs. rockfall hazard should be discussed. It is also important to have a thorough knowledge of the extreme variations of trajectories within a certain area. They define the decisive fractiles relevant for the mapping process. However, all this is of no avail, if the reliability of models with a proper physical basis is not checked properly.

- Secondly, a specific design level has to be uniformly defined for protection measures. This can be achieved by quantifying the risk level, the vulnerability of the protection countermeasures and the involved costs for lifecycles of the mitigation measure and for overall risk reduction. Of course, standardized evaluation and verification procedures for the countermeasures need to be defined.

- Further, more discussion on what is the best way to classify a single rockfall event is needed. It could be satisfactorily described using either the energy in $\mathrm{kJ}$ or the impulse in Ns. The first is more common and stateof-the-art, but the latter is sometimes more exact when considering impact and rebound effects.

- Finally, it is becoming increasingly important for researchers from different disciplines to establish close collaboration. Today's demands on applicability and efficiency rule out isolated studies lacking interaction. Such collaboration could result in valuable products like this paper or a book on rockfall (Lambert and Nicot, 2011).

Acknowledgements. Without the work of a lot of researches world wide this summary article wouldn't contain so much information. The authors further thank E. G. Prater for the harmonization and improvement of this article, Johanna Scheidegger for her work on the reference list and two reviewers who did an excellent job.

Edited by: T. Glade

Reviewed by: M. Mölk and another anonymous referee.

\section{References}

Acosta, E., Agliardi, F., Crosta, G. B., and Rios Aragùes, S.: Regional rockfall hazard assessment in the Benasque Valley (Centra Pyrenees) using a 3-D numerical approach, in: 4th EGS Plinius Conference - Mediterranean Storms, 555-563, Universitat des Illes Balears, Mallorca, Spain, 2003.

Agliardi, F. and Crosta, G.: High resolution three-dimensionnal numerical modelling of rockfalls, Int. J. Rock. Mech. Min., 40, 455-471, 2003.

Agliardi, F., Crosta, G. B., and Frattini, P.: Integrating rockfall risk assessment and countermeasure design by 3D modelling techniques, Nat. Hazards Earth Syst. Sci., 9, 1059-1073, doi:10.5194/nhess-9-1059-2009, 2009.

Akkaraju, L.: Dynamic Analysis of Cable Structures, Master's thesis, University of Colorado, Boulder, masterthesis, University of Colorado at Boulder, 1994. 
Aksoy, H. and Ercanoglu, M.: Determination of the rockfall source in an urban settlement area by using a rule-based fuzzy evaluation, Nat. Hazards Earth Syst. Sci., 6, 941-954, doi:10.5194/nhess-6-941-2006, 2006.

Anderheggen, E., Elmer, H., and Maag, H.: Nichtlineare FiniteElement-Methoden: Eine Einführung für Ingenieure, Institut für Informatik, Zürich, 1986.

Anderheggen, E., Volkwein, A., and Grassl, H.: Computational Simulation of Highly Flexible Rockfall Protection Systems, in: Proc. Fifth World Congress on Computational Mechanics (WCCM V), edited by: Mang, H., Rammerstorfer, F., and Eberhardsteiner, J., Vienna University of Technology, 2002.

ASTRA: Steinschlag - Naturgefahr für die Nationalstrassen, Schlussbericht der ASTRA Expertengruppe, Tech. rep., Bundesamt für Strassen, 2003.

ASTRA and SBB: Einwirkungen auf Steinschlagschutzgalerien, Richtlinie, Tech. rep., Bundesamt für Baudirektion SBB, 18 pages, Bern, 1998.

ASTRA: Einwirkungen infolge Steinschlags auf Schutzgalerien, Tech. rep., Bundesamt für Strassen, Baudirektion SBB, Eidgenössische Drucksachen- und Materialzentrale, 2008.

Azimi, C. and Desvarreux, P.: Calcul de chutes de blocs et vérification sur modèle réduit, Association pour le développement des recherches sur les glissements de terrain, Grenoble, 1977.

Azimi, C. and Desvarreux, P.: Les chutes de pierres: Exemple No2 (Galerie de protection), Stage paravalanches, E.N.P.C., Paris, 1988.

Azimi, C., Desvarreux, P., Giraud, A., and Martin-Cocher, J.: Méthode de calcul de la dynamique des chutes de blocs - Application à l'étude du versant de la montagne de La Pale (Vercors), Bulletin de liaison des laboratoires des ponts et chaussées, 122, 93-102, 1982.

Azzoni, A. and De Freitas, M.: Experimentally gained parameters, decisive for rock fall analysis, Rock Mech. Rock Eng., 28, 111124, 1995.

Azzoni, A., La Barbera, G., and Zaninetti, A.: Analysis and prediction of rock falls using a mathematical model, Int. J. Rock Mech. Min., 32, 709-724, 1995.

Azzoni, A., Rossi, P. P., Drigo, E., Giani, G. P., and Zaninetti, A.: In situ observation of rockfall analysis parameters, in: Sixth International Symposium of Landslides, 307-314, Rotterdam, The Netherlands, 1992.

BAFU Bundesamt für Umwelt: Zugelassene Steinschlagschutzsysteme, Tech. rep., Swiss Federal Office for the Environment, Berne, http://www.umwelt-schweiz.ch/typenpruefung, 2011.

Baillifard, F.: Detection par SIG des zones rocheuses à fortessusceptibilités d'éboulement, Ph.D. thesis, University of Lausanne, 2005.

Baillifard, F., Jaboyedoff, M., and Sartori, M.: Rockfall hazard mapping along a mountainous road in Switzerland using a GISbased parameter rating approach, Nat. Hazards Earth Syst. Sci., 3, 435-442, doi:10.5194/nhess-3-435-2003, 2003.

Baillifard, F., Jaboyedoff, M., Rouiller, J. D., Couture, R., Locat, J., Robichaud, G., and Gamel, G.: Towards a GIS-based hazard assessment along the Quebec City Promontory, in: Landslides Evaluation and stabilization, edited by: Lacerda, W., Ehrlich, A., Fontoura, M., and Sayao, A., 207-213, Taylor \& Francis, Quebec, Canada, 2004.
Bathe, K.-J.: Finite Element Methoden, Springer-Verlag, Berlin, 2001.

Baumann, P.: Lastfälle und Bemessungsansatz bei Sturzprozessen, in: FAN - Herstkurs 2008, Fachleute Naturgefahren Schweiz, Bellinzona, 2008.

Berger, F. and Dorren, L.: Objective comparison of rockfall models using real size experimental data, in: Disaster mitigation of debris flows, slope failures and landslides, 245-252, Universal Academy Press, Inc, Tokyo, Japan, 2006.

Berger, F. and Dorren, L. K. A.: Principles of the tool Rockfor.NET for quantifying the rockfall hazard below a protection forest, Schweizerische Zeitschrift für Forstwesen, 158, 157-165, 2007.

Berthet-Rambaud, P.: Structures rigides soumises aux avalanches et chutes de blocs: modélisation du comportement mécanique et caractérisation de l'interaction phénomène-ouvrage, $\mathrm{Ph} . \mathrm{D}$. thesis, Universite Grenoble, 2004.

Bertrand, D., Nicot, F., Gotteland, P., and Lambert, S.: Modelling a geo-composite cell using discrete analysis, Comput. Geotech., 32, 564-577, 2006.

Bieniawski, Z. T.: Engineering classification of jointed rock masses, Trans. S. Afr. Inst. Civ. Engrs, 15, 335-344, 1973.

Bieniawski, Z. T.: Classification of rock masses for engineering: the RMR system and future trends, Comprehensive Rock Eng., 3, 553-573, 1993.

Blais-Stevens, A.: Landslide Hazards and their mitigation along the sea to sky corridor, British Columbia, in: 4th Canadian Conference on Geohazards: from causes to management, edited by Locat, J., Perret, D., Turmel, D., Demers, D., and Leroueil, S., Quebec, Canada, 2008.

Blovsky, S.: Model tests on protective barriers against rockfall, in: 15th EYGEC - European Young Geotechnical Engineers Conference, 2002.

Bourrier, F.: Modélisation de l'impact d'un bloc rocheux sur un terrain naturel, application à la trajectographie des chutes de blocs, Ph.D. thesis, Institut Polytechnique de Grenoble, Grenoble, 2008.

Bourrier, F., Nicot, F., and Darve, F.: Physical processes within a 2D granular layer during an impact, Granular Matter, 10, 415-437, 2008.

Bourrier, F., Dorren, L., Nicot, F., Berger, F., and Darve, F.: Towards objective rockfall trajectory simulation using a stochastic impact model, Geomorphology, 110, 68-79, 2009a.

Bourrier, F., Eckert, N., Nicot, F., and Darve, F.: Bayesian stochastic modeling of a spherical rock bouncing on a coarse soil, Nat. Hazards Earth Syst. Sci., 9, 831-846, doi:10.5194/nhess-9-8312009, 2009b.

Bozzolo, D. and Pamini, R.: Simulation of rock falls down a valley side, Acta Mech., 63, 113-130, 1986.

Bozzolo, D., Pamini, R., and Hutter, K.: Rockfall analysis - A mathematical model and its test with field data, in: 5th International Symposium on Landslides, 555-563, Balkema, Rotterdamm, Lausanne, Switzerland, 1988.

Brabb, E.: Innovative approaches to landslide hazard and risk mapping, 4th International Symposium on Landslides, 1, 307-323, 1984.

Brang, P.: Resistance and elasticity: promising concepts for the management of protection forests in the European Alps, Forest Ecol. Manage., 145, 107-119, doi:10.1016/S03781127(00)00578-8, 2001. 
Brideau, M.-A., Stead, D., Roots, C., and Orwin, J.: Geomorphology and engineering geology of a landslide in ultramafic rocks, Dawson City, Yukon, Eng. Geol., 89, 171-194, 2007.

Broili, L.: In situ tests for the study of rockfall, Geologia Applicata e Idrogeologia, 8, 105-111, 1973.

Broili, L.: Relations between scree slope morphometry and dynamics of accumulation processes, in: Meeting on Rockfall dynamics and protective works effectiveness, 11-23, Bergamo, Italy, 1977.

Budetta, P.: Assessment of rockfall risk along roads, Nat. Hazards Earth Syst. Sci., 4, 71-81, doi:10.5194/nhess-4-71-2004, 2004.

Budetta, P. and Santo, A.: Morphostructural evolution and related kinematics of rockfalls in Campania (southern Italy): A case study, Eng. Geol., 36, 197-210, 1994.

Bugnion, L., Denk, M., Shimojo, K., Roth, A., and Volkwein, A.: Full-scale experiments on shallow landslides in combination with flexible protection barriers, in: First World Landslide Forum, 99-102, United Nations University, Tokyo, 2008.

Bunce, C. M., Cruden, D., and Morgenstern, N.: Assessment of the hazard from rock fall on a highway, Can. Geotech. J., 34, 344356, 1997.

Burroughs, D., Henson, H. H., and Jiang, S.: Full scale geotextile rock barrier wall testing, analysis and prediction, Geosynthetics' 93, 1993.

Calvetti, F.: Distinct Element evaluation of the rock-fall design load for shelters, Rivista Italiana di Geotecnica, 3, 63-83, 1998.

Calvetti, F. and Di Prisco, C.: An uncoupled approach for the design of rockfall protection tunnels, Struct. Eng. Int., 19, 342-347, 2009.

Calvetti, F., Di Prisco, C., and Vecchiotti, M.: Experimental and numerical study of rock-fall impacts on granular soils, Rivista Italiana di Geotecnica, 4, 95-109, 2005.

Camponuovo, G.: ISMES experience on the model of St. Martino, in: Meeting on Rockfall dynamics and protective works effectiveness, 25-38, Bergamo, Italy, 1977.

Cancelli, A. and Crosta, G.: Hazard and risk assessment in rockfall prone areas, Risk Reliability in Ground Engineering, Thomas Telford, 1993.

Carere, K., Ratto, S., and Zanolini, F., eds.: Prévention des mouvements de versants et des instabilités de falaises, Programme Interreg IIC - Falaises, Méditerranée occidentale et Alpes latines, confrontation des méthodes d'étude des éboulements dans l'arc alpin, 2001.

Casanovas, M.: Dimensionamiento de galerias de proteccion frente a desprendimientos de rocas, Master's thesis, Universitat Politècnica de Catalunya, 2006.

Cazzani, A., Mongiovi, L., and Frenez, T.: Dynamic Finite Element Analysis of Interceptive Devices for Falling Rocks, Int. J. Rock Mech., 39, 303-321, 2002.

CEN: EN 1997-1 - Eurocode 7 - Geotechnical Design, Tech. rep., European Committee for Standardization, Brussels, 2010.

Chau, K. T., Chan, L. C. P., Wu, J. J., Liu, J., Wong, R. H. C., and Lee, C. F.: Experimental studies on rockfall and debris flow, in: One Day Seminar on Planning, Design and Implementation of Debris Flow and Rockfall Hazards Mitigation Measures, 115128, Hongkong, China, 1998a.

Chau, K. T, Wong, R., Liu, J., Wu, J. J., and Lee, C. F.: Shape effects on the coefficient of restitution during rockfall impacts, in: 9th International Congress on Rock Mechanics, 541-544, Paris, France, 1999a.
Chau, K. T., Wu, J., Wong, R., and Lee, C.: The coefficient of restitution for boulders falling onto soil slopes with various values of dry density and water content, in: International Symposium on Slope Stability Engineering: Geotechnical and Geoenvironmental Aspects, 1355-1360, Matsuyama, Japan, 1999b.

Chau, K. T., Wong, R., and Wu, J.: Coefficient of restitution and rotational motions of rockfall impacts, Int. J. Rock Mech. Min., 39, 69-77, 2002.

Chau, K. T., Wong, R., Liu, J., and Lee, C.: Rockfall hazard analysis for Hong Kong based on rockfall inventory, Rock Mech. Rock Eng., 36, 383-408, 2003.

Chau, K. T., Wong, R., and Lee, C. F.: Rockfall Problems in Hong Kong and some new Experimental Results for Coefficients of Restitution, Int. J. Rock Mech. Min., 35, 662-663, 1998b.

Chikatamarla, R.: Optimisation of cushion materials for rockfall protection galleries, Ph.D. thesis, Swiss Federal Institute of Technology ETHZ, Zurich, 2006.

Christen, M., Bartelt, P., and Gruber, U.: RAMMS - a modelling system for snow avalanches, debris flows and rockfalls based on IDL., PFG Photogrammetrie - Fernerkundung - Geoinformation, 4, 289-292, 2007.

Coe, J. A. and Harp, E. L.: Influence of tectonic folding on rockfall susceptibility, American Fork Canyon, Utah, USA, Nat. Hazards Earth Syst. Sci., 7, 1-14, doi:10.5194/nhess-7-1-2007, 2007.

Comité-Euro-International du Béton, C.: Concrete Structures under Impact and Impulsive Load, Lausanne, 1988.

Copons, R. and Vilaplana, J.: Rockfall susceptibility zoning at a large scale: From geomorphological inventory to preliminary land use planning, Eng. Geol., 102, 142-151, 2008.

Corominas, J., Copons, R. J. M., Vilaplana, J., Altimir, J., and Amigo, J.: Quantitative assessment of the residual risk in a rockfall protected area, Landslides, 2, 343-357, 2005.

Crosta, G. B. and Agliardi, F.: A methodology for physically based rockfall hazard assessment, Nat. Hazards Earth Syst. Sci., 3, 407-422, doi:10.5194/nhess-3-407-2003, 2003.

Crosta, G. B. and Agliardi, F.: Parametric evaluation of 3D dispersion of rockfall trajectories, Nat. Hazards Earth Syst. Sci., 4, 583-598, doi:10.5194/nhess-4-583-2004, 2004.

Crosta, G., Agliardi, F., Frattini, P., and Imposato, S.: A threedimensional hybrid numerical model for rockfall simulation, Geophys. Res. Abstr., 6, 2004.

Cundall, P.: A computer model for simulating progressive, largescale movements in blocky rock systems, in: Symp. Int. Soc. Rock Mech., 1, Paper No. II-8, Nancy, France, 1971.

del Coz Díaz, J., Nieto, P. G., Castro-Fresno, D., and RodríguezHernández, J.: Nonlinear explicit analysis and study of the behaviour of a new ring-type brake energy dissipator by FEM and experimental comparison, Appl. Math. Comput., 216, 1571$1582,2010$.

Derron, M.-H., Jaboyedoff, M., and Blikra, L. H.: Preliminary assessment of rockslide and rockfall hazards using a DEM (Oppstadhornet, Norway), Nat. Hazards Earth Syst. Sci., 5, 285-292, doi:10.5194/nhess-5-285-2005, 2005.

Descoeudres, F.: Aspects géomécaniques des instabilités de falaises rocheuses et des chutes de blocs, Publications de la société suisse de mécanique des sols et des roches, 135, 3-11, 1997.

Descoeudres, F. and Zimmermann, T.: Three-dimensional dynamic calculation of rockfalls, in: Sixth International Congress on Rock Mechanics, pp. 337-342, International Society for Rock Me- 
chanics, Montreal, Canada, 1987.

Dhakal, S., Bhandary, N. P., Yatabe, R., and Kinoshita, N.: Numerical investigation of the effects of idealized rock-block shapes and impact points on the performance of Long-span Pocket-type Rock-net, in: 46th National Conference on Geotechnical Engineering, pp. 1185-1186, Japanese Geotechnical Society JGS, Kobe, Japan, 2011a.

Dhakal, S., Bhandary, N. P., Yatabe, R., and Kinoshita, N.: Constitutive modeling of friction damper for numerical simulation of Long-span Pocket-type Rock-net, in: Annual Conference of Japan Society of Civil Engineers JSCE, pp. 1185-1186, Shikoku Branch, Kagawa, Japan, 2011b.

Dimnet, E.: Mouvement et collisions de solides rigides ou déformables, Ph.D. thesis, Ecole Nationale des Ponts et Chaussées, Paris, 2002.

Dimnet, E. and Frémond, M.: Instantaneous collisions of solids, in: European Congress on Computational Methods in Applied Sciences and Engineering, 11-17, Barcelona, Spain, 2000.

Dorren, L. and Berger, F.: Stem breakage of trees and energy dissipation at rockfall impacts, Tree Physiol., 26, 63-71, 2006.

Dorren, L. and Seijmonsbergen, A.: Comparison of three GISbased models for predicting rockfall runout zones at a regional scale, Geomorphology, 56, 49-64, 2003.

Dorren, L. K. A., Berger, F., and Putters, U. S.: Real-size experiments and 3-D simulation of rockfall on forested and nonforested slopes, Nat. Hazards Earth Syst. Sci., 6, 145-153, doi:10.5194/nhess-6-145-2006, 2006.

Dorren, L., Berger, F., Jonnson, M., Krautblatter, M., Moelk, M., Stoffel, M., and Wehrli, A.: State of the art in rockfall - forest interactions, Schweizerische Zeitschrift für Forstwesen, 158, 128-141, 2007.

Dorren, L. K. A.: Rockyfor3D revealed - description of the complete 3D rockfall model, Tech. rep., EcorisQ, http://www.ecorisq. org, 2010.

Dorren, L. K. A., Maier, B., Putters, U. S., and Seijmonsbergen, A.C.: Combining field and modelling techniques to assess rockfall dynamics on a protection forest hillslope in the European Alps, Geomorphology, 57, 151-167, 2004.

Dudt, J. and Heidenreich, B.: Treatment of the uncertainty in a three-dimensional numerical simulation model for rock falls, in: International Conference on Landslides - Causes, Impacts and Countermeasures, 507-514, Davos, Switzerland, 2001.

Duffy, J. D.: Flexible Wire Rope Rockfall Nets, in: Soils, Geology, and Foundations - Rockfall prediction and Control and landslide case histories (Transportation Research Record No. 1343), 3035, Trans. Res. B., 1992.

Duffy, J. D. and Haller, B.: Field Tests of Flexible Rockfall Barriers, in: Proc. Transportation Facilities through Difficult Terrain, edited by: Wu, J. T. and Barrett, R. K., 465-473, Balkema, 1993.

Dussauge-Peisser, C., Helmstetter, A., Grasso, J.-R., Hantz, D., Desvarreux, P., Jeannin, M., and Giraud, A.: Probabilistic approach to rock fall hazard assessment: potential of historical data analysis, Nat. Hazards Earth Syst. Sci., 2, 15-26, doi:10.5194/nhess-2-15-2002, 2002.

Dussauge-Peisser, C., Grasso, J.-R., and Helmstetter, A.: Statistical analysis of rockfall volume distributions: Implications for rockfall dynamics, J. Geophys. Res. Sol. Ea., 108, 1-11, 2003.

Einstein, H. H.: Landslide risk assessment procedure, in: 5th International Symposium on Landslides, 2, 1075-1090, Balkema,
Rotterdamm, Lausanne, Switzerland, 1988.

EOTA: ETAG 027 - guideline for the European technical approval of falling rock protection kits, Tech. rep., European Organization for Technical Approvals, Brussels, 2008.

Evans, S. and Hungr, O.: The assessment of rockfall hazard at the base of talus slopes, Can. Geotech. J., 30, 620-636, 1993.

Falcetta, J.: Un nouveau modèle de calcul de trajectoires de blocs rocheux, Revue Française de Géotechnique, 30, 11-17, 1985.

Fell, R., Ho, K., Lacasse, S., and Leroi, E.: A framework for landslide risk assessment and management, in: Landslide Risk Management, edited by: Hungr, O. and E., F. R. C. R. E., 3-26, Taylor and Francis, London, 2005.

Fell, R., Corominas, J., Bonnard, C., Cascini, L., Leroi, E., and Savage, W.: Guidelines for landslide susceptibility, hazard and risk zoning for land use planning, Eng. Geol., 102, 85-98, 2008.

Fornaro, M., Peila, D., and Nebbia, M.: Block falls on rock slopes - application of a numerical simulation program to some real cases, in: 6th International Congress IAEG, Rotterdam, The Netherlands, 1990.

Frattini, P., Crosta, G., Carrara, A., and Agliardi, F.: Assessment of rockfall susceptibility by integrating statistical and physicallybased approaches, Geomorphology, 94, 419-437, 2008.

Frayssines, M.: Contribution à l'évaluation de l'aléa éboulement rocheux (rupture), Ph.D. thesis, Université Josef Fourier, 2005.

Frehner, M., Wasser, B., and Schwitter, R.: Nachhaltigkeit und Erfolgskontrolle im Schutzwald - Wegleitung für Pflegemassnahmen in Wäldern mit Schutzfunktion, Tech. rep., Swiss Federal Office for the Environment FOEN, Bern, 2005.

Frémond, M.: Rigid bodies collisions, Phys. Lett. A., 204, 33-41, 1995.

GEO: Landslides and boulder falls from natural terrains: interim risk guidelines, GEO Report 75, Geotechnical Engineering Office, Civiel Engineering Department, Hong Kong, 1998.

Gerber, W.: Richtlinie über die Typenprüfung von Schutznetzen gegen Steinschlag, Tech. rep., Bundesamt für Umwelt, Wald und Landschaft (BUWAL), Eidgenössische Forschungsanstalt WSL, Bern, 2001a.

Gerber, W.: Vergleich zwischen Vertikal- und Schrägwurfanlagen zur Typenprüfung von flexiblen Steinschlschutzverbauungen, Tech. rep., Eidg. Forschungsanstalt für Wald, Schnee und Landschaft WSL, Birmensdorf, 2001b.

Gerber, W.: Einwirkungen bei Steinschlag, in: FAN - Herstkurs 2008, Fachleute Naturgefahren Schweiz, Bellinzona, 2008.

Gerber, W. and Volkwein, A.: Different flexible Rockfall Barriers comparative Results from Type Testing, Geophys. Res. Abstr., 9, 2007.

Ghadimi-Khasraghy, S., Kishi, N., and Vogel, T.: Numerical simulation of consecutive rockfall impacts on reinforced concrete slabs, Tech. rep., 33rd IABSE Symposium, Sustainable Infrastructure, Environment Friendly, Safe and Resource Efficient, Bangkok, Thailand, 2009.

Giacomini, A., Buzzi, O., Renard, B., and Giani, G.: Experimental studies on fragmentation of rock falls on impact with rock surfaces, Int. J. Rock Mech. Min., 46, 708-715, 2009.

Giani, G. P.: Rock Slope Stability Analysis, Taylor \& Francis, Balkema, 1992.

Glover, J., Volkwein, A., Dufour, F., Denk, M., and Roth, A.: Rockfall attenuator and hybrid drape systems - design and testing considerations, in: Third Euro-Mediterranean Symposium on Ad- 
vances in Geomaterials and Structures, edited by: Darve, F., Doghri, I., El Fatmi, R., Hassis, H., and Zenzri, H., 379-384, Djerba, 2010.

Gokceoglu, C., Sonmez, H., and Ercanoglu, M.: Discontinuity controlled probabilistic slope failure risk maps of the Altindag (settlement) region in Turkey, Eng. Geol., 55, 277-296, 2000.

Goldsmith, W.: Impact, The theory and physical behaviour of colliding solids, Edward Arnold Publishers, Dover, 1960.

Gottardi, G. and Govoni, L.: Full-scale Modelling of Falling Rock Protection Barriers, Rock Mech. Rock Eng., 43, 261-274, doi:10.1007/s00603-009-0046-0, 2010.

Govi, M.: Photo-interpretation and mapping of the landslides triggered by the Friuli earthquake (1976), Bulletin of the International Association of Eng. Geol., 15, 67-72, 1977.

Grassl, H. G.: Experimentelle und numerische Modellierung des dynamischen Trag- und Verformungsverhaltens von hochflexiblen Schutzsystemen gegen Steinschlag, Ph.D. thesis, Eidgenössische Technische Hochschule Zürich, 2002.

Grenon, M. and Hadjigeorgiou, J.: A design methodology for rock slopes susceptible to wedge failure using fracture system modelling, Eng. Geol., 96, 78-93, 2008.

Gruner, U.: Climatic and meteorological influences on rockfall and rockslides ("Bergsturz"), in: Protection of populated territories from floods, debris flow, mass movements and avalanches, 2630 May, 2008, 147-158, 2008.

Guenther, A., Carstensen, A., and Pohl, W.: Automated sliding susceptibility mapping of rock slopes, Nat. Hazards Earth Syst. Sci., 4, 95-102, doi:10.5194/nhess-4-95-2004, 2004.

Günther, A.: SLOPEMAP: programs for automated mapping of geometrical and kinematical properties of hard rock hill slopes, Comput. Geosci., 29, 865-875, 2003.

Guzzetti, F., Carrara, A., Cardinali, M., and Reichenbach, P.: Landslide hazard evaluation: a review of current techniques and their application in a multi-scale study, Central Italy, Geomorphology, 31, 181-216, 1999.

Guzzetti, F., Crosta, G., Detti, R., and Agliardi, F.: STONE: a computer program for the three dimensional simulation of rock-falls, Comput. Geosci., 28, 1079-1093, 2002.

Guzzetti, F., Reichenbach, P., and Wieczorek, G. F.: Rockfall hazard and risk assessment in the Yosemite Valley, California, USA, Nat. Hazards Earth Syst. Sci., 3, 491-503, doi:10.5194/nhess-3491-2003, 2003.

Guzzetti, F., Reichenbach, P., and Ghigi, S.: Rockfall hazard and risk assessment along a transportation corridor in the Nera Valley, central Italy, Environ. Manage., 34, 191-208, 2004.

Habib, P.: Note sur le rebondissement des blocs rocheux, in: Rockfall dynamics and protective works effectiveness, ISMES publication no. 90, 123-125, Bergamo, Italy, 1976.

Hamberger, M. and Stelzer, G.: Neue Erkenntnisse aus Tests von dynamischen Seilsperren - Auswirkungen auf die Baupraxis, Tech. rep., Trumer Schutzbauten, Kuchl, 2007.

Hearn, G., Barrett, R. K., and McMullen, M. L.: CDOT Flexpost Rockfall Fence Development, Testing and Analysis, in: Soils, Geology, and Foundations - Rockfall prediction and Control and landslide case histories (Transportation Research Record No. 1343), pp. 23-29, Transportation Research Board, National Academy Press, Washington, D.C., 1992.

Heidenreich, B.: Small and half scale experimental studies of rockfall impacts on sandy slopes, Ph.D. thesis, Ecole Polytechnique
Fédérale de Lausanne, Lausanne, 2004.

Heierli, W.: Viadotto Bosco di Bedrina No2 - Steinschlagschutz: Verhalten von Kies - Sand - Dämpfungsschichten, Tech. rep., Dipartimento Pubbliche Costruzioni, Ufficio Strade Nazionali, Bellinzona, 1984.

Herrmann, N.: Experimentelle Erfassung des Betonverhaltens unter Schockwellen, Ph.D. thesis, TH Karlsruhe, 2002.

Hoek, E.: Rockfall: a computer program for prediction rockfall trajectories, ISRM News J, 2, 4-16, 1987.

Hoek, E.: Strength of rock and rock masses, ISRM News, 2, 4-16, 1994.

Hoek, E. and Bray, J.: Rock Slope Engineering, E \& FN Spon, London, 3rd edn., 1981.

Hopkins, M.: Eiger loses face in massive rockfall, http://www. nature.com/news/2006/060717/full/news060717-3.html, 2006.

Hudson, J. A.: Rock Engineering systems: Theory and Practice, Ellis Horwood, Chichester, 1992.

Hungr, O. and Evans, S.: Engineering evaluation of fragmental rockfall hazards, in: 5th International Symposium on Landslides, 1, 685-690, Balkema, Rotterdamm, Lausanne, Switzerland, 1988.

Hungr, O., Evans, S., and Hazzard, J.: Magnitude and frequency of rockfalls and rock slides along the main transportation corridors of south-western British Columbia, Can. Geotech. J., 36, 224238, 1999.

Hungr, O., Fell, R., Couture, R., and Eberhardt, E.: Landslide Risk Management, Taylor and Francis, 2005.

Ishikawa, N.: Recent progress on rock-shed studies in Japan, in: Joint Japan-Swiss Scientific Seminar on Impact Load by Rock Falls and Design of Protection Structures, 1-6, Kanazawa, Japan, 1999.

Jaboyedoff, M. and Derron, M.-H.: Integrated risk assessment process for landslides, in: Landslide risk management, edited by Hungr, O., Fell, R., Couture, R. R., and Eberhardt, E., 776, Taylor and Francis, 2005.

Jaboyedoff, M. and Labiouse, V.: Preliminary assessment of rockfall hazard based on GIS data, in: 10th International Congress on Rock Mechanics ISRM 2003 - Technology roadmap for rock mechanics, 575-578, Johannesburgh, South Africa, 2003.

Jaboyedoff, M., Baillifard, F., Hantz, D., Heidenreich, B., and Mazzoccola, D.: Terminologie, in: Prévention des mouvements de versants et des instabilités de falaises, edited by Carere, K., Ratto, S., and Zanolini, F. E., 48-57, 2001.

Jaboyedoff, M., Baillifard, F., Philippossian, F., and Rouiller, J.-D.: Assessing fracture occurrence using "weighted fracturing density": a step towards estimating rock instability hazard, Nat. Hazards Earth Syst. Sci., 4, 83-93, doi:10.5194/nhess-4-83-2004, 2004.

Jaboyedoff, M., Baillifard, F., Couture, R., Locat, J., and Locat, P.: New insight of geomorphology and landslide prone area detection using DEM, in: Landslides: Evaluation and Stabilization, edited by Lacerda, W. A., Ehrlich, M., Fontoura, S. A. B., and Sayo, A., 191-198, Taylor \& Francis, London, 2004b.

Jaboyedoff, M., Baillifard, F., Derron, M.-H., Couture, R., Locat, J., and Locat, P.: Switzerland modular and evolving rock slope hazard assessment methods, in: Landslide and avalanches, edited by: Senneset, K., Flaate, K. A., and Larsen, J., ICFL, 2005a.

Jaboyedoff, M., Dudt, J. P., and Labiouse, V.: An attempt to refine rockfall hazard zoning based on the kinetic energy, frequency and 
fragmentation degree, Nat. Hazards Earth Syst. Sci., 5, 621-632, doi:10.5194/nhess-5-621-2005, 2005b.

Jaboyedoff, M., Metzger, R., Oppikofer, T., Couture, R., Derron, M.-H., Locat, J., and Turmel, D.: New insight techniques to analyze rock-slope relief using Dem and 3D-imaging cloud points: COLTOP-3D, in: Rock mechanics: Meeting Society's Challenges and demands. 1st Canada-US Rock Mechanics Symposium, edited by: Eberhardt, E., Stead, D., and Morrison, T., 1, Taylor and Francis, Vancouver, Canada, 2007.

Jacquemoud, J.: Swiss guideline for the design of protection galleries: background, safety concept and case histories, in: Joint Japan-Swiss Scientific Seminar on Impact Load by Rock Falls and Design of Protection Structures, 95-102, Kanazawa, Japan, 1999.

Jancke, O., Dorren, L., Berger, F., Fuhr, M., and Köhl, M.: Implications of coppice stand characteristics on the rockfall protection function, Forest Ecol. Manag., 259, 124-131, 2009.

Japan Road Association: Rockfall Handbook, Tokyo, Japan, 1983.

Japan Road Association: Manual for anti-impact structures against falling rocks, Tokyo, Japan, 2000.

Japanese highway public corporation: Research report on rock falling tests, 1973.

Jones, C. L., Higgins, J., and Andrew, R.: Colorado Rockfall Simulation Program Version 4.0, Tech. rep., Colorado Department of Transportation, Denver, http://dnr.state.co.us/geostore/ ProductInfo.aspx? productid=MI-66, 2000.

Jonsson, M.: Energy absorption of trees in a rockfall protection forest, Ph.D. thesis, ETH Zürich, Zürich, 2007.

Kalberer, M.: Quantifizierung und Optimierung der Schutzwaldleistung gegenüber Steinschlag, Ph.D. thesis, Albert-Ludwigs-Universität, Freiburg im Breisgau, 2007.

Kamijo, A., Onda, S., Masuya, H., and Tanaka, Y.: Fundamental test on restitution coefficient and frictional coefficient of rock fall, in: 5th Symposium on Impact Problems in Civil Engineering, 83-86, 2000.

Kawahara, S. and Muro, T.: Effect of soil slope gradient on motion of rockfall, in: International Symposium on Slope Stability Engineering, 2, 1343-1348, Matsuyama, Japan, 1999.

Kemeny, J., Turner, K., and Norton, B.: LIDAR for Rock Mass Characterization: Hardware, Software, Accuracy and BestPractices, in: Workshop on Laser and Photogrammetric Methods for Rock Mass Characterization: Exploring New Opportunities, Golden, Colorado, USA, 2006.

Kirkby, M. and Statham, I.: Surface stone movement and scree formation, J. Geol., 83, 349-362, 1975.

Kishi, N., Nakano, O., Matsuoka, K., and Nishi, H.: Field test on absorbing capacity of a sand cushion , J. Struct. Eng., 39A, 15871597, 1993 (in Japanese).

Kishi, N., Okada, S., and Konno, N.: Numerical Impact Response Analysis of Rockfall Protection Galleries, Struct. Eng. Int., 19, 313-320, 2009.

Kobayashi, Y., Harp, E., and Kagawa, T.: Simulation of Rockfalls triggered by earthquakes, Rock Mech. Rock Eng., 23, 1-20, 1990.

Konno, H., Ishikawa, H., Okada, S., and Kishi, N.: Prototype impact test of steel-concrete composite type rock-sheds, in: Interdisciplinary workshop on rockfall protection, edited by Volkwein, A., Labiouse, V., and Schellenberg, K., 46-48, Swiss Fed. Research Inst. WSL, Morschach, Switzerland, 2008.
Krummenacher, B. and Keusen, H.: Rockfall simulation and hazard mapping based on Digital Terrain Modell (DTM), European Geologist, 12, 33-35, 1996.

Krummenacher, B., Schwab, S., and Dolf, F.: Assessment of natural hazards by three calculations of rockfall behaviour, in: Interdisciplinary Workshop on Rockfall Protection, edited by: Volkwein, A., Labiouse, V., and Schellenberg, K., 49-51, Swiss Fed. Research Inst. WSL, Morschach, Switzerland, 2008.

Labiouse, V.: Fragmental rockfall paths: comparison of simulations on Alpine sites and experimental investigation of boulder impacts, in: 9th International Symposium on Landslides, 1, 457466, Balkema, 2004.

Labiouse, V., Descoeudres, F., and Montani, S.: Experimental study of rock sheds impacted by rock blocks, Struct. Eng. Int., 6, 171176, 1996.

Labiouse, V. and Heidenreich, B.: Half-scale experimental study of rockfall impacts on sandy slopes, Nat. Hazards Earth Syst. Sci., 9, 1981-1993, doi:10.5194/nhess-9-1981-2009, 2009.

Labiouse, V., Heidenreich, B., Desvarreux, P., Viktorovitch, M., and Guillemin, P.: Études trajectographiques, in: Prévention des mouvements de versants et des instabilités de falaises, edited by: Carere, K., Ratto, S., and Zanolini, F., 155-211, Aosta, Italy, 2001.

Lambert, S. and Bourrier, F.: Design of rockfall protection embankments: a critical review, Earth Surf. Proc. Land ., in press, 2011.

Lambert, S. and Nicot, F., eds.: Rockfall engineering, ISBN 9781-84821-26-5, 464 pages, John Wiley \& Sons, ISTE Ltd., New York, London, 2011.

Lambert, S., Gotteland, P., and Nicot, F.: Experimental study of the impact response of geocells as components of rockfall protection embankments, Nat. Hazards Earth Syst. Sci., 9, 459-467, doi:10.5194/nhess-9-459-2009, 2009.

Lan, H., Martin, D., and Lim, C.: RockFall analyst: A GIS extension for three-dimensional and spatially distributed rockfall hazard modeling, Comput. Geosci., 33, 262-279, 2007.

Lang, H.-J.: Erdgasleitungen in der Gemeinde Innertkirchen, Transitgas AG, Zurich, 1974.

Lato, M., Diederichs, M. S., Hutchinson, D. J., and Harrap, R.: Optimization of LIDAR scanning and processing for automated structural evaluation of discontinuities in rockmasses, Int. J. Rock Mech. Min., 46, 194-199, 2009.

Le Hir, C., Dimnet, E., and Berger, F.: Étude de la trajectographie des chutes de blocs en forêts de montagne, Bull. Lab. Ponts Chaussées, 263/264, 85-101, 2006.

Lepert, P. and Corté, J.: Etude en centrifugeuse de límpact de gros blocs rocheux sur un remblai de protection, in: Centrifuge ' 88 , 1988.

Leroueil, S. and Locat, J.: Slope Movements - Geotechnical Characterization, Risk Assessment and Mitigation, in: XI DanubeEuropean Conf. on Soil Mechanics and Geotechnical Engineering, edited by: Lisac and Szavits-Nossan, Balkema, Porec, Croatia, 1998.

Lied, K.: Rockfall problems in Norway, ISMES Publication, 90, 51-53, 1977.

Liniger, M. and Bieri, D.: A2, Gotthardautobahn, Felssturz Gurtnellen vom 31 Mai 2006, Beurteilung und Massnahmen, in: Pub. Soc. Suisse Mécanique Soles Roches, 153, 81-86, 2006.

Lorentz, J., Donzé, F., Perrotin, P., and Plotto, P.: Experimental study of the dissipative efficiency of multylayered protec- 
tive structure against rockfall impact, Revue européenne de génie civil, 10, 295-308, 2006.

Lorentz, J., Perrotin, P., and Donzé, F.: A new sandwich design structure for protection against rockfalls, in: Interdisciplinary workshop on rockfall protection, edited by Volkwein, A., Labiouse, V., and Schellenberg, K., Swiss Fed. Research Inst. WSL, Morschach, Switzerland, 2008.

Loye, A., Jaboyedoff, M., and Pedrazzini, A.: Identification of potential rockfall source areas at a regional scale using a DEMbased geomorphometric analysis, Nat. Hazards Earth Syst. Sci., 9, 1643-1653, doi:10.5194/nhess-9-1643-2009, 2009.

Luckman, B. H.: Rockfalls and Rockfall inventory data: some obervations from Surprise Valley, Jasper National Park, Canada, Earth Surf. Proc., 1, 287-298, 1976.

Lundström, T.: Mechanical stability and growth performance of trees, Ph.D. thesis, University of Bern, Bern, 2010.

Maegawa, K., Yoshida, H., Fujii, T., Shiomi, M., and Ohmori, K.: Weight falling tests on the rock-shed composed of CFTmembers, in: Tubular Structures X, edited by: Jaurrieta, A. C., Alonso, A., and Alonso, A., 533-540, Swets \& Zeitlinger, Lisse, 2003.

Maerz, N., Youssef, A., and Fennessey, T. W.: New RiskConsequence Rockfall Hazard Rating System for Missouri Highways using Digital Image Analysis, Environ. Eng. Geosci., 11, 229-249, 2005.

Magnier, S.-A. and Donzé, F.: Numerical simulations of impacts using a discrete element method, Mech. Cohes.-Frict. Mat., 3, 257-276, 1998.

Malamud, B., Turcotte, D., Guzzetti, F., and P., R.: Landslide inventories and their statistical properties, Earth Surf. Proc. Land., 29, 687-711, 2004.

Margreth, S.: Snow Pressure Measurements on Snow Net Systems, in: Acte de colloque, 241-248, Chamonix, 1995.

Masuya, H.: Design Method of Structures under Impact Action by Concept of Performance Based Design, Japan Society of Civil Engineers, Committee of Structural Engineering, Subcommittee concerning Performance Based Design of Structures against Impact Action, 2007.

Masuya, H. and Kajikawa, Y.: Numerical analysis of the collision between a falling rock and a cushion by distinct element method, Computer Methods and Advances in Geomechanics, 493-498, 1991.

Masuya, H. and Nakata, Y.: Development of numerical model combining distinct element and finite element methods and application to rock shed analysis, in: Proc. Japan Soc. Civil Eng., 710-I, 113-128, Japan, 2001.

Masuya, H., Tanaka, Y., Onda, S., and Ihara, T.: Evaluation of Rock falls on slopes and Simulation of the Motion of Rock Falls in Japan, in: Joint Japan-Swiss Scientific Seminar on Impact Load by Rock Falls and Design of Protection Structures, 21-28, Kanazawa, Japan, 1999.

Masuya, H., Ihara, T., Onda, S., and Kamijo, A.: Experimental Study on Some Parameters for Simulation of Rock Fall on Slope, in: Fourth Asia-Pacific Conf. on Shock and Impact Loads on Structures, 63-69, Japan, 2001.

Masuya, H., Amanuma, K., Nishikawa, Y., and Tsuji, T.: Basic rockfall simulation with consideration of vegetation and application to protection measure, Nat. Hazards Earth Syst. Sci., 9, 1835-1843, doi:10.5194/nhess-9-1835-2009, 2009.
Matsuoka, N.: Frost weathering and rockwall erosion in the southeastern Swiss Alps: Long-term (1994-2006) observations, Geomorphology, 99, 353-368, 2008.

Matsuoka, N. and Sakai, H.: Rockfall activity from an alpine cliff during thawing periods, Geomorphology, 28, 309-328, 1999.

Mavrouli, O. and Corominas, J.: Vulnerability of simple reinforced concrete buildings to damage by rockfalls, Landslides, 7, 169-180, http://dx.doi.org/10.1007/s10346-010-0200-5, 10.1007/s10346-010-0200-5, 2010.

Mazzoccola, D. and Sciesa, E.: Implementation and comparison of different methods for rockfall hazard assessment in the Italian Alps, in: 8th International Symposium on Landslides, 2, 10351040, Balkema, Rotterdam, Cardiff, UK, 2000.

Mazzoccola, D. F. and Hudson, J. A.: A comprehensive method of rock mass characterisation for indicating natural slope instability, Q. J. Eng. Geol. Hydroge., 29, 37-56, 1996.

Meissl, G.: Modellierung der Reichweite von Felsstürzen: Fallbeispiele zur GIS-gestützten Gefahrenbeurteilung, Ph.D. thesis, Institut für Geographie. Univ. Innsbruck, 1998.

Meissl, G.: Modelling the runout distances of rockfall using a geographic information system, Z. Geomorphol., 125, 129-137, 2001.

Monnet, J., Mermin, E., Chanussotz, J., and Berger, F.: Tree top detection using local maxima filte-ring: a parameter sensitivity analysis, in: Silvila-ser 2010, 10th International Conference on LiDAR Applications for Assessing Forest Ecosystems, 1-9, Freiburg, Germany, 2010.

Montani-Stoffel, S.: Sollicitation dynamique de la couverture des galeries de protection lors de chutes de blocs, Ph.D. thesis, École Polytechnique Fédérale de Lausanne, Lausanne, 1998.

Murata, S. and Shibuya, H.: Measurement of impact loads on the rockfall prevention walls and speed of falling rocks using a middle size slope model, in: 2nd Asia-Pacific Conference on Shock \& Impact Loads on Structures, 383-393, Melbourne, Australia, 1997.

Mustoe, G. G. W. and Huttelmaier, H.: Dynamic Simulation of a Rockfall Fence by the Discrete Element Method, Microcomputer in Civil Engineering, 8, 423-437, 1993.

Nakano, O., Sato, M., Kishi, N., Matsuoka, K., and Nomachi, S.: Full scale impact tests of PC multi-girder with three-layered absorbing system, in: 13th International Conference on SMiRT, IV, 201-206, 1995.

Nakata, Y., Masuya, H., Kajikawa, Y., and Okada, T.: The Analysis of Impact Behaviour of Rock-Shed by Combination of Distinct Element Method and Finite Element Method, in: 2nd AsiaPacific Conference on Shock \& Impact Loads on Structures, 403-410, Melbourne, Australia, 1997.

Nicot, F.: Etude du comportement méchanique des ouvrages souples de protection contre les éboulements rocheux, Ph.D. thesis, Ecole Centrale de Lyon, 1999.

Nicot, F., Nouvel, P., Cambou, B., Rochet, L., and Mazzoléni, G.: Etude du comportement mecanique des ouvrages souples de protection contre les eboulements rocheux, Revue française de génie civil, 3, 295-319, 1999.

Nicot, F., Cambou, B., and Mazzoléni, G.: Design of Rockfall Restraining Nets from a Discrete Element Modelling, Rock Mech. Rock Eng., 34, 99-118, 2001.

Nicot, F., Gay, M., Boutillier, B., and Darve, F.: Modelling of Interaction between a Snow Mantel and a Flexible Structure using 
a Discrete Element Method, in: Proc. Num. Models in Geomechanics NUMOG VIII, edited by: Pande, G. N. and Pietruszcak, S., 699-703, Swets \& Zeitlinger, 2002a.

Nicot, F., Gay, M., and Tacnet, J.: Interaction between a Snow Mantel and a Flexible Structure: A new Method to Design Avalanche Nets, Cold Reg. Sci. Technol., 34, 67-84, 2002 b.

Nicot, F., Gotteland, P., Bertrand, D., and Lambert, S.: Multi-scale approach to geo-composite cellular structures subjected to impact, International Journal for Numerical and Analytical Methods in Geomechanics, 31, 1477-1515, 2007.

Norrish, N. and Wyllie, D.: Landslides - Investigation and mitigation, in: Rock slope stability analysis, edited by: Turner, A. and Schuster, R. L., Transportation Research Board, special report 247, 673, National Academy Press, Washington, DC, 1996.

Oppikofer, T., Jaboyedoff, M., and Coe, J. A.: Rockfall hazard at Little Mill Campground, Uinta National 150 Forest: Part 2. DEM analysis, in: 1st North American Landslide Conference, edited by: Schaefer, V. R., Schuster, R. L., and Turner, A. K., AEG Special Publication no. 23, 1351-1361, Vail, Colorado, USA, 2007.

Oppikofer, T., Jaboyedoff, M., and Keusen, H.-R.: Collapse at the eastern Eiger flank in the Swiss Alps, Nat. Geosci., 1, 531-535, 2008.

Paronuzzi, P.: Probabilistic approach for design optimization of rockfall protective barriers, Q. J. Eng. Geol., 22, 175-183, 1989.

Peila, D. and Ronco, C.: Technical Note: Design of rockfall net fences and the new ETAG 027 European guideline, Nat. Hazards Earth Syst. Sci., 9, 1291-1298, doi:10.5194/nhess-9-1291-2009, 2009.

Peila, D., Pelizza, S., and Sassudelli, F.: Evaluation of Behaviour of Rockfall Restraining Nets by Full Scale Tests, Rock Mech. Rock Eng., 31, 1-24, 1998.

Peila, D., Castiglia, C., Oggeri, C., Guasti, G., Recalcati, P., and Rimoldi, P.: Testing and modelling geogrid reinforced soil embankments subject to high energy rock impacts, in: 7th International conference on geosynthetics, 2002.

Peila, D., Oggeri, C., and Castiglia, C.: Ground reinforced embankments for rockfall protection, design and evaluation of full scale tests, Landslides, 4, 255-265, 2007.

Perret, S., Stoffel, M., and Kienholz, H.: Spatial and temporal rock fall activity in a forest stand in the Swiss Prealps - a dendrogeomorphological case study, Geomorphology, 74, 219-231, 2006.

Pfeiffer, T. and Bowen, T.: Computer Simulation of Rockfalls, Bulletin of the Association of Engineering Geologists, 26, 135-146, 1989.

Pichler, B., Hellmich, C., and Mang, H.: Impact of rocks onto gravel - Design and evaluation experiments, Int. J. Impact Eng., 31, 559-578, 2005.

Pierson, L. A., Davis, S. A., and Van Vickle, R.: Rockfall Hazard Rating System Implementation Manual, Oregon, 1990.

Piteau, D. and Clayton, R.: Computer Rockfall Model, in: Meeting on Rockfall Dynamics and Protective Works Effectiveness, no. 90 in ISMES Publication, 123-125, Bergamo, Italy, 1976.

Piteau, D. and Clayton, R.: Discussion of paper C̈omputerized design of rock slopes using interactive graphics for the input and output of geometrical databy Cundall, P., in: Proceedings of the 16th Symposium on Rock Mechanics, Minneapolis, USA, 6263, 1977

Plassiard, J., Donzé, F., and Plotto, P.: High energy impact on enbamkments - a numerical discrete approach, in: 9th International Congress on Numerical Models in Geomechanics NUMOG, 609-614, Ottawa, Canada, 2004.

Plassiard, J.-P. and Donzé, F.-V.: Rockfall Impact Parameters on Embankments: A Discrete Element Method Analysis, Struct. Eng. Int., 19, 333-341, 2009.

Raetzo, H., Lateltin, O., Bollinger, D., and Tripet, J.: Hazard assessment in Switzerland - Code of practice for mass movements, B. Eng. Geol. Environ., 61, 263-268, 2002.

Rammer, W., Brauner, M., Dorren, L., Berger, F., and Lexer, M.: Validation of an integrated 3D forest - rockfall model, Geophys. Res. Abstr., Vol. 9, 04634, Vienna, 2007.

Rammer, W., Brauner, M., Dorren, L. K. A., Berger, F., and Lexer, M. J.: Evaluation of a 3-D rockfall module within a forest patch model, Nat. Hazards Earth Syst. Sci., 10, 699-711, doi:10.5194/nhess-10-699-2010, 2010.

Rapp, A.: Recent development of mountain slopes in Karkevagge and surroundings, northern Scandinavia, Geogr. Ann., 42, 65200, 1960.

Ritchie, A.: Evaluation of rockfall and its control, Highway research record, 17, 13-28, 1963.

Rochet, L.: Development of numerical models for the analysis of propagation of rock-falls, 6th Int. Congress on Rock Mech, 1, 479-484, 1987a.

Rochet, L.: Application des modèles numériques de propagation à l'étude des éboulements rocheux, Bulletin de liaison des laboratoires des ponts et chaussées, 150-151, 84-95, $1987 \mathrm{~b}$.

Romana, M.: Practice of SMR classification for slope appraisal, in: 5th International Symposium on Landslides, Balkema, Rotterdamm, Lausanne, Switzerland, 1988.

Romana, M.: A geomechanical classification for slopes: slope mass rating, Comprehensive Rock Engineering, Pergamon, Oxford, 1993.

Rouiller, J.-D. and Marro, C.: Application de la méthodologie MATTEROCK à lévaluation du danger lié aux falaises, Eclogae Geologicae Helvatiae, 90, 393-399, 1997.

Rouiller, J. D., Jaboyedoff, M., Marro, C., Phlippossian, F., and Mamin, M.: Pentes instables dans le Pennique valaisan. Matterock: une méthodologie dáuscultation des falaises et de détection des éboulements majeurs potentiels, Rapport final du PNR31, vdf Hochschulverlag AG an der ETH Zürich, Zürich, Switzerland, 1998.

Santi, M. P., Russel, C. P., Higgins, J. D., and Spriet, J. I.: Modification and statistical analysis of the Colorado Rockfall Hazard Rating System, Eng. Geol., 104, 55-65, 2008.

Sasiharan, N., Muhunthan, B., Badger, T., Shu, S., and Carradine, D.: Numerical analysis of the performance of wire mesh and cable net rockfall protection systems, Eng. Geol., 88, 121-132, doi:10.1016/j.enggeo.2006.09.005, http: //www.sciencedirect.com/science/article/B6V63-4M69JSG-1/2/ 74d8147926832f9eb71fccc4859396f4, 2006.

Sato, M., Kishi, N., Iwabuchi, T., Tanimoto, T., and Shimada, T.: Shock Absorbing Performance of Sand Cushion, in: 1st AsiaPacific Conference on Shock and Impact Loads on Structures, 393-400, Singapore, 1996.

Schellenberg, K.: On the design of rockfall protection galleries, No. 17924, ETHZ, Institute of Structural Engineering, Zurich, 2008.

Schellenberg, K.: On the design of rockfall protection galleries - 
An analytical approach for a performance based design, SVH Verlag, 2009.

Schellenberg, K. and Vogel, T.: Swiss Rockfall Galleries - Impact Load, in: Structures and Extreme Events, 302-303 and CDROM file LIS099.PDF, 1-8, IABSE Symposium Lisbon 2005, IABSE, Zurich, 2005.

Schellenberg, K. and Vogel, T.: A Dynamic Design Method for Rockfall Protection Galleries, Struct. Eng. Int., 19(3), 321-326, 2009.

Schellenberg, K., Volkwein, A., Roth, A., and Vogel, T.: Largescale impact tests on rockfall galleries, in: 7th Int. Conference on Shock \& Impact Loads on Structures, 17-19 October 2007, 497-504, Bejing, 2007.

Schellenberg, K., Volkwein, A., Denk, M., and Vogel, T.: Falling weight tests on rock fall protection galleries with cushion layers, in: Interdisciplinary Workshop on Rockfall Protection, edited by: Volkwein, A., Labiouse, V., and Schellenberg, K., Swiss Fed. Research Inst. WSL, Morschach, Switzerland, 2008.

Schneuwly, D. M. and Stoffel, M.: Changes in spatio-temporal patterns of rockfall activity on a forested slope - a case study using dendrogeomorphology, Geomorphology, 102, 522-531, 2008.

Scioldo, G.: Slope instability recognition, analysis, and zonation, in: Rotomap: analisi statistica del rotolamento dei massi, 81-84, Milano, 1991.

Scioldo, G.: User guide ISOMAP \& ROTOMAP - 3D surface modelling and rockfall analysis, http://www.geoandsoft.com/ manuali/english/rotomap.pdf, 2006.

Selby, M. J.: A rock mass strength classification for geomorphic purposes: with tests from Antartica and New Zealand, Z. Geomorphologie, 24, 31-51, 1980.

Selby, M. J.: Controls on the stability and inclinations of hillslopes formed on hard rock, Earth Surf. Proc. Land., 7, 449-467, 1982.

Shu, S., Muhunthan, B., Badger, T. C., and Grandorff, R.: Load testing of anchors for wire mesh and cable net rockfall slope protection systems, Eng. Geol., 79, 162-176, doi:10.1016/j.enggeo.2005.01.008, http://www. sciencedirect.com/science/article/B6V63-4FWKDWV-1/2/ 24d31d12a77ea868edf8184abb781f6d, 2005.

SIA261: Einwirkungen auf Tragwerke, Tech. rep., Schweizerische Ingenieure und Architekten, Bern, 2003.

Soeters, R. and Van Westen, C.: Slope instability recognition, analysis, and zonation, in: Landslides - Investigation and Mitigation - Special Report 247, edited by Turner, A. and Schuster, R., 129-177, Trans. Res. B., National Research Council, National Academy Press, Washington, D.C., USA, 1996.

Sonoda, Y.: A study on the simple estimation method of impact load by the one dimensional stress wave analysis, in: Joint JapanSwiss Scientific Seminar on Impact Load by Rock Falls and Design of Protection Structures, 43-50, Kanazawa, Japan, 1999.

Spang, R. and Bolliger, R.: Vom Holzzaun zum Hochenergienetz die Entwicklung des Steinschlagschutzes von den Anfängen bis zur Gegenwart, Geobrugg Schutzsysteme, Romanshorn, 2001.

Spang, R. and Rautenstrauch, R.: Empirical and mathematical approaches to rockfall protection and their practical applications, in: 5th International Symposium on Landslides, 1237-1243, Balkema, Rotterdamm, Lausanne, Switzerland, 1988.

Spang, R. and Sönser, T.: Optimized rockfall protection by "Rockfall”, in: 8th Int. Congr. Rock Mech., 3, 1233-1242, Tokyo, 1995.
Statham, I.: A simple dynamic model of rockfall: some theoretical principles and model and field experiments, in: ISMES: International Colloquium on Physical and Geomechanical Models, 237-258, Bergamo, Italy, 1979.

Statham, I. and Francis, S.: Hillslope processes, in: Influence of scree accumulation and weathering on the development of steep mountain slopes, edited by: Abrahams, A., Allen and Unwin, Winchester, 1986.

Stevens, W. D.: Rocfall: A tool for probablistic analysis, design of remedial measures and prediction of rockfalls, Master's thesis, University of Toronto, http://www.rocscience.com/library/ pdf/rf_3.pdf, 1998.

Strahler, A. N.: Quantitative geomorphology of erosional landscapes, in: Compt. Rend. 19th Intern. Geol. Cong., 13, 341-354, 1954.

Straub, D. and Schubert, M.: Modelling and managing uncertainties in rock-fall hazards, Georisk, 2, 1-15, 2008.

Stronge, W. J.: Impacts mechanics, Cambridge University Press, Cambridge, 2000.

Studer, C.: Simulation eines Bremsrings im Steinschlagschutzsystem, Master's thesis, Eidgenössische Technische Hochschule Zürich, diplomarbeit am Institut für Baustatik und Konstruktion, ETH Zürich, 2001.

Sturzenegger, M., Stead, D., Froese, C., Moreno, F., and Jaboyedoff, M.: Mapping the geological structure of Turtle Mountain, Alberta: A critical interpretation of field, Dem and LIDAR based techniques, in: Rock mechanics: Meeting Society's Challenges and demand. 1st Canada-US Rock Mechanics Symposium, edited by: Eberhardt, E., Stead, D., and Morrison, T., 2, Taylor \& Francis Ltd, Vancouver, Canada, 2007a.

Sturzenegger, M., Yan, M., Stead, D., and Elmo, D.: Application and limitations of ground-based laser scanning in rock slope characterisation, in: Rock mechanics: Meeting Society's challenges and demands. 1st Canada-US Rock Mechanics Symposium, edited by: Eberhardt, E., Stead, D., and Morrison, T., 1, 29-36, Taylor \& Francis, London, Vancouver, Canada, 2007b.

Tajima, T., Maegawa, K., Iwasaki, M., Shinohara, K., and Kawakami, K.: Evaluation of Pocket-type Rock Net by Full Scale Tests, in: IABSE Symposium Bangkok 2009: Sustainable Infrastructure. Environment Friendly Safe and Resource Efficient, 96, IABSE reports, International Association for Bridge and Structural Engineering, 2003.

Teraoka, M., Iguchi, H., Ichikawa, T., Nishigaki, Y., and Sakurai, S.: Analysis of motion for rock falling on a natural slope by using digital video image, in: 5th Symposium on Impact Problems in Civil Engineering, 87-90, Japan, 2000.

Thommen, R. A.: Testing of various types of rockfall flexible wire rope mitigation barrier: an overview of testing to date, in: 59th Highway Geology Symposium, Santa Fe, 2008.

Tonello, J.: Généralités et approche de modèles simples, in: Stage paravalanches, E.N.P.C., Paris, 1988.

Tonello, J.: Couverture pare-blocs structurellement dissipante, Tech. rep., METL/DRAST, Label IVOR 01.1. Mission Génie Civil, http://www.equipement.gouv.fr/recherche/incitatif/ ivor, 2001.

Toppe, R.: Terrain models - A tool for natural hazard mapping, IAHS, Publication, 162, 1987a.

Toppe, R.: Avalanche formation, movement and effects, chapitre Terrain models - a tool for natural hazard mapping, IAHS Publi- 
cation, 162, 629-638, 1987b.

Turner, R., Duffy, J. D., and Turner, J. P.: Post Foundations for Flexible Rockfall Fences, in: Proc. 60th Highway Geology Symposion, 2009.

Ujihira, M., Takagai, N., and Iwasa, T.: An experimental study on the characteristics of the impact load of falling rock, International Journal of Surface Mining and Reclamation, 7, 81-89, 1993.

Urciuoli, G.: Sperimentazione sulla caduta di blocchi lungo un pendio nella formazione calcareo-dolomitica della Penisola Sorrentina: Convengo sul tema, in: Convengo sul tema: Cartografia e monitoraggio dei movimenti franosi, 35-54, Bologna, Italy, 1988.

Urciuoli, G.: Giornata di Studio su La protezione contro la caduta massi dai versanti rocciosi, 29-36, Torino, Italy, 1996.

Ushiro, T., Shinohara, S., Tanida, K., and Yagi, N.: A study on the motion of rockfalls on Slopes, in: 5th Symposium on Impact Problems in Civil Engineering, 91-96, Japan, 2000.

Van Dijke, J. and van Westen, C.: Rockfall hazard: a geomorphological application of neighbourhood analysis with ILWIS, ITC Journal, 1, 40-44, 1990.

Van Westen, C.: Geo-information tools for landslide risk assessment: an overview of recent developments, in: 9th International Symposium on Landslides, Balkema, 2004.

Vangeon, J.-M., Hantz, D., and Dussauge, C.: Rockfall predictibility: a probabilistic approach combining historical and geomechanical studies, Revue Française de Géotechnique, 95/96, 143 154,2001

Varnes, D. J.: IAEG Commission on Landslides \& other Mass Movements, in: Landslide hazard zonation: a review of principles and practice, 63, UNESCO Press, Paris, 1984.

Vogel, T., Labiouse, V., and Masuya, H.: Rockfall Protection as an Integral Task, Struct. Eng. Int., 19(3), 321-326, 2009.

Volkwein, A.: Numerische Simulation von flexiblen Steinschlagschutzsystemen, Ph.D. thesis, Eidgenössische Technische Hochschule Zürich, 2004.

Volkwein, A., Roth, A., Gerber, W., and Vogel, A.: Flexible rockfall barriers subjected to extreme loads, Struct. Eng. Int., 19, 327$331,2009$.

Voyat, I., Roncella, R., Forlani, G., and Ferrero, A. M.: Advanced techniques for geo structural surveys in modelling fractured rock masses: application to two Alpine sites, in: Symposium on Rock Mechanics (USRMS), American Rock Mechanics Association ARMA, 2006.

Wagner, A., Leite, E., and Olivier, R.: Rock and debris-slides risk mapping in Nepal - A user-friendly PC system for risk mapping, in: 5th International Symposium on Landslides, edited by Bonnard, C., 2, 1251-1258, A. A. Balkema, Rotterdam, Lausanne, Switzerland, 1988.

Wendeler, C.: Murgangrückhalt in Wildbächen. Grundlagen zu Planung und Berechnung von flexiblen Barrieren, Ph.D. thesis, Institute of Structural Engineering, ETH Zurich, diss ETH No. 17916, 2008.
Wentworth, C. M., Ellen, S. D., and Mark, S. D.: Improved analysis of regional engineering geology using GIS, in: GIS'87, San Francisco, California, 1987.

Wieczorek, G. F., Morrissey, M. M., Iovine, G., and Godt, J.: Rockfall potential in the Yosemite Valley, California, Tech. rep., U.S. Geological Survey, 1999.

Wienberg, N., Weber, H., and Toniolo, M.: Testing of flexible barriers - behind the guideline, in: Interdisciplinary workshop on rockfall protection, edited by Volkwein, A., Labiouse, V., and Schellenberg, K., 114-116, Swiss Fed. Research Inst. WSL, Morschach, Switzerland, 2008.

Woltjer, M., Rammer, W., Brauner, M., Seidl, R., Mohren, G. and Lexer, M.: Coupling a 3D patch model and a rockfall module to assess rockfall protection in mountain forests, J. Environ. Manag., 87, 373-388, 2008.

Wong, R., Ho, K., and Chau, K. T.: Shape and mechanical properties of slope material effects on the coefficient of restitution on rockfall study, in: 4th North American Rock Mechanics Symposium, 507-514, Seattle, Washington, USA, 2000.

Wong, R. H., Ho, K., and Chau, K. T.: Experimental study for rockfall simulation, in: Construction challenges into the next century, 92-97, Hong-Kong, China, 1999.

Wu, S.: Rockfall evaluation by computer simulation, Transportation Research Record, 1031, 1-5, 1985.

Wu, T. H., Wilson, H. T., and Einstein, H. H.: Landslides - Investigation and mitigation, 1996.

Wyllie, D. C. and Mah, C. W.: Rock slope engineering: Civil and Mining, Spon Press, 4 edn., 2004.

Yang, M., Fukawa, T., Ohnishi, Y., Nishiyama, S., Miki, S., Hirakawa, Y., and Mori, S.: The application of 3-dimensional DDA with a spherical rigid block for rockfall simulation, Int. J. Rock Mech. Min., 41, 1-6, 2004.

Yoshida, H.: Movement of boulders on slope and its simulation, Recent studies on rockfall control in Japan, Tech. rep., 1998.

Yoshida, H.: Recent experimental studies on rockfall control in Japan, in: Joint Japan-Swiss Scientific Seminar on Impact Load by Rock Falls and Design of Protection Structures, Kanazawa, Japan, 1999.

Yoshida, H., Masuya, H., and Ihara, T.: Experimental Study of Impulsive Design Load for Rock Sheds, Struct. Eng. Int., P-127/88, 61-74, 1988.

Zaitsev, A., Sokovikh, M., and Gugushvily, T.: Field testing of net structures for railway track protection in rocky regions, in: 7th International Conference on Physical Modelling in Geotechnics (ICPMG 2010), Zurich, 2010.

Zinggeler, A., Krummenacher, B., and Kienholz, H.: Steinschlagsimulation in Gebirgswäldern, Berichte und Forschungen der Geographisches Institut der Universität Freiburg, 3, 61-70, 1990. 